\title{
Una mirada investigativa en la ingeniería.Gestión energética y telecomunicaciones
}

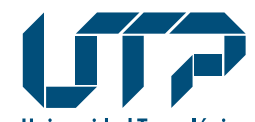

Universidad Tecnológica de Pereira
Juan Carlos Castillo Herrera

Juan Camilo López

Juan Esteban Tibaquirá

Álvaro Hernán Restrepo

Ana María López Echeverry
Jovany Bedoya Guapacha

Sebastián López Flórez

Ángel Andrade

Álvaro Restrepo

David A. Serrato 



\title{
Una mirada investigativa en la ingeniería.Gestión energética y telecomunicaciones
}

\author{
Juan Carlos Castillo Herrera \\ Juan Camilo López \\ Juan Esteban Tibaquirá \\ Álvaro Hernán Restrepo \\ Ana María López Echeverry \\ Jovany Bedoya Guapacha \\ Sebastián López Flórez \\ Ángel Andrade \\ Álvaro Restrepo \\ David A. Serrato
}

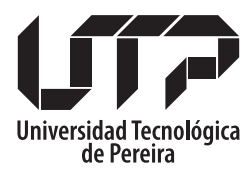

Vicerrectoría de Investigaciones, Innovación y Extensión Universidad Tecnológica de Pereira 2020 
Una mirada investigativa en la ingeniería. Gestión energética

y telecomunicaciones / Juan Carlos Castillo Herrera y

otros. - Pereira : Editorial Universidad Tecnológica de

Pereira, 2020.

147 páginas. -- (Colección Trabajos de investigación).

e-ISBN: 978-958-722-497-9

1. Eficiencia energética 2. Consumo de energía 3. Biomasa

4. Vehículos livianos - Emisiones 5. Consumo de combustible

6. Arritmia cardiaca 7. Transformada Wavelet 8. Máquinas de

soporte vectorial 9. Biogás 10. Aprovechamiento de energía

11. Relleno sanitario 12. Gasificación

CDD. 620.1

Una mirada investigativa en la ingeniería.Gestión energética y telecomunicaciones

(C) Vicerrectoría de Investigaciones, Innovación y Extensión

(c) Universidad Tecnológica de Pereira

Publicación financiada con recursos de la Vicerrectoría de Investigaciones, Innovación y

Extensión de la Universidad Tecnológica de Pereira

eISBN: 978-958-722-497-9

Trabajo de Investigación

Universidad Tecnológica de Pereira

Vicerrectoría de Investigaciones, Innovación y Extensión

Editorial Universidad Tecnológica de Pereira

Pereira, Colombia

Coordinador editorial:

Luis Miguel Vargas Valencia

luismvargas@utp.edu.co

Teléfono 3137381

Edificio 9, Biblioteca Central "Jorge Roa Martínez"

Cra. 27 No. 10-02 Los Álamos, Pereira, Colombia

www.utp.edu.co

Montaje y producción:

María Alejandra Henao Jiménez

Universidad Tecnológica de Pereira

Pereira 


\section{CONTENIDO}

\section{CAPÍTULO 1.}

Determinación del consumo de combustible y emisiones en vehículos livianos bajo pruebas dinámicas / Determination of the fuel consumption and the emissions of light duty vehicles by Dynamic tess

Juan Carlos Castillo Herrera, Juan Camilo López, Juan Esteban Tibaquirá

\section{CAPÍTULO 2.}

Eficiencia energética para vehículos livianos en Colombia /

Energy efficiency for light vehicles in Colombia.

Juan Carlos Castillo Herrera, Álvaro Hernán Restrepo, Juan Esteban Tibaquirá

\section{CAPÍTULO 3.}

Caracterización de señales electrocardiográficas para identificación de arritmias cardiacas / Characterization of electrocardiographic signals for identification of cardiac arrhythmias.

Ana María López Echeverry, Jovany Bedoya Guapacha, Sebastián López Flórez

\section{CAPÍTULO 4.}

Modelos de estimación de biogás de relleno sanitario /

Landfill biogas models

Ángel Andrade, Álvaro Restrepo

\section{CAPÍTULO5.}

Potencial productivo, energético y exergético de biomasa residual agrícola para propósitos de gasificación / Productive, energy and exergy potential of agricultural biomass residues for gasification

David A. Serrato, Álvaro Restrepo, Juan Esteban Tibaquirá 



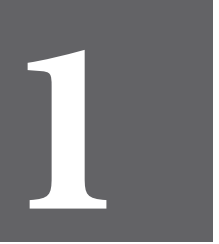

CAPÍTULO

UNO 



\title{
DETERMINACIÓN DEL CONSUMO DE COMBUSTIBLE Y EMISIONES EN VEHÍCULOS LIVIANOS BAJO PRUEBAS DINÁMICAS \\ DETERMINATION OF THE FUEL CONSUMPTION AND THE EMISSIONS OF LIGHT DUTY VEHICLES BY DYNAMIC TESTS
}

\author{
Juan Carlos Castillo, Juan Camilo López, Juan Esteban Tibaquirá \\ Universidad Tecnológica de Pereira \\ jccastillo@utp.edu.co,juanc,lopez@utp.edu.co, juantiba@utp.edu.co
}

\section{Resumen}

Los vehículos livianos del sector transporte son responsables de altos porcentajes de dema energética y de emisiones de dióxido de carbono en el mundo. Por lo tanto, se requieren desarrc normativas que permitan monitorear la energía consumida y las emisiones consecuentes $d \epsilon$ operación, con el fin de identificar estrategias que permitan reducir los impactos negati asociados a su operación. En la actualidad, Colombia no cuenta con una normativa que evalú consumo de energía y emisiones de los vehículos comercializados en el país. Por este motivo estructuró una metodología de medición de consumo de combustible y de emisiones soportada criterios metrológicos, considerando las capacidades técnicas y tecnológicas de los laboratorios país. En este documento, se describe el protocolo de pruebas, el ciclo de conducción, los princi] metrológicos, las características de los equipos, los modelos de cálculo y la evaluación di incertidumbre de la medición.

Palabras claves: metodología, eficiencia energética, consumo de energía, vehículos livianos, emisiones.

\begin{abstract}
Around the world the fleet of light duty vehicles consumes large amounts of energy and prodi a high percentage of the $\mathrm{CO}_{2}$ emissions. Therefore, it is necessary to develop regulations strategies that allow measuring the energy consumed and the consequent emissions from operation. Currently, Colombia does not have a regulation that assesses the energy consump and emissions of the light duty vehicles commercialized in the country. For this reason, a methodology for measuring fuel consumption and emissions was designed. This methodolog
\end{abstract}


ported by metrological criteria and is based on the technical capabilities of the laboratories in country. In this work we present: the test protocol, the driving cycle, the metrological principles, materials and methods, the calculation models and the evaluation of the measurement ertainty.

words: methodology, energy efficiency, energy consumption, light duty vehicles, emissions. oducción

$\exists 1$ sector transporte es fundamental en el desarrollo económico y social de los países, puesto , agiliza las actividades económicas, aporta al fortalecimiento de los mercados, y permite la rilidad de personas y mercancías alrededor del mundo. Sin embargo, este sector está ıcterizado por ser uno de los principales consumidores de recursos fósiles, los cuales demandan rentes procesos de transformación energética que generan productos perjudiciales para el siente, tales como calor, ruido, emisiones contaminantes, y gases de efecto invernadero (GEI). : hecho, ha incentivado a diferentes entidades gubernamentales y no gubernamentales, a blecer políticas, programas y estrategias, que hagan del transporte un sector energéticamente enible y amigable con el ambiente.

Jna de las estrategias implementadas en los últimos años en diferentes países es el etiquetado rgético, el cual, consiste en medir y regular tanto las emisiones como el consumo de combustible los vehículos livianos, para así, imponer cargos tributarios a aquellos que presenten altos sumos y emisiones, $\mathrm{u}$ ofrecer beneficios económicos y de circulación a los que presenten bajos res de estos índices, incentivando el uso de vehículos más eficientes. Esta estrategia es posible arla a cabo, si se tienen definidos protocolos de medición, de tal forma que todos los vehículos ı evaluados bajo las mismas condiciones de operación. Para ello, es necesario conocer variables libles del vehículo, que faciliten un criterio de comparación y definir una metodología para su lición. Por lo tanto, en este documento se identifica el consumo de combustible como el ısurando a través del cual podría establecerse la evaluación, el control y la regulación de la iencia de operación de los vehículos. Adicionalmente, se describe una metodología repetible y oducible basada en lineamientos internacionales, que se puede emplear para la medición de sumo de combustible en vehículos livianos mediante pruebas dinámicas automotrices, la cual, stablece como punto de partida para impulsar el etiquetado energético vehicular en Colombia. 


\section{rianteamiento aes prodiema y justircacion}

Ante las necesidades actuales de hacer eficiente el uso de la energía y los compromisos globa de disminuir las emisiones de gases contaminantes y de efecto invernadero - GEI relaciona con los procesos de transformación energética, el sector transporte como el usuario del $20 \% \mathrm{~d}$ energía y el productor del $23 \%$ del $\mathrm{CO}_{2}$ a nivel mundial [1], se ve obligado a identificar estratę para realizar su evaluación, monito y constante mejora, de tal forma que se propenda alcanzar transporte sostenible [2].

En este sentido, la evaluación del desempeño ambiental y la eficiencia de los vehículos livi: del sector transporte por carretera se ha vuelto una necesidad, puesto que, permite extraer indicadores y establecer regulaciones o políticas [3]. Actualmente, algunos países propon implementar etiquetas energéticas obligatorias en los vehículos que están siendo comercializa con el fin de informar sobre el consumo de combustible y las emisiones de $\mathrm{CO}_{2}$ que los vehíc presentan, así concientizar el uso al consumidor desde la compra e incentivar a la compr aquellos que presentan mejores estándares [4-7]. La industria automotriz a nivel mundial re: la medición del consumo de combustible mediante ensayos basados en pruebas dinámicas cuales, se llevan a cabo en equipos dinamométricos que simulan las condiciones de operació ruta de los vehículos. Para ello, es necesario establecer metodologías confiables donde se pur cuantificar las incertidumbres e introducir factores a las métricas realizadas $[8,9]$.

En Colombia, no se realizan evaluaciones bajo prueba dinámica a los vehículos comercializ en el territorio nacional, dado que la legislación únicamente reglamenta los niveles permisible emisiones de gases contaminantes, los cuales son evaluados mediante prueba estática en los cer de diagnóstico automotriz, y únicamente exige en la importación presentar un certificado de emisiones bajo el protocolo de Montreal. Por lo tanto, se identifica que establecer una metodol de medición de consumo de combustible bajo pruebas dinámicas, es el paso inicial para evalu eficiencia energética de los vehículos en Colombia. Para identificar el potencial de mejor estrategias tecnológicas u operacionales, y fomentar el etiquetado energético vehicular, lo podría contribuir a la seguridad energética, reducir la contaminación y ayudar a los consumid 


\section{Objetivos}

\section{Objetivo general:}

Describir los procedimientos generales y los métodos de cálculo para la medición del consumo de combustible y emisiones de los vehículos livianos bajo pruebas dinámicas automotrices en Colombia.

\section{Objetivos específicos:}

1. Establecer una metodología de medición de consumo de combustible para vehículos livianos, basada en estándares internacionales, considerando los coeficientes de resistencia al movimiento y las capacidades de los laboratorios nacionales.

2. Desarrollar un modelo de estimación de la incertidumbre del proceso de medición de las variables físicas involucradas en la determinación de los coeficientes de resistencia al movimiento del vehículo.

3. Definir el modelo de estimación de la incertidumbre de los procesos de medición asociados a la metodología.

\section{Referente teórico}

La Comisión Panamericana de Normas Técnicas - COPANT tiene diferentes proyectos que están siendo desarrollados y que involucran directamente a Colombia, uno de estos es la propuesta de norma de Eficiencia Energética en Vehículos Livianos de Pasajeros y Comerciales Livianos, mediante la cual, se establecen las características que deben poseer las etiquetas de eficiencia energética de los vehículos livianos de pasajeros y comerciales livianos. Para ello, el proyecto de norma tiene como referentes las siguientes normativas internacionales: el Reglamento No. 83 de la Comisión Económica de las Naciones Unidas para Europa (CEPE), y el CFR (Code of Federal Regulations de los Estados Unidos de América) Título 40 - Parte 86. Sin embargo, considerando que el alrededor del $40 \%$ de los vehículos comercializados en Colombia provienen de países que implementan protocolos de pruebas vehiculares basados en la metodología estadounidense, se determina me ec la mác anta nara la realizarión de encavoc 


\section{Generalidades en la medición del consumo de combustible}

La medición del consumo de combustible se realiza con base en los lineamientos del códig regulación CFR 40 de los Estados Unidos. Esta metodología establece que la medición pı realizarse mediante tres métodos: balance de carbonos, gravimétrico y volumétrico. En este documento se analiza el método gravimétrico, puesto que permite realizar un seguimiento centralizado de una sola variable en tiempo real y se ajusta a las capacidades técnicas y tecnológ de los laboratorios del país. Este método, consiste en medir la masa del combustible empl durante la ejecución del ciclo de conducción. De esta forma, midiendo la distancia recorrid masa y la densidad del fluido, puede estimarse el consumo de combustible del vehículo.

La metodología utiliza el Procedimiento Federal de Prueba (FTP-75), el cual es un cicl conducción urbano empleado para ser simulado en dinamómetro de rodillos, y surge como derivación del ciclo FTP-72, con una adición de una tercera fase de 505 segundos, idéntica primera fase del FTP-72 pero con arranque en caliente, tal como se muestra en la Figura 1.

\section{Figura 1.}

Ciclo de conducción estadounidense EPA FTP-75.

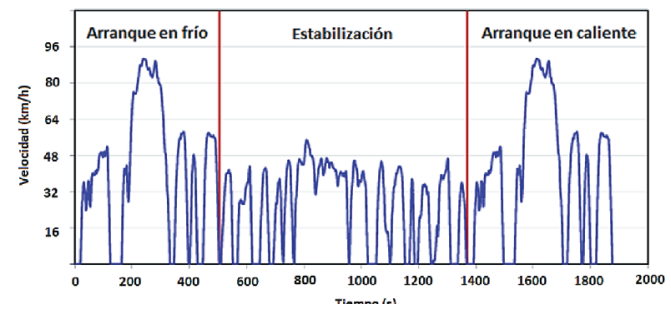

\section{Esquema metodológico}

La metodología de consumo de combustible está compuesta por tres etapas. La primera, con: en el ensayo de desaceleración libre en ruta, también conocido como Coast Down, donde se esti los coeficientes de resistencia al movimiento de cada vehículo. En la segunda etapa, $\epsilon$ coeficientes se ingresan al programa de control del dinamómetro de rodillos, con el fin de ajı 
iza la prueba de consumo de combustible considerando los coeficientes de resistencia al ıimiento estimados para cada vehículo en particular.

rocedimiento metodológico técnico general se presenta a continuación en la Figura 2.

ura 2.

cedimiento metodológico para la medición del consumo de combustible.

ESACELERACIÓN LIBRE

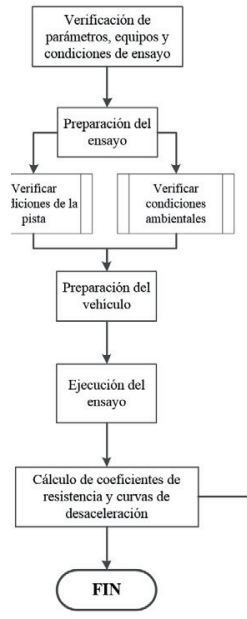

EN LABORATORIO

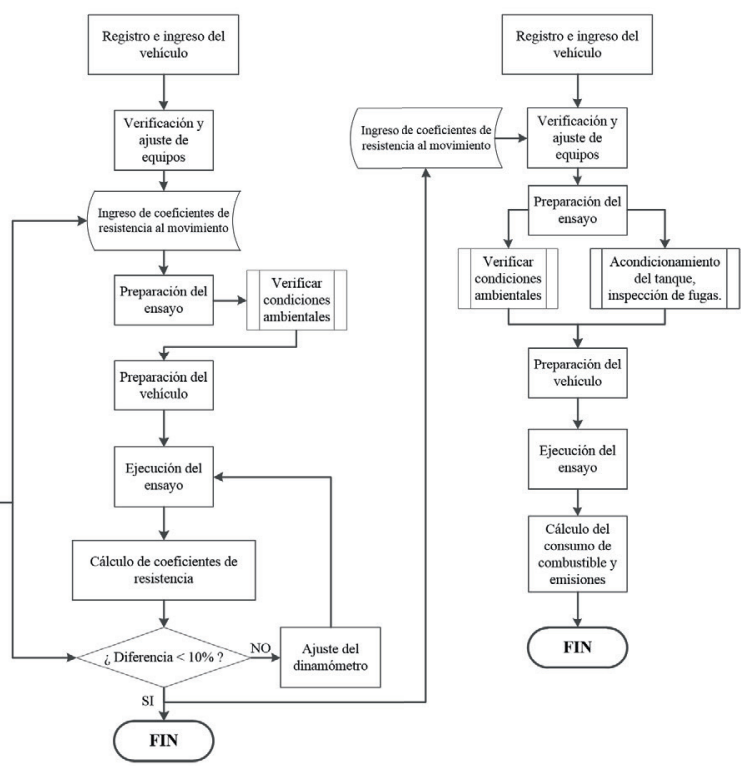

todología

sntinuación, se definen las características de los equipos utilizados, el protocolo para las rentes pruebas existentes en la metodología de medición del consumo de combustible de los 


\section{Equipos}

Balanza: para la medición de la masa de combustible consumida durante el ensayo. Especificación mínima:

- División de escala: $0,5 \mathrm{~g}$.

Unidad meteorológica: para la medición de las condiciones ambientales. Especificación míni

- Medición de velocidad de viento con una precisión de $\pm 2 \%$.

- Medición de temperatura ambiente con una precisión de $\pm 0,5^{\circ} \mathrm{C}$ a $25^{\circ} \mathrm{C}$.

- Medición de humedad con una precisión de $\pm 2 \% \mathrm{HR}$ a $50 \% \mathrm{HR}$, y una resolución de $0,1 \% \mathrm{HR}$.

- Medición de presión absoluta y relativa, con una precisión de $\pm 1,5 \mathrm{hPa}$ a $25^{\circ} \mathrm{C}$.

Termómetro infrarrojo: para la medición de la temperatura de los rodillos o ruta antes, dura y después de la ejecución de las pruebas. Especificación mínima:

- Resolución: $0,5 / 1{ }^{\circ} \mathrm{C}$.

- Tiempo de respuesta: $0,25 \mathrm{~s}$.

Hidrómetro o densímetro de vidrio de inmersión: para la medición de la densidad del combustible de prueba. Especificación mínima:

- Precisión $0,001 \mathrm{~g} / \mathrm{cm}^{3}$ a $20^{\circ} \mathrm{C}$.

Cinta métrica: para la medición del diámetro de los rodillos del dinamómetro. Especificaciór mínima:

- Resolución: 0,01 mm. Precisión: $\pm 0,03 \mathrm{~mm}$.

Contador digital programable: para el conteo de revoluciones del rodillo, a partir de la seña del encoder del dinamómetro.

Especificación mínima:

- Estabilidad de 6 dígitos LED.

Manómetro: para el ajuste de la presión de los neumáticos del vehículo. 
sración del vehículo. Es utilizado para identificar variables de interés, tales como: velocidad, oluciones del motor, flujo de combustible, velocidad, altitud, entre otras.

\section{sayo de desaceleración libre}

ensayo de desaceleración libre (Coast Down) en ruta, consiste en desacelerar el vehículo en ı pista recta y plana, desde una velocidad inicial hasta una velocidad final establecida por la ıeba. El ensayo se realiza con la transmisión en neutro, se determina el tiempo requerido por el lículo para completar la desaceleración. Esto permite estimar los coeficientes de resistencia a odadura y aerodinámica del vehículo. El procedimiento para llevar a cabo los ensayos se senta a continuación:

\section{rificación de parámetros de ensayo}

Registrar la magnitud de la temperatura ambiente y humedad relativa.

Verificar que la temperatura ambiente permanezca entre $5^{\circ} \mathrm{C}$ y $35^{\circ} \mathrm{C}$ a la sombra [10].

Registrar la magnitud de la presión atmosférica.

Verificar que la prueba se realice a una presión atmosférica entre $91 \mathrm{kPa}$ y $104 \mathrm{kPa}$.

Registrar la magnitud de las componentes tangencial y transversal de la velocidad del viento.

Registrar la magnitud de temperatura de la pista.

Realizar recorrido piloto a lo largo de la pista a una velocidad constante entre $40 \mathrm{~km} / \mathrm{h}$ y 60 $\mathrm{km} / \mathrm{h}$, registrar las variaciones de nivel de la pista.

Verificar que la pista de prueba sea lisa, se encuentre seca, y la pendiente no exceda el $0,5 \%$. El desnivel del final de la pista respecto al inicio no debe exceder el $1,5 \%$.

Verificar que la profundidad de sus surcos de las cubiertas de las llantas se encuentre entre el 90\% y el 50\% del valor del neumático sin uso.

Ajustar la presión de los neumáticos de acuerdo con las recomendaciones del fabricante o a las especificaciones de la etiqueta del neumático.

Inspeccionar la superficie de los neumáticos y verificar que no se presenten incrustaciones que alteren la rodadura, 
12. Verificar que la instalación de los dispositivos de medición no altere el desempeño, estabilidad y aerodinámica el vehículo, así como las condiciones de manejo del conductor [11].

13. Antes de la realización de las pruebas, verificar la correcta operación de los equipos.

\section{Recomendaciones previas a la ejecución del ensayo}

1. Verificar el balanceo de las ruedas, la regulación de la suspensión y los frenos, así como la alineación de la dirección del vehículo.

2. Verificar que las superficies del vehículo se encuentran limpias y las ventanas se encuentran cerradas antes y durante la ejecución de los ensayos.

3. Desconectar o dejar inoperante el sistema de acondicionamiento de aire del vehículo y otros equipos auxiliares como sistemas de iluminación y entretenimiento.

4. Realizar 20 ensayos, agrupados en 10 pares (ida y vuelta - ambos sentidos de la pista seleccionada), de las cuales se seleccionan los 5 mejores pares para el cálculo de los coeficientes de resistencia aerodinámica y a la rodadura.

5. Si durante la prueba es necesario accionar los frenos, el ensayo debe ser interrumpido.

6. Realizar la medición de la presión, la temperatura, la humedad relativa y la velocidad del viento en la mitad de la pista.

7. Incluir la masa de los equipos de medición, así como la masa del personal que realiza la prueba como parte la masa del vehículo.

8. La masa de los equipos de medición y del personal deben ser de $136 \mathrm{~kg}$ [10]. De no alcanzarse este valor, debe añadirse un lastre.

9. La pista debe ser recta, y su superficie debe ser de hormigón o asfalto en buen estado.

10. Verificar que sobre la superficie de la pista no se encuentren restos de materiales punzantes y/o desperdicios que afecten la rodadura.

11. La presión y la temperatura estándar requeridas para la corrección de los resultados debe ser: $101,325 \mathrm{kPa}$ y $293,15 \mathrm{~K}$.

12. La prueba no debe ser ejecutada si se presenta niebla que dificulte la visibilidad.

13. Suspender la realización de los ensayos si se presentan velocidades del viento superiores a $3 \mathrm{~m} / \mathrm{s}$ para la componente longitudinal y/o $2 \mathrm{~m} / \mathrm{s}$ para la componente transversal. Las mediciones deben realizarse a una altura aproximada de $70 \mathrm{~cm}$ de la pista de ensayos.

14. Realizar los ensayos con el tanque de combustible lleno. 
No se requiere utılizar combustible patron.

Realizar un precalentamiento del vehículo por alrededor de 30 minutos.

\section{cución del ensayo}

Posicionar el vehículo en la línea de partida.

Girar el volante completamente de izquierda a derecha y de derecha a izquierda.

Registrar la magnitud de la temperatura ambiente y humedad relativa.

Registrar la magnitud de la presión atmosférica.

Registrar la magnitud de las componentes tangencial y transversal de la velocidad del viento.

Registrar la magnitud de temperatura de la pista.

Acelerar el vehículo manteniendo un curso recto y constante hasta alcanzar una velocidad igual o superior a $85 \mathrm{~km} / \mathrm{h}(23,61 \mathrm{~m} / \mathrm{s})$ e iniciar la desaceleración libre del vehículo desacoplando la transmisión sin accionar el freno y evitando dejar accionado el embrague. En el momento en el que el vehículo alcance una velocidad de $80 \mathrm{~km} / \mathrm{h}(22,22 \mathrm{~m} / \mathrm{s})$ iniciar el registro de velocidad y tiempo hasta que la velocidad del vehículo llegue a un valor de 3( $\mathrm{km} / \mathrm{h}(8,33 \mathrm{~m} / \mathrm{s})$.

Repetir inmediatamente el ensayo, conduciendo en dirección opuesta sin accionar el freno al girar.

Ejecutar los pasos 3 a 9, hasta completar diez (10) pares de registros (ida y vuelta).

Calcular los coeficientes de resistencia al movimiento.

\section{sayo de desaceleración libre en laboratorio}

znsayo de desaceleración libre (Coast Down) en laboratorio, consiste en desacelerar el tículo en el dinamómetro de rodillos, desde una velocidad inicial hasta una velocidad final ablecida por la prueba, e ingresando al programa de control del equipo los coeficientes de istencia al movimiento obtenidos a través del ensayo de desaceleración libre en ruta. El ensayc ealiza con la transmisión en neutro, se determina el tiempo requerido por el vehículo para npletar la desaceleración, con el fin de estimar las cargas ejercidas por el dinamómetro sobre rehículo, y posteriormente ejecutar los procedimientos de ajuste del equipo para replicar las gas obtenidas en ruta. 


\section{Verificación de parámetros y condiciones de prueba}

1. Registrar la magnitud de temperatura ambiente y humedad relativa.

2. Verificar que la prueba se realice a una temperatura ambiente entre $5^{\circ} \mathrm{C} \mathrm{y} 35^{\circ} \mathrm{C}$.

3. Registrar la magnitud de la presión atmosférica.

4. Registrar la magnitud de temperatura de los rodillos.

5. Ajustar la presión de los neumáticos de acuerdo con las recomendaciones del fabricante o como se especifica en la etiqueta del neumático.

6. Inspeccionar la superficie de los neumáticos y verificar que no presenten incrustaciones que alteren la rodadura.

7. Verificar que la instalación de los dispositivos de medición no altere el desempeño y estabilidad del vehículo, así como las condiciones de ejecución de la prueba.

8. Verificar la correcta operación de los equipos.

\section{Recomendaciones previas generales}

1. Verificar el balanceo de las ruedas, el funcionamiento regular de la suspensión y los frenos, así como la alineación de la dirección del vehículo.

2. Desconectar o dejar inoperante el sistema de acondicionamiento de aire del vehículo y otros equipos auxiliares como sistemas de iluminación y entretenimiento.

3. Incluir la masa de los equipos de medición, así como la masa del personal que realiza la prueba como parte de la masa del vehículo.

4. El vehículo de prueba debe tener mínimo $3000 \mathrm{~km}$ de rodaje.

5. Realizar los ensayos con el tanque de combustible lleno.

6. No se requiere utilizar combustible patrón para la ejecución de los ensayos.

\section{Ejecución del ensayo}

1. Verificar las condiciones del vehículo.

2. Posicionar y alinear el vehículo sobre el dinamómetro de rodillos.

3. Anclar el vehículo y ubicar el extractor de gases en el tubo de escape.

4. Verificar la correcta operación de los sistemas del dinamómetro.

5. Fijar la inercia equivalente y la potencia indicada en el dinamómetro. 
Ingresar los valores de los coeticientes de resistencia al movimiento $f$ " y $f_{\#}$, obtenidos en la prueba de desaceleración en ruta, al programa de control del dinamómetro. Conectar los dispositivos de medición de velocidad y tiempo.

Precalentar el vehículo accionando el dinamómetro hasta alcanzar una velocidad constante de $80 \mathrm{~km} / \mathrm{h}$, por un tiempo mínimo de 20 minutos [10]. Después de los 20 minutos, desacelerar el vehículo a $0 \mathrm{~km} / \mathrm{h}$.

Iniciar el ensayo acelerando el vehículo a una velocidad igual o superior a $105 \mathrm{~km} / \mathrm{h}$ e iniciar la desaceleración libre del vehículo desacoplando la transmisión, dejando la marcha en neutro sin accionar el freno.

Dejar desacelerar el vehículo hasta alcanzar una velocidad de $30 \mathrm{~km} / \mathrm{h}$.

Repetir el procedimiento de desaceleración del vehículo (Pasos 11 y 12) hasta alcanzar diez (10) repeticiones.

Realizar el proceso de cálculo de los coeficientes de restricción al movimiento en laboratorio.

zrior al cálculo, se comparan las curvas de desaceleración obtenidas en ruta con las obtenidas boratorio y se procede a realizar el respectivo ajuste. En caso tal de que los resultados no sean parables, se deben reajustar los coeficientes de resistencia al movimiento ingresados en el vare del dinamómetro, y ejecutar nuevamente el ensayo. Este proceso debe ser reiterativo hasta ner una desviación no mayor al 10\%.

nterior es realizado con el fin de ajustar las cargas ejercidas por el dinamómetro y ejecutar los yos de consumo de combustible. Por último, se efectúa el ensayo de consumo de combustible, omo se describe a continuación.

\section{tyo de consumo de combustible}

nedición del consumo de combustible se realiza mediante el método gravimétrico, el cual iste en medir la masa de combustible consumido durante la ejecución del ciclo de conducción. sta forma, midiendo la distancia recorrida y la densidad del combustible, puede estimarse el umo de combustible del vehículo.

\section{raciones previas}

La ejecución de los ensayos debe realizarse con combustible patrón.

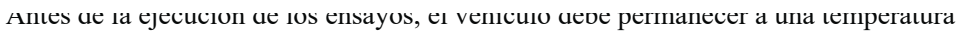
ambiente controlada entre $20^{\circ} \mathrm{C}$ y $30^{\circ} \mathrm{C}$, por un lapso mínimo de una (1) hora. 
r. Ajustar la presión de aire de las llantas del vehículo al valor recomendado por el fabrican o como se especifica en la etiqueta del neumático.

i. Inspeccionar la superficie de las llantas y verificar que estas no presenten incrustaciones que alteran la rodadura.

i. Fijar la inercia equivalente y la potencia indicada en el dinamómetro.

b. Ingresar los valores de los coeficientes de resistencia al movimiento $f_{\text {" }}$ y $f_{\#}$ ajustados, obtenidos en la prueba de desaceleración libre en laboratorio, al programa de control del dinamómetro.

3. Posicionar el vehículo sobre el dinamómetro con el motor apagado.

1. Anclar el vehículo.

0. Conectar el ducto de extracción de los gases de escape, al tubo de escape del vehículo.

1. Abrir el capó del vehículo y posicionar el ventilador de refrigeración.

2. Desconectar o dejar inoperante el sistema de acondicionamiento de aire del vehículo y ot equipos auxiliares como sistemas de iluminación y entretenimiento.

3. Conectar el dispositivo de medición de masa de combustible.

4. Verificar que la temperatura ambiente esté entre $20^{\circ} \mathrm{C}$ y $30^{\circ} \mathrm{C}$, que la humedad relativa menor al 75\%, y registrar la presión atmosférica de la prueba.

\section{Zjecución del ensayo}

Encender el dispositivo de medición de masa de combustible, el medidor de tiempo, y el indicador gráfico del ciclo de conducción, y proceder a encender el motor. Este momentc corresponde al instante cero del ciclo de conducción.

$\therefore \quad$ Engranar la $1^{\mathrm{a}}$. Marcha $15 \mathrm{~s}$ después de encender el motor.

i. Comenzar la aceleración inicial del vehículo en el ciclo de conducción y operar de acuer con el ciclo de conducción.

เ. Apagar el motor dos segundos después de finalizar la última desaceleración.

i. Registrar la masa de combustible consumido.

i. Registrar el número de revoluciones del rodillo y ajustar el cero del contador. 


\section{ıdelos de cálculo}

:ontinuación, se presentan los modelos de cálculo de los coeficientes de resistencia al vimiento y del consumo de combustible.

\section{Iculo de coeficientes de resistencia al movimiento}

; coeficientes de resistencia al movimiento por rodadura, $f^{\prime \prime}$, y por arrastre aerodinámico, $f_{\# \text {, }}$ ı obtenidos a partir de las ecuaciones (1) y (2).

$$
f^{\prime \prime}=f^{\prime \prime}\left[1+k_{+}(T-T ")\right]
$$

ado,

Coeficiente de resistencia a la rodadura corregido [N].

$f^{\prime \prime}$ : Coeficiente de resistencia a la rodadura sin corrección [N].

$k_{+}$: Factor de corrección por temperatura, estimado en $8,6 \times 10^{-3} \mathrm{~K}^{-1}$.

$T$ : Temperatura ambiente en la pista en cada desaceleración, expresada en $\mathrm{K}$.

$T n$ : Temperatura de referencia, igual a $293,15 \mathrm{~K}$.

$$
\begin{gathered}
f \#=2 P " T T " 4\left(f^{\prime} \#-\right. \\
\left.K 6 f^{\prime \prime \prime}\right)+K 6 f^{\prime \prime} \\
P
\end{gathered}
$$

ndo,

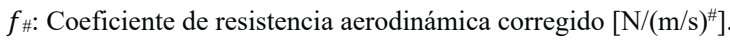

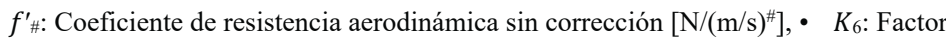
corrección por temperatura, estimado en $2,503 \times 10^{-4}(\mathrm{~m} / \mathrm{s})$;\#.

$P$ : Presión atmosférica en la pista en cada desaceleración, expresada en $\mathrm{kPa}$.

$P ":$ Presión de referencia, igual a 101,325 kPa.

s coeficientes de resistencia a la rodadura $f^{\prime \prime}$ y aerodinámica del vehículo $f^{\prime}$, se calculan no el promedio de los coeficientes calculados para cada ensayo, como se expresa en las taciones (3) v (4).

$$
f^{\prime \prime=} \begin{gathered}
1 \\
1 \\
f^{\prime} f^{\prime \prime, ?}
\end{gathered}
$$




$$
f^{\prime} \#=<2 n 4 f^{\prime} \#, ?
$$

?AB

Los coeficientes $f^{\prime \prime}, ?, f^{\prime} \#, ?$ son obtenidos a través de curvas experimentales modeladas para c desaceleración, tal como se presenta en la Tabla 1. Así, estos coeficientes son calculados pos medio de las ecuaciones (5) y (6).

Tabla 1. Determinación de los coeficientes de resistencia al movimiento.

\begin{tabular}{|c|c|c|c|c|c|c|}
\hline & $v_{\mathrm{M}}$ & $\begin{array}{l}v \\
=\underline{\mathrm{MPB}}_{\Delta t}- \\
\underline{\mathrm{I}}\end{array}$ & $\bar{v}=\frac{v}{2}+v$ & $\overline{v \mathrm{M} \#}$ & $\overline{v \mathrm{MT}}$ & $a \mathrm{M} \overline{v \mathrm{\Lambda}}$ \\
\hline . & . & . & . & . & . & . \\
\hline . & . & . & . & . & . & . \\
\hline . & . & . & . & . & . & . \\
\hline \multirow[t]{2}{*}{$n$} & $\cdots$ & - & -. & $\cdots \cdots-$ & $\cdots \cdots$ & $\cdots \cdots$ \\
\hline & & $\begin{array}{l}\text { a } \\
< \\
a_{\mathrm{M}}\end{array}$ & $\begin{array}{l}\stackrel{a}{\overline{v_{\mathrm{M}}}}< \\
\mathrm{MAB}\end{array}$ & $\begin{array}{l}@ \\
< \\
\overline{v_{\mathrm{M}}}\end{array}$ & $\begin{array}{l}\stackrel{a}{a}< \\
\bar{v}_{\mathrm{M}}^{\mathrm{T}} \\
\mathrm{MAB}\end{array}$ & $\begin{array}{l}\text { @) } \\
< \\
a \mathrm{M} \overline{v \mathrm{M}} \\
\ldots \times \mathrm{n}\end{array}$ \\
\hline
\end{tabular}

\section{[}

$\Sigma$

$(n-1) \sum @ \mathrm{MAB} a \mathrm{M} v \overline{\mathrm{M}} \#-\mathrm{V} \sum @ \mathrm{MAB} \bar{v} \mathrm{M} \# \mathrm{X}\left(\sum @ \mathrm{MAB}\right.$ 


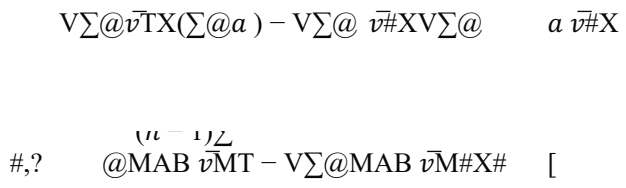

do $k$ es el número de ensayos, y $m_{[}$la masa equivalente del vehículo, expresada $c$

- $\quad m$ : Masa del vehículo

[kg].

- $m_{\mathrm{M} @]^{\wedge}}$ : Masa de los equipos e instrumentos de medición [kg].

- $m_{-}$: Masa de conductor y ocupantes [kg].

- $m$ ‘a: Masa equivalente a la inercia de rotación $[\mathrm{kg}]$.

La masa equivalente de inercia de rotación ser estimada como aproximadamente el 3\% de la suma de la masa del vehículo, la masa de los equipos de medición y la masa de los ejecutantes, tal como se presenta en las ecuaciones (8) [10]:

$$
\left.m^{`} \mathrm{a}=e^{\%}(m \backslash+m \mathrm{M} @]^{\wedge}+m \_\right)
$$

- $e_{\%}=0,03$

Se debe considerar que el coeficiente de variación $C V$ obtenido para los coeficientes $f^{\prime}$,, $f^{\prime}$ \# debe ser menor al 10\% [10]. Estos coeficientes, permiten establecer la variabilidad de los coeficientes de resistencia al movimiento $f^{\prime}$ ", $f^{\prime}$ \# respecto al valor de su media estimada $f \mathrm{dd}^{\prime} \mathrm{d}$ "d, $f \mathrm{dd}^{\prime} \mathrm{d}_{\# \mathrm{~d}} \mathrm{y}$ pueden calcularse mediante la ecuación (9).

$$
\begin{aligned}
& C V \mathrm{~g}^{\prime} \mathrm{i}=\sigma f \mathrm{ddg}^{\prime} \mathrm{dk}^{\prime \prime} \mathrm{d} 1, \\
& C V \mathrm{~g}^{\prime} 1=\sigma f \mathrm{ddg}^{\prime} \mathrm{dk} \# \mathrm{dl}
\end{aligned}
$$

- $\sigma_{\text {gki, }}$ representan la desviación estándar de los coeficientes de resistencia a la rodadura.

- $\sigma_{\mathrm{gkl}}$, resistencia aerodinámica calculados para cada ensayo. 
El cálculo del consumo de combustible se realiza mediante la ecuación (10):

$$
C=\frac{\pi \cdot N \cdot D \cdot \rho{ }^{\mathrm{rst}}}{m}
$$

- $C$, es el consumo de combustible del vehículo en $\mathrm{km} / \mathrm{l}$,

- $\quad m$, es la masa consumida de combustible,

- $\quad N$, el número de vueltas dadas por el rodillo durante la prueba,

$D$, es el diámetro de los rodillos,

$\rho_{\text {comb }}$, es la densidad del combustible de prueba.

\section{Cálculo de consumo de combustible corregido}

El consumo de combustible corregido es calculado a partir de la ecuación (11).

$$
\begin{gathered}
C \\
C_{-}=\Delta E^{\prime} 2 W_{\mathrm{s}} 4
\end{gathered}
$$

Siendo $W_{\mathrm{s}}$ la energía total requerida por el vehículo para vencer las fuerzas resistivas impuest: durante la ejecución del ciclo de manejo FTP-75, $\Delta E^{\prime}$ la disipación de energía debido a la presencia de fuerzas de resistencia al movimiento por rodadura y fuerzas aerodinámicas y $C, \mathrm{c}$ consumo de combustible calculado a partir de la ecuación (10). La estimación del gasto energético, $W_{\mathrm{s}}$, es obtenido a partir de la ecuación (12):

S

$$
W \mathrm{~s}=<\mathrm{VPx}, \mathrm{M}+P \mathrm{x}, \mathrm{MPBX} \Delta t \mathrm{M}
$$

La energía total requerida $\Delta E^{\prime}$ puede calcularse mediante la ecuación (13). 
nergía total disipada durante la simulación del ciclo de manejo FTP-75, $\Delta E_{\mathrm{yz}}$, asociada a las ras resistivas por rodadura y efectos aerodinámicos puede expresarse a través de la ecuación

$$
\begin{gathered}
\Delta E \mathrm{yz}= \\
\quad \mathrm{MAB} P \backslash \mathrm{M}+P \backslash, \mathrm{MPBX} \Delta t \mathrm{M} \\
\mathrm{MAB}
\end{gathered}
$$

le, la potencia debido a las fuerzas resistivas debido a la rodadura y los efectos aerodinámicos :fine a través de la ecuación (15).

$$
P \backslash f^{\prime \prime} v(t)+f_{\# v^{\prime}}(t)
$$

ı: Dadas las condiciones de ejecución de los ensayos y las capacidades técnicas y ológicas empleadas en el desarrollo y validación de la presente metodología, puede iderarse un valor de referencia para la incertidumbre por repetibilidad de aproximadamente $72 \mathrm{~km} / 1$.

ulo de las emisiones de $\mathrm{CO}_{2}$

srior al cálculo de consumo de combustible, se procede a realizar la estimación de las iones de $\mathrm{CO}_{2}$ de los vehículos.

vehículos a gasolina, las emisiones de $\mathrm{CO}_{2}$ pueden estimarse a partir de la ecuación (16)

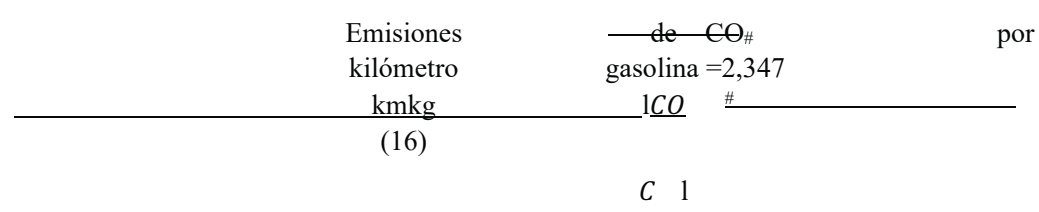

vehículos livianos diésel, las emisiones de $\mathrm{CO}_{2}$ pueden estimarse con la ecuación (17) [12]. 


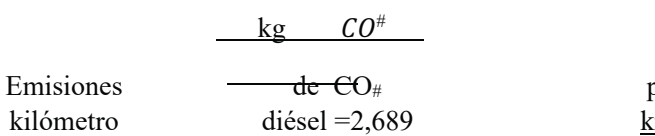

C 1

\section{esultados y conclusiones}

omo resultado del trabajo realizado se obtuvo una metodología para la medición del consumo z combustible y las emisiones de EI para vehículos livianos en Colombia, la cual estuvo basada en el Código de Regulación zderal de los Estados Unidos - CFR 40, y el ciclo de manejo FTP 75. Esta metodología fue .plementada en el Laboratorio de Pruebas Dinámicas Automotrices de la Universidad ecnológica de Pereira, y se evaluó en un vehículo Chevrolet Aveo modelo 2010 con motor de $500 \mathrm{~cm}^{3}$. Los resultados fueron comparados con información disponible en los programas de iquetado vehicular de Estados Unidos y de Chile, obteniéndose una diferencia del 5,18\% en el snsumo de combustible y $1,11 \%$ en las emisiones de $\mathrm{CO}_{2}$.

or otro lado, se definieron los procedimientos, las especificaciones técnicas de los equipos, y el otocolo de pruebas para llevar a cabo la medición del consumo de combustible a través del étodo gravimétrico, puesto que las capacidades tecnológicas y de infraestructura de los boratorios en Colombia favorecen su implementación. Así mismo, se establecieron los criterio ¿ aseguramiento metrológico necesarios para garantizar la repetibilidad y confiabilidad en los sultados. Adicionalmente, se construyó un modelo matemático para el cálculo de consumo de mbustible y para el ensayo Coast Down, así como el cálculo de la incertidumbre del proceso c edición

rr último, mediante la colaboración al personal del laboratorio de Pruebas Dinámicas utomotrices de la Universidad Tecnológica de Pereira y del Instituto Nacional de Metrología, olombia cuenta con una metodología estructurada a través de rigurosos criterios metrológicos, te permite garantizar la repetibilidad, reproducibilidad y confiabilidad de los resultados, la cua : posiciona como la base para establecer un protocolo nacional de medición de consumo de smbustible y emisiones para vehículos livianos en Colombia. 
EXO 1 - Modelo de estimación de incertidumbre de los coeficientes de resistencia al vimiento

ontinuación, en la ecuación (1) se presenta el modelo de cálculo de la varianza combinada de variable de interés, en función de las mediciones realizadas para su estimación [13].

$$
\begin{array}{r}
u_{-}^{\#}(y)=<2 \partial^{\partial x_{X}} x_{\mathrm{M}}^{\# \#} \\
4 u\left(x_{\mathrm{M}}\right)+u_{\mathrm{a}}
\end{array}
$$

$\mathrm{AB}$

$u_{-}^{\#}(y)$ : Varianza combinada,

_.: Coeficientes de sensibilidad,

$i c$

$u\left(x_{\mathrm{M}}\right)$ : Incertidumbre estimada asociada a cada entrada $x_{\mathrm{M}}$,

: Varianza estimada por repetibilidad,

$Y$ : Mensurando. Para el caso de estudio $Y$ hace referencia a los coeficientes de resistencia al movimiento,

$y$ : Coeficientes de resistencia al movimiento, asociado al modelo analítico.

incertidumbre típica combinada, $u_{-}(y)$, equivale a la raíz cuadrada de la varianza combinada, 'y), y es una medida de la dispersión de los valores atribuidos al mensurando, $Y$, y es igual a la latoria de la varianza de la salida, $y$. Es decir, la varianza combinada equivale a la sumatoria cuadrado de la incertidumbre de cada entrada, $x_{\mathrm{M}}$, multiplicado por el coeficiente de sibilidad, $£ \_$_ $¥$ para cada una de las entradas [13].

ic

\section{imación de la incertidumbre expandida}

ontinuación, se presenta el modelo de estimación de la varianza combinada $u^{\#}\left(f^{\prime \prime}\right), u^{\#}\left(f_{\#)}\right)$,

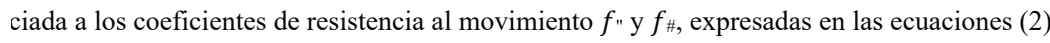
i): 


$$
\left.\begin{array}{c}
\partial f \# \\
-u\left(f^{\prime \prime}-\right.
\end{array}\right) \#=2 \partial T^{\prime \prime} 4 u(T)
$$

$$
\begin{gathered}
\partial f \# \# \quad \# \quad \partial f \# \\
u(f \#)^{\#}=2 \partial T 4 u(T)+2 \partial P \# 4 u(P) \#+2 \partial \partial f f^{\prime} \# \# 4 \# u\left(f^{\prime} \#\right)+2 \partial \partial f f^{\prime} \# " 4 \# u\left(f^{\prime \prime \prime}\right) \#+ \\
2 \partial \partial f f \# " 4 \# u\left(f^{\prime \prime}\right) \#
\end{gathered}
$$

donde, el intervalo de confianza de los coeficientes de resistencia al movimiento se expresa:

$$
\begin{gathered}
f \mathrm{I}-U(f) \leq f \mathrm{I} \leq f \mathrm{I}+U(f), \\
f \mathrm{I}_{\#}-U\left(f_{\#}\right) \leq f \mathrm{I}_{\#} \leq f \mathrm{I}_{\#}+U\left(f_{\#}\right)
\end{gathered}
$$

$U\left(f^{\prime \prime}\right), U\left(f_{\#}\right)$ son la incertidumbre expandida de los coeficientes de resistencia a la rodadura y resistencia aerodinámica respectivamente, los cuales puede ser calculados como se presenta a continuación:

$$
\begin{aligned}
& U\left(f_{"}\right)=k \cdot u\left(f_{"}\right), \\
& U\left(f_{\#)}\right)=k \cdot u\left(f_{\#)}\right)
\end{aligned}
$$

- $k$ el factor de cobertura

- $u\left(f^{\prime \prime}\right)$, incertidumbre combinada estimada para el coeficiente de resistencia a la rodadura

- $u\left(f_{\#)}\right)$ incertidumbre combinada estimada para el coeficiente de resistencia aerodinámica

El factor de cobertura $k$ es 2, permitiendo establecer un nivel de confianza de aproximadament $95 \%$, si se considera una distribución de probabilidad normal [13].

A continuación, se presenta el modelo de incertidumbre asociado a la medición de las variables físicas en los ensayos de desaceleración. Para ello, se realiza un cambio de variable en las ecuaciones (6) y (7), redefiniendo $a_{\mathrm{M}}=\left(v_{\mathrm{MPB}}-v_{\mathrm{M}}\right) \Delta \mathrm{t}$ y $\overline{v_{\mathrm{M}}}=\left(v_{\mathrm{MPB}}+v_{\mathrm{M}}\right) 2$ así:

$$
\begin{gathered}
v^{\mathrm{P}}=v_{\mathrm{MPB}}+v_{\mathrm{M}} \\
v^{;}=v_{\mathrm{MPR}}-v_{\mathrm{M}}
\end{gathered}
$$


rarianza combinada $u^{\#}\left(f^{\prime \prime}\right), u^{\#}\left(f^{\prime} \#\right)$ para los coeficientes de resistencia al movimiento, se resa a través de las ecuaciones (9) y (10).

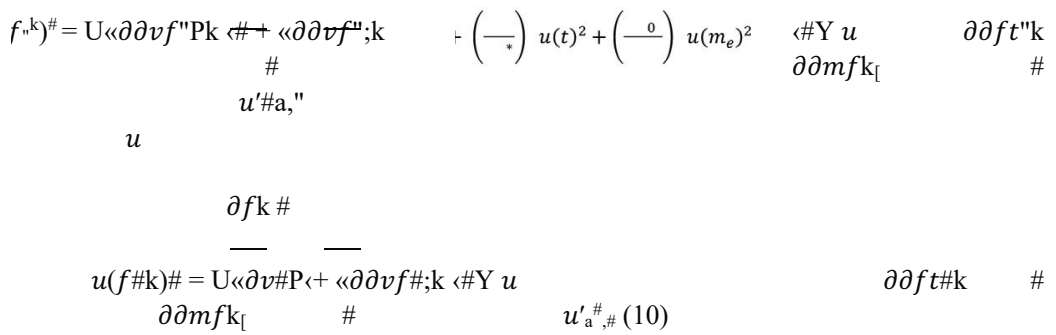

\section{zrtidumbre por repetibilidad}

ncertidumbre por repetibilidad de los coeficientes de resistencia al movimiento sin corrección

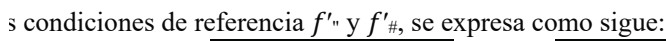

$$
\begin{gathered}
u_{\mathrm{a}, "}^{\prime}=m(n-1) *<\mathrm{V} f^{\prime}{ }_{", ?}-\overline{-f^{\prime \prime} \mathrm{X}}, \\
u_{\mathrm{a}, \#}^{\prime}=>n(n-1) *<\mathrm{V} f^{\prime}{ }_{\#, ?}-f^{\prime}{ }_{\#} \mathrm{X}
\end{gathered}
$$

?AB

$n$ : Número de repeticiones.

$f^{\prime \prime, M}$ : Coeficiente de resistencia a la rodadura sin corrección para la i-ésima repetición.

$f_{\#, M}^{\prime}$ : Coeficiente de resistencia aerodinámica sin corrección para la i-ésima repetición.

$f \mathrm{dd}$ 'd"d: Coeficiente de resistencia a la rodadura promedio.

$f \mathrm{dd}^{\prime} \mathrm{d}_{\#} \mathrm{~d}$ : Coeficiente de resistencia aerodinámica promedio.

\section{culo de la incertidumbre de la medición}

ncertidumbre de las variables involucradas en el proceso de medición se expresa en la ación (12): 
- $u\left(x_{\mathrm{M}}\right)^{\#}: \quad$ Varianza estimada asociada a la variable $x_{\mathrm{M}}$.

- $u\left(x_{\mathrm{M}}\right)_{-}^{\#} \mathrm{fl}$ : Varianza estimada asociada a la variable $x_{\mathrm{M}}$ por calibración.

- $u\left(x_{\mathrm{M}}\right)_{\mathrm{a}]}^{\#}$ : Varianza estimada asociada a la variable $x_{\mathrm{M}}$ por resolución.

A continuación, se presentan los coeficientes de sensibilidad asociados al cálculo de los coeficientes de resistencia al movimiento sin corregir $f^{\prime \prime}$ y $f^{\prime}{ }_{\# \text {. }}$

\section{Estimación de los coeficientes de sensibilidad}

Los coeficientes de sensibilidad describen como la salida, $y$, varía respecto a los cambios en los valores de entrada $x_{\mathrm{B}}, x_{\#} \ldots, x$. El cambio en la salida generado por un cambio diferencial, $\Delta x_{\mathrm{M}}$, en la entrada $x_{\mathrm{M}}$, está dado como $\Delta y_{\mathrm{M}}=\left(\partial y / \partial x_{\mathrm{M}}\right) \Delta x_{\mathrm{M}}$. Si el cambio en la salida es generado por la incertidumbre estándar $u_{\mathrm{M}}$ de la entrada $x_{\mathrm{M}}$, la correspondiente variación está dada por $\left(\partial y / \partial x_{\mathrm{M}}\right) u\left(x_{\mathrm{M}}\right)$ [13]. Las ecuaciones (13) y (14) presentan el cálculo de los coeficientes de sensibilidad.

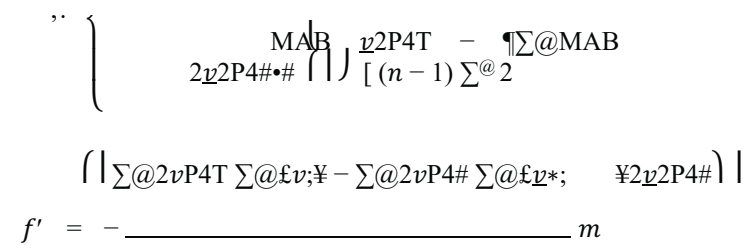

$\sum \mathrm{MAB} £ t *$

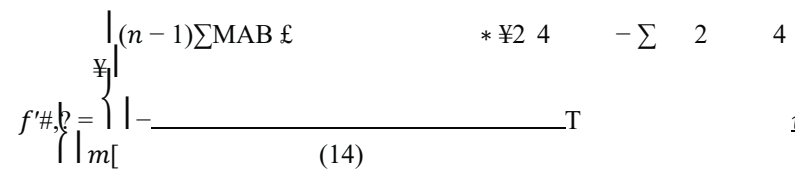


rtidumbre asociada al coeficiente de resistencia sin corregir ıcertidumbre asociada a los coeficientes de resistencia a la rodadura y aerodinámica sin egir, se expresa en las ecuaciones (15) y (16).

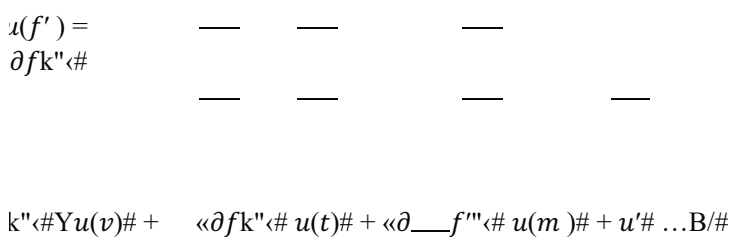

rtidumbre asociada al coeficiente de resistencia corregido

ıcertidumbre asociada al coeficiente de resistencia al movimiento corregido $f_{\text {" y }} f_{\# \text {, se }}$ esa en las ecuaciones (17) y (18):

$$
u\left(f^{\prime}\right)=q 2 \partial \partial T f^{\prime \prime} 4 \# u(T) \#+\quad \quad 2 \partial \partial f f^{\prime \prime "}+4 \# u\left(f^{\prime \prime \prime}\right) \# \cdot \mathrm{B} / \#
$$

$:)=\boldsymbol{q} 2 \partial f \# 4 \# u(T) \#+2 \partial f \# 4 \# u(P) \#+2 \partial f \# 4 \# u\left(f^{\prime \#}\right) \#+2 \partial \partial f f^{\prime} \#=4 \# u\left(f^{\prime \prime \prime}\right) \#+2 \partial \partial f f^{\prime \prime} \# 4 \#$ ') $\# \cdot B / \#$

$$
\partial T \quad \partial P \quad \partial f^{\prime} \#
$$

rtidumbre por calibración y resolución de los instrumentos de medición

ıcertidumbre por calibración de los instrumentos $u_{-}, \mathrm{M}$ se presenta en la Ec (19).

$U_{-}$ 


$$
u_{-}, \mathrm{M}=k_{-}
$$

- $U_{-}$: Incertidumbre expandida de calibración,

- $k_{-}$: Factor de cobertura por calibración.

La incertidumbre por resolución de los instrumentos análogos está dada por la ecuación (20).

$$
u_{\mathrm{afl}, \mathrm{M}} r^{\mathrm{fl}}
$$

La incertidumbre por resolución de los instrumentos digitales está dada por la ecuación (21).

$$
\mathrm{a}_{i}, \mathrm{M}
$$

- $r_{i}$ : Resolución del instrumento digital.

\section{ANEXO 2 - Modelo de estimación de incertidumbre del consumo de combustible}

La varianza combinada estimada para el consumo de combustible está dada por la ecuación (1

$u$

$$
\begin{gathered}
2=\left(\frac{\partial N}{\partial N}\right) u(N)^{2}+\left(\frac{\overline{\partial D}}{\partial D} u(D)^{2}+\left(\frac{}{\partial T^{*}}\right) u\left(T^{*}\right)^{2}+\left(\frac{\partial}{\partial \rho_{c}}\right) u\left(\rho_{c}\right)^{2}+\left(\frac{\partial m}{\partial m}\right) u(m)\right. \\
+2 \partial \partial C \rho \# \#+u(\alpha) \#+ \\
u \text { a\# } 4 u(\rho)
\end{gathered}
$$

donde el intervalo de confianza se expresa mediante la ecuación (2):

$$
\bar{C}-U(C) \leq C \leq \bar{C}+U(C)
$$

donde, $U(C)$ es la incertidumbre expandida es calculada mediante la ecuación (3):

$$
U(C)=k \cdot u(C)
$$


do $k$ el factor de cobertura y $u(C)$ la incertidumbre combinada. permitiendo establecer un I de confianza de aproximadamente $95 \%$, si se considera una distribución de probabilidad ıal. La incertidumbre asociada a la repetibilidad $u_{\mathrm{a}}$ está dada por la Ecuación (4):

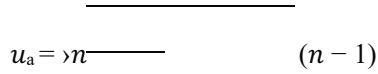

(4)

$\mathrm{AB}$

$\imath$ : Número de repeticiones.

วM: Consumo de combustible para la i-ésima repetición.

$\bar{\Upsilon}$ Consumo medio de combustible.

ıcertidumbre por calibración de los instrumentos $u_{-}, \mathrm{M}$ se presenta en la ecuación (5):

$$
u_{-}, \mathrm{M}={ }_{k_{-}-}
$$

$J_{-}$: Incertidumbre expandida de calibración (Certificado de calibración)

:: Factor de cobertura por calibración

ıcertidumbre por resolución de los instrumentos análogos está dada por la ecuación (6).

$$
\text { U }
$$

$$
u \text { afl,M } \quad \text { fl }
$$


La incertidumbre por resolución de los instrumentos digitales está dada por la ecuación (7).

$$
\mathrm{a}_{i}, \mathrm{M}
$$

- $r_{i}$ : Resolución del instrumento digital.

\section{Bibliografía}

[1] Lin B, Raza MY. Energy substitution effect on transport sector of Pakistan: A trans-log production function approach. J Clean Prod 2020;251:119606. https://doi.org/10.1016/j.jclepro.2019.119606.

[2] Ben Abdallah K, Belloumi M, De Wolf D. International comparisons of energy and environmental efficiency in the road transport sector. Energy 2015;93:2087-101. https://doi.org/10.1016/j.energy.2015.10.090.

[3] Xie C, Bai M, Wang X. Accessing provincial energy efficiencies in China's transport sector. Energy Policy 2018;123:525-32. https://doi.org/10.1016/j.enpol.2018.09.032.

[4] Ministerio de Energía - Gobierno de Chile. Inicio | Consumo Vehicular n.d. http://www.consumovehicular.cl/inicio\#/ (accessed April 9, 2020).

[5] Portal del consumidor de la comunidad de Madrid. Etiquetado energético de los vehícul n.d.

http://www.madrid.org/cs/Satellite?c=FRAME_Contenido_FA\&childpagename=Portal sumidor\%2FFRAME_Conteni

do_FA\%2FPTCS_contenidoGenerico\&cid=1343066080796\&p=1343064183275\&page me=PTCS_wrapper (accessed April 9, 2020).

[6] Ministério de Minas e Energia -Brazil. Programa Brasileiro de Etiquetagem Veicular Conpet n.d.

http://www.conpet.gov.br/portal/conpet/pt_br/conteudo-gerais/etiquetagem-veicular.shtm (accessed April 9, 2020).

[7] U.S.Department of Energy - Office of Energy Efficiency \& Renovable Energy. Find anc Compare Cars n.d.

https://www.fueleconomy.gov/feg/findacar.shtml (accessed April 9, 2020). 
different labelling schemes could affect consumer response to price changes. Energy Policy 2020;137:111181. https://doi.org/10.1016/j.enpol.2019.111181.

Martin NPD, Bishop JDK, Choudhary R, Boies AM. Can UK passenger vehicles be designed to meet 2020 emissions targets? A novel methodology to forecast fuel consumption with uncertainty analysis. Appl Energy 2015;157:929-39. https://doi.org/10.1016/j.apenergy.2015.03.044.

ABNT. NBR 10312 - Veículos rodoviários automotores leves - Determinação da resistência ao deslocamento por desaceleração livre em pista de rolamento e simulação em dinamômetro 2014.

Bureau of Indian Standards. Automotive vehicles - Determination of Road-Load Constants By Coast Down Test Method.

New Delhi, India: 2000.

EPA. Greenhouse Gas Emissions from a Typical Passenger Vehicle. 2014. https://doi.org/EPA-420-F-14-040a.

Joint Committee for Guides in Metrology. GUM-Guia para a expressão da incerteza de mediçao. 2008. 


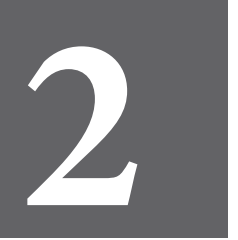

CAPÍTULO DOS 

Eficiencia energética para vehículos livianos en Colombia.

Energy efficiency for light vehicles in Colombia.

\section{Juan Carlos Castillo Herrera, Álvaro Hernán Restrepo, Juan Esteban Tibaquirá. Universidad Tecnológica de Pereira jccastillo@utp.edu.co,arestrep@utp.edu.co,juantiba@utp.edu.co}

\section{Resumen}

La creciente demanda en el consumo de energéticos en el mundo ha fomentado la búsqueda de racional y eficiente de la energía en los sectores productivos. Particularmente, el sector trans] es el principal usuario de los combustibles derivados del petróleo y el sector productivo mayores pérdidas de energía, puesto que, los motores de combustión interna ostentan una eficiencia de operación. La reducción del consumo de combustible en este sector se puede la usando diferentes estrategias enfocadas a la operación adecuada y al aumento de la eficienc los vehículos. Sin embargo, en Colombia no se cuenta con una metodología bajo pruebas dinán regulada que permita evaluar el consumo de combustible de los vehículos, lo que lleva a un desconocimiento sobre su rendimiento real en carretera, o el potencial que tiene una estrateg eficiencia energética tecnológica u operacional al ser aplicada. En este sentido, el objetivo ge de la investigación se centró en evaluar una estrategia de eficiencia energética en vehículos livi del sector transporte en Colombia mediante una metodología de medición del consumo de combustible. Por lo tanto, en este documento se identifican estrategias de eficiencia energ aplicables en vehículos livianos, y se propone una metodología basada en la Regulación CF de los Estados Unidos y COPANT para la evaluación de estrategias en ruta, la cual implemer métndo oravimétrién nara la medición del consumn de combuctihle Como recultado se 1 
lementar la conducción eficiente en un vehículo liviano sobre la ciudad de Pereira, obteniendo rres de rendimiento dentro de un rango aceptable según la desviación estándar. Adicionalmente, dentificó que la estrategia en la ciudad de Pereira puede proporcionar una reducción del sumo de combustible de hasta un $20 \%$, y que al conducir de forma eficiente existe un aumento nedio de 4,47\% y $6,8 \%$ en el tiempo de ejecución de las pruebas para horas pico y horas valle ıectivamente, los cual son valores poco significativos en comparación con la mejora en el limiento.

ıbras claves: eficiencia, vehículos, metodología, consumo de combustible. tract.

growing energy demand in the world has fostered the need of rational and efficient energy Itions across the different productive sectors. Particularly, the transport sector is the main sumer of oil derivatives and the one with most energy losses, given the low operational ziency of internal combustion engines. Fuel consumption reductions in this sector, through the lementation of adequate operation practices and increasing vehicles efficiency. However, in ombia, a regulated methodology that allows the assessment of fuel consumption under dynamic , has not being developed, which yields to unknown performance of vehicles under real driving ditions, or weakening the potential of implementing energy efficiency strategies. Thus, the eral objective in this research was focused on assessing a single energy efficiency strategy lied to light vehicles in the Colombian transport sector, through the measurement of fuel sumption. In this document, different energy efficiency strategies applicable to light vehicles identified, and a methodology based on the CFR 40 regulation from the United Stated and the PANT is proposed to evaluate on road approaches, which uses a gravimetric method to measure consumption. As result, efficient driving strategies were implemented on a light vehicle in the 
Additionally, reductions up to $20 \%$ in fuel consumption were obtained by implementing the ene efficiency strategy, with average times of displacement through the city of Pereira increasing $4,47 \%$ and $6.8 \%$ during peak and off-peak hours respectively, which in comparison with performance improvement, are not significant.

Keywords: efficiency, vehicles, methodology, fuel consumption.

\section{Introducción}

El esfuerzo de los entes gubernamentales por reducir el consumo de energéticos, están orientados a impulsar hábitos conducentes al uso racional y eficiente de la energía, los cuale: han reforzado mediante la implementación de programas de gestión energética, usando difereı estrategias enfocadas a la operación adecuada y al aumento de la eficiencia de los procesos sectores productivos, tales como: industrial, agropecuario, comercial, público, minero y transp [1]. Particularmente, el sector transporte ha sido reconocido mundialmente como el ser productivo con mayores pérdidas de energía, puesto que, los motores de combustión inte presentan una baja eficiencia de operación. Además, los vehículos aportan significativamente g: de efecto invernadero (GEI), gases contaminantes, ruido y calor, productos de la combustión tránsito urbano [2].

En la mayoría de los países, el sector transporte representa una parte sustancial del total nacic de las emisiones de $\mathrm{CO}_{2}$, por lo tanto, cualquier intento de abordar el cambio climático, debe pre atención a las emisiones del transporte, convirtiéndose en un punto clave para la formulaciór políticas y estrategias efectivas de mitigación del cambio climático [3]. Estados Unidos, Ch México, Brasil, Chile y algunos de la Unión Europea, evalúan el consumo energético del ser 
culos. Entre las soluciones se encuentra el uso de tecnologías, combustibles más limpios, lucción eficiente y la implementación del etiquetado energético con la intención de sientizar de manera global a los usuarios desde la compra y la operación [4]-[8]. Algunos stigadores, identifican la necesidad de medir las variables que inciden en el aumento del ;umo de combustible y evaluar estrategias que pretenden mejorar el rendimiento del sector [9], . Por lo tanto, en este documento se identifican estrategias tecnológicas y operacionales que permitido mejorar la eficiencia de los vehículos, con el fin de implementar y evaluar una de ; en Colombia. Adicionalmente, se define una metodología para la medición del consumo de bustible, con la cual se puede definir de manera precisa si la estrategia es efectiva, de esta ıa, poder proporcionar información valiosa para la toma de decisiones de quienes buscan sar el rendimiento del transporte en Colombia.

\section{Iteamiento del problema y justificación}

estudios relacionados con el transporte a nivel global ratifican la importancia de establecer tes para las emisiones presentes en el sector, y la necesidad de diseñar e implementar ologías alternativas, incluyendo biocombustibles y políticas que estructuren medidas de gación adecuadas [11]. Puesto que, actualmente se presenta una alta dependencia de los rsos fósiles en los vehículos, además, las emisiones contaminantes afectan directamente la d de los habitantes y la economía de los países [12], [13]. Por lo general, las tecnologías nativas se dividen en dos opciones; cambio de combustible y eficiencia energética. La opción ambio de combustible podría reducir significativamente la cantidad de emisiones de GEI en un o de tiempo relativamente corto, aunque estará limitado por sus recursos de suministro y por zonomía de escala de los vehículos que los emplean, mientras que, la opción de la eficiencia 
inversión por parte de fabricantes y consumidores [14]. Por ejemplo, se identifica que los vehíct uíbridos alimentados con pila de combustible (FC-HEV) y los vehículos eléctricos híbridos 1 'Plug -In" (PHEV-FC), están siendo considerados por la industria automotriz como la tecnolc que podría sustituir la convencional. Sin embargo, estas tecnologías plantean nuevos retos svalúan la importancia de las condiciones de conducción, los costos de inversión, la eficiencic los vehículos y el impacto del ciclo de vida[15].

Je estima que, en Colombia, el sector transporte es el responsable del $44 \%$ del consumo energé y el principal consumidor de combustibles derivados del petróleo. Según la Unidad de Planeac Minero-Energética (UPME) [16], este sector consume casi el 47\% del diésel de todo el país y $29 \%$ de las gasolinas, además sus emisiones presentan una trayectoria ascendente. Estudios sroyección del consumo energético del transporte realizados en Colombia, han generado ગreocupación y un compromiso por parte del gobierno en la reducción del consumo de combusti y las emisiones de $\mathrm{CO}_{2}$. Actualmente, la Unidad de Planeación Minero Energética (UPME) plar :emáticas y actividades, con el fin de cumplir con este objetivo, entre las cuales se encuentra Mesa de Trabajo con la Secretaria Distrital de Ambiente, donde se impulsa la introducción de té əléctricos en Bogotá, la Mesa Interministerial (Ministerio de Ambiente y Desarrollo Sostenib] MinTransporte - UPME), donde se impulsa la incorporación de tecnologías vehiculares limpias nesa de formulación (UPME, MinTransporte e ICONTEC), por la cual se realizan propue: ıormativas de estándares de eficiencia energética para vehículos y la propuesta de incentivos $\mathrm{F}$ ecnologías eficientes en el sector transporte público por parte de la Autoridad Nacional Licencias Ambientales (ANLA) y la UPME [17].

छn resumen, la reducción en el consumo de energía del sector transporte está en una posición cla 
sustible por kilómetro recorrido, en otras palabras, aumentar su rendimiento. Las medidas para r esto requieren un enfoque integrado de la formulación de políticas a nivel nacional, rtamental y local [18]. Por lo tanto, la implementación de estrategias de gestión energética : los vehículos del sector transporte por carretera en Colombia y su evaluación mediante una dología de pruebas adecuada, resulta ser atractiva tanto para el país como para el usuario, ya 1o sólo se puede obtener un impacto positivo sobre la matriz energética y dar soporte a las aciones o políticas energéticas y ambientales, sino también adquirir beneficios económicos los usuarios.

\section{tivos}

sar una estrategia de eficiencia energética en un vehículo liviano del sector transporte ante una metodología de medición del consumo de combustible.

Identificar estrategias de eficiencia energética aplicables a vehículos livianos del sector transporte.

Definir la metodología de pruebas para la medición del consumo de combustible.

Implementar una estrategia de eficiencia energética en un vehículo liviano del sector transporte en Colombia.

Realizar un análisis comparativo de la estrategia de eficiencia energética implementada, con miras al aumento de la eficiencia en los vehículos livianos del sector transporte.

\section{rente teórico}

En Colombia, el estudio del consumo de energéticos en el sector transporte presenta que el de la energía disponible se consume en el transporte por carretera. Esta energía se encuentra 
con una participación del 37\% y 40\% respectivamente [19]. En el Diésel, los mayores responsables del consumo son los camiones con un $34 \%$ y los buses con un $26 \%$. Por otro lado, las motocicletas participan con un $22 \%$, mientras que los automóviles representan un $42 \%$ en el uso final de gasolina destinada al transporte. Con base en lo anterior, se destaca que, en lo concerniente con el consumo de gasolina, tanto las motocicletas como los automóviles son un objetivo relevante de estudio a la hora de buscar reducir el consumo de combustibles en el sector.

Específicamente, en automóviles convencionales sólo un tercio de la energía química contenida en el combustible se convierte en energía de movimiento, aquella que no se convirtió en trabajo útil, se transforma principalmente en energía térmica, la cual se libera en el medio ambiente en forma de calor residual [20]. La Figura 1 muestra el balance de energía de un vehículo tipo automóvil, se puede observar que tan sólo el $12,6 \%$ de la energía química del combustible se transforma en energía mecánica en las ruedas. Lo anterior, se debe a que un $62,4 \%$ de la energía se disipa a través del motor de combustión interna (en forma de calor, refrigeración y energía química), mientras que el $17,2 \%$ se pierde o se disipa en los periodos de ralentí, el 2,2\% se disipa en el funcionamiento de los accesorios del vehículo y un 5,6\% se pierde en la transmisión del movimiento (engranajes, acoples, entre otros) hasta llegar a las ruedas. Por último, la energía se utiliza para vencer las fuerzas a la aerodinámica, rodadura e inercia, o para restringir la velocidad haciendo uso del freno.

\section{Figura 1.}

Balance de energía en automóviles [20].

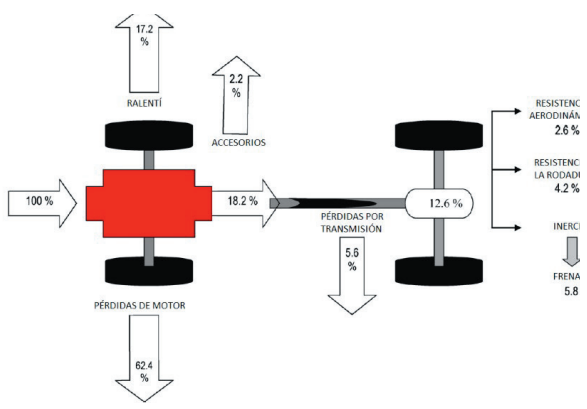

Eficiencia energética en vehículos 


\section{:iencia energética en vehículos}

Inte las necesidades actuales de hacer uso eficiente de la energía y los compromisos a nivel ıdial de disminuir los impactos negativos sobre el ambiente relacionados con los procesos de sformación energética, el sector transporte, como protagonista en cuanto al consumo en la asta energética mundial, se ve obligado a establecer estrategias que mitiguen los problemas ıcionados, efectuando estudios con miras a evaluar, idear e implementar eficiencia energética rehículos [21].

tctualmente, los esfuerzos se concentran en mejorar los factores tecnológicos en el vehículo y ranos en la operación. La revisión bibliográfica, permitió identificar tecnologías que han sido lementadas y evaluadas para aumentar el rendimiento de combustible en vehículos livianos con ores de encendido por chispa, algunas consideradas en las políticas federales de ahorro de ıbustible (Corporate Average Fuel Economy - CAFE) de los Estados Unidos [22]-[27]. A tinuación, en la Tabla 1 se presentan algunas tecnologías evaluadas las cuales se enfocan en dar beneficios tangibles a los consumidores.

la 1.

nologías implementadas en vehículos livianos [22]-[27].

\begin{tabular}{ll}
\hline & \\
\hline & rranque - Parada (Start-Stop) \\
& rranque - Parada con freno regenerativo (Start-Stop + KERS) \\
& 'álvula de actuación variable (VVA) \\
& Tejoras en el sistema de inyección directa (DI) \\
& iempo variable de válvula de admisión (VVT) \\
Motor & educir la capacidad del motor con turbocargadores o \\
& Jbrealimentación (TRBDS) \\
& elación de compresión variable (VC-T) \\
& lesconexión selectiva de cilindros (COD) \\
& ubricación de menor viscosidad (RV)
\end{tabular}

Transmisión ransmisión de doble embrague o "clutch" (DCT) ransmisiones automáticas (AT) educción de la fricción de componentes mecánicos (RF)

Funcionamiento y conducción .educción del $10 \%$ en el peso del vehículo $(\mathrm{R}-\mathrm{W})$

.educción de ralentí (R Ralentí)

istemas inteligentes de transporte (SIT) 
n Ia rigura $\angle$, se presentan Ios rangos de reauccion del consumo de combustibie de las zcnologías expuestas en la tabla anterior, identificando que aquellas que involucran transición zcnológica influyen con mayor efectividad sobre la eficiencia del vehículo.

igura 2.

'anoos do rodursión dol sonsumo onoroótien nor fartoros tornolóoisos $1277-1277$

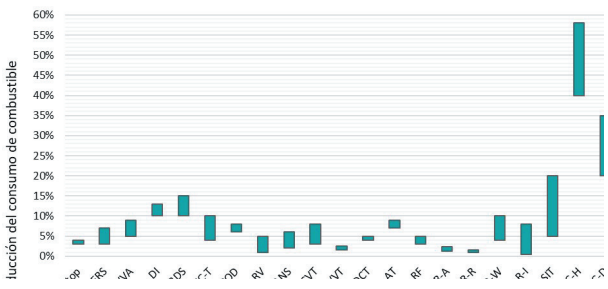

Desde el punto de vista económico, algunos estudios identifican que los compradores de əhículos están dispuestos a implementar tecnologías para el ahorro del combustible que no scedan el $76 \%$ del valor de los posibles ahorros futuros, teniendo en cuenta que las tecnologías ə deben afectar negativamente la conducción, el confort, u otras propiedades [28].

Para realizar un análisis sucinto de cual estrategia tecnológica podría ser más eficaz y atractiva ara su implementación, Simmons et al [29], identifican que el consumidor promedio puede ıvertir hasta \$1490 dólares para mejorar el rendimiento de combustible en un 17,3\% anual. Sin nbargo, el ahorro en promedio no es insuficiente para cubrir los costos de implementación de la cnología en un año, generando una reducción de interés por parte del consumidor. Por lo tanto, : identifican que las estrategias de reducción más eficaces deben incluir medidas de smportamiento combinadas con el desarrollo tecnológico. Las tecnologías necesitan tiempo para Itrar al mercado y generar aceptación por los usuarios, en cambio, las mejoras en la operación en incipio podrían ser implementadas mucho más rápido [30], [31].

Por otro lado, la conducción eficiente ha mostrado alcanzar altos resultados en la reducción del snsumo de combustible y en los costos asociados al transporte. En Australia, los entrenamientos 
1 de 106,49 dólares australianos (AUD) [32]. Ho et al. obtuvieron un ahorro del 16\% en el umo de combustible en Singapur, concluyendo que aplicar esta estrategia puede generar sciones inmediatas sin el tiempo de espera para la transformación del vehículo [33].

n Colombia, aún se están planificando actividades de concientización ambiental y energética, el fin de impulsar el uso racional y eficiente de la energía como parte habitual del jortamiento de las personas. Debido a lo anterios, la inversión económica en tecnologías para mento del rendimiento de combustible por parte de particulares es reducida. Por lo tanto, la ementación global de la conducción eficiente; en principio, podría verse reflejado mucho más lo en la mejora de la calidad del aíre y en la reducción del consumo del combustible de los zulos en el país, considerando que el costo de inversión es bajo y los beneficios obtenidos yen tanto en el conductor (reducción del estrés, confort, economía y seguridad), como en el sulo (mantenimiento y vida útil), aportando sobre la construcción de un transporte sostenible. base en lo anterior, para implementar y evaluar las diferentes estrategias tecnológicas u ıcionales, se tomó a consideración la disponibilidad de recursos tecnológicos presentes en el rratorio de Pruebas Dinámicas Automotrices de la Universidad Tecnológica de Pereira, y se gió evaluar la conducción eficiente como estrategia de eficiencia energética en vehículos nos.

dología

:visión de las posibles estrategias de eficiencia energética que pueden ser aplicables tanto en sulos (nuevas tecnologías) como en el transporte (gestión y operación) identificó que el cto o resultados obtenidos sólo puede ser determinado por un sistema de medición confiable. 'olombia, la normativa que rige el transporte Resolución 910 de 2008 únicamente reglamenta iveles permisibles de emisiones contaminantes para fuentes móviles en prueba estática y la 
norma técnica NTC 42-45 determina las emisiones de vehículos prototipo, sin describir de ma1 detallada procedimientos, requerimientos técnicos, personal o instrumentos para la ejecución d€ pruebas dinámicas.

En ese sentido, considerando que Colombia no cuenta con una normativa que regule la medis del consumo de combustible en vehículos bajo pruebas dinámicas de laboratorio o ruta, se identi la necesidad de adoptar una metodología de pruebas internacional que sea aplicable al par automotor colombiano. Por lo tanto, siguiendo los lineamientos de la Comisión Panamerican: Normas Técnicas (COPANT), entidad encargada de regular las normas técnicas, incluyendo ensayos vehiculares, se identifican dos metodologías destacadas en la medición del consumc combustible: el Código Federal de Regulación - CFR 40 de los Estados Unidos y el Reglamı No 83 de la Comisión Económica de las Naciones Unidas para Europa. Los países pertenecie: a la COPANT realizan pruebas a los automotores bajo estándares americanos a excepciór Argentina, quien sigue el modelo europeo. La evaluación comparativa de estas dos metodolo. fue desarrollada en detalle por el Parlamento Europeo, mencionando que ambos sistemas preten garantizar que los vehículos cumplan con las normas pertinentes de consumo de combustib emisiones. Sin embargo, el objetivo inicial de la legislación europea estuvo orientado a no prot‘ a los fabricantes de vehículos nacionales sin dañar el sistema del mercado interno. Esto condu un sistema de aprobaciones de tipo nacional en homologación con una supervisión permisiva. cambio, los sistemas de los Estados Unidos se interesaron menos por el comercio y más pc cumplimiento de las normativas, generando diferencias en los procesos de aprobación, los ci de prueba y en los dispositivos de detección de infracción. Igualmente, se denota que existen puntos clave que contribuyen a una mayor efectividad del sistema americano; el mandato d United States Enviromental Protection (EPA) por la protección de la salud humana y el mı 
biente, la mayor experiencia y recursos para dar cumplimiento a los casos de infracción y li ta de claridad de la Unión Europea respecto a los casos de infracción [34].

Además, se identifica que la metodología de los Estados Unidos presenta una velocidad máxim: el ciclo FTP-75 acorde con las condiciones de operación y reglamentos del parque automoto ombiano. Así mismo, Colombia hace parte de los países pertenecientes a COPANT, los cuale su mayoría se basan en el CFR 40 de los Estados Unidos y en la norma de Brasil - NBR 702. a la medición del consumo de combustible y las emisiones. Por lo tanto, con base en la acterísticas técnicas y la orientación Panamericana, se determina que la metodología american: la más apropiada para la realización de ensayos a vehículos livianos en el territorio nacional.

\section{:dición de consumo de combustible}

La CFR 40 de los Estados Unidos en cuanto a la determinación del consumo de combustible dı vehículos livianos, así como sus adaptaciones ABNT - NBR 7024, establecen que la medició ¿de realizarse mediante tres métodos: balance de carbonos, gravimétrico y volumétrico. Lo ultados deben ser presentados en términos de rendimiento en [km/l] para vehículos a gasolina nol o diésel y en $\left[\mathrm{km} / \mathrm{m}^{3}\right]$ para vehículos a GNV [35]-[39].

Las características técnicas y tecnológicas del Laboratorio de Pruebas Dinámicas Automotrice .PDA de la UTP, permiten implementar el método gravimétrico, en el cual, se mide la cantidar masa de combustible consumida en un recorrido establecido en ruta o al realizar un ciclo de ıducción en laboratorio. Trabajos paralelos realizados con el Instituto Nacional de Metrología mitieron establecer los procedimientos y métodos de cálculo del consumo y rendimiento d nbustible, incluyendo el cálculo de la incertidumbre en la medición [40].

Con base en lo anterior, se definió la ec. (1), la cual expresa de manera general las variables ə se requiere medir para el cálculo del rendimiento de combustible: 


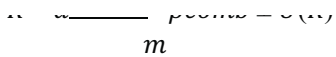

siendo,

$d$ : distancia recorrida por el vehículo [km].

$\rho_{\text {comb }}$ : densidad del combustible de prueba $[\mathrm{kg} / \mathrm{l}]$.

$m$ : masa consumida de combustible $[\mathrm{kg}]$.

$U(R)$ : incertidumbre expandida asociada a la medición de las variables $[\mathrm{km} / \mathrm{l}]$.

Por otro lado, el consumo de combustible es el reciproco del rendimiento, el cual puede ser calculado para las pruebas de laboratorio y ruta mediante la ec. (2):

$$
C=\frac{100}{R}
$$

donde, $C$ es el consumo de combustible expresado en $[1 / 100 \mathrm{~km}]$.

Debido a que la conducción eficiente involucra no sólo factores humanos, sino también condiciones de tráfico, topografía e infraestructura de las carreteras, es necesario evaluar di estrategia en ruta, por lo tanto, se desarrolló un protocolo de pruebas basado en el mét gravimétrico y los estándares internacionales, el cual se presenta la Figura 3 [35], [41].

La medición de las condiciones ambientales (presión, temperatura y humedad relativa) se c realizar mediante una unidad meteorológica, la densidad del combustible por medio de densímetro de gasolina, para la masa de combustible se puede usar una balanza; además, se requ de un sistema de diagnóstico a bordo del vehículo o un OBD-II y un sistema de posicionami para medir segundo a segundo la distancia durante el recorrido.

\section{Figura 3.}


Una mirada investigativa en la ingeniería.Gestión energética y telecomunicaciones

Ira 3.

tocolo de pruebas de consumo de combustible en ruta

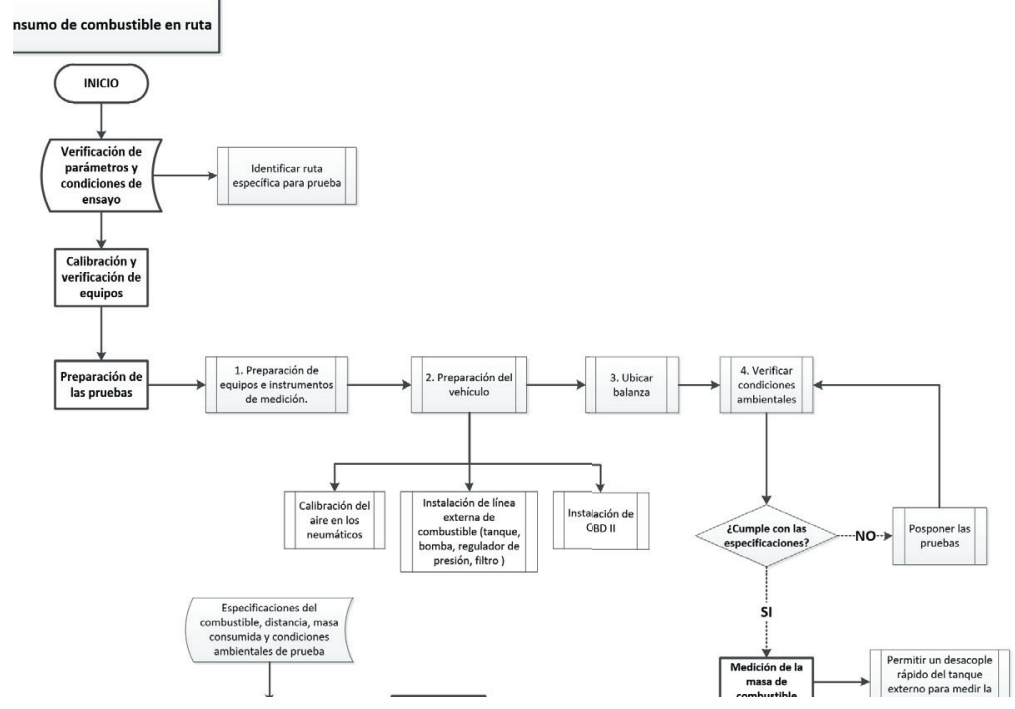

ıdicionalmente, se debe simular la línea de combustible del vehículo, tal como se presenta en igura 4, con el fin de poder extraer para cada prueba el tanque externo de combustible y realizar nediciones.

\section{igura 4.}

istema externo para alimentación del motor en pruebas de ruta.

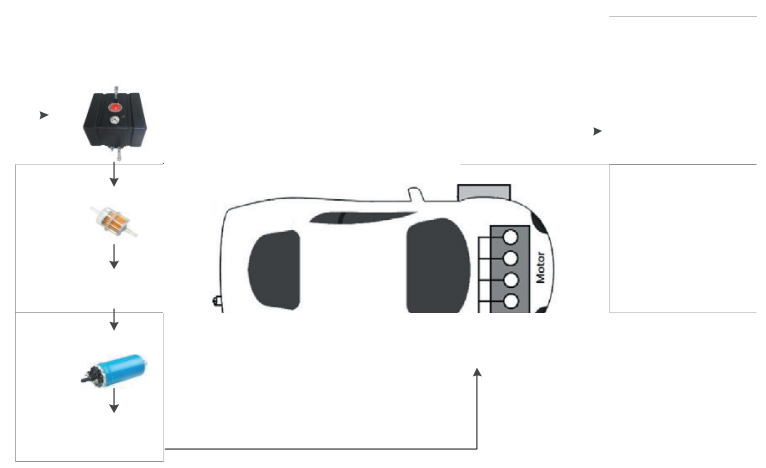




\section{Resultados}

En la búsqueda de la reducción del consumo de combustible de los vehículos livianos y d determinación del potencial de la estrategia, se planteó implementar la conducción eficiente sı un vehículo liviano en la ciudad de Pereira. Por lo tanto, para abordar la estrategia y realizal ensayos se ejecutó el procedimiento ilustrado en la Figura 5.

\section{Figura 5.}

Procedimiento para la evaluación de la conducción eficiente.

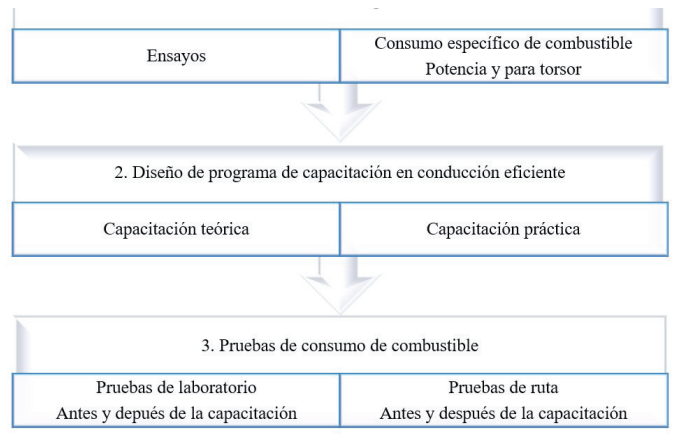

Para efectuar una conducción eficiente es importante conocer la situación actual de operación del vehículo, en este sentido haciendo uso del equipo dinamómetro de chasis - Dynapack 2000 del Laboratorio de Pruebas Dinámicas Automotrices y considerando los lineamientos de la norma SAE J1349, se realizaron pruebas de potencia, par torsor y consumo específico de combustible del vehículo a diferentes regímenes de revolución, empezando en 1500 RPM e incrementando 500 RPM hasta llegar a 4000 RPM. En los datos obtenidos, se puede identificar que el par máximo del vehículo es de 114,22 Nm, y que el vehículo a 2500 RPM presenta condiciones de operación de consumo específico mínimo con un par cercano al máximo. La Figura 6, presentan la relación entre el consumo específico de combustible y el torque del vehículo.

\section{Fionra 6.}


ura 6.

rebas de Consumo Especifico Vs Torque.

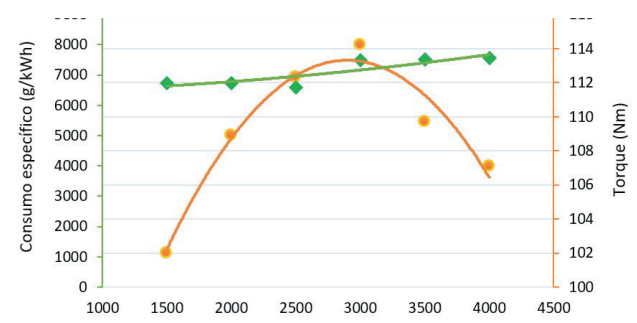

or lo tanto, con base en los resultados mencionados y dando un sustento práctico a la teoría de uentes bibliográficas consultadas [42], [43], se infiere que para realizar una conducción ente en un vehículo liviano tipo automóvil con un motor de $1600 \mathrm{~cm}^{3}$ del sector transporte por :tera, se debe operar en un rango de revoluciones de 2000 RPM a 2500 RPM, y realizar los jios de marcha deben realizarse a máximo 2500 RPM.

\section{bas de ruta}

ara el desarrollo de las pruebas de conducción eficiente, se identificó una vía representativa la ciudad de Pereira, teniendo en cuenta las rutas estudiadas para la generación del ciclo de ucción del área metropolitana centro occidente, con una modificación debida a la necesidad ledición de masa de combustible en el laboratorio y a los cambios en la infraestructura vial de udad [44]. La ruta inicia en el Laboratorio de Pruebas Dinámicas Automotrices de la 'ersidad Tecnológica de Pereira, pasa por la calle 17 rumbo al terminal de transporte, sigue por enida Las Américas en el tramo comprendido entre el Museo de Arte y Mercasa, se realiza el no por la rotonda vía Cartago-Manizales, se devuelve por el mismo tramo, hasta llegar al ro Comercial la 14, en donde se escoge la vía Armenia y se cruza hacia el túnel de la calle 15, 
Los ensayos de rendimiento de combustible en ruta se realizaron con el apoyo de cu conductores (tres hombres y una mujer). De los cuales dos operaron en horas pico (7 - 8 am) ( $2 \mathrm{pm})$ y tres en horas valle $(8-12 \mathrm{am})(2 \mathrm{a} 6 \mathrm{pm})$ de manera aleatoria, con el fin de involucra tráfico habitual. Cada recorrido presenta una duración de aproximadamente 45 minutos y se ejecutaron siguiendo los requerimientos de condiciones ambientales de las normat: internacionales [35], [41].

Inicialmente, se realizaron un número representativo de pruebas iniciales con el fin determinar el rendimiento de combustible promedio que presenta un conductor en la seleccionada. Seguido a esto, se realizó una capacitación teórica donde se dio a conocer prácticas a seguir durante los recorridos, y en constante monitoreo durante la ejecución di prueba, se desarrolló el mismo número de pruebas que en la parte inicial.

Por otro lado, la conducción eficiente contiene conceptos teóricos y prácticos, que fueron incorporados en un programa de capacitación, el cual busca introducir de forma clara las práct a realizar e incentivar al conductor para incluirlas en su comportamiento habitual, entre los tes tratados durante la capacitación y el desarrollo de las pruebas se encuentran:

- Funcionamiento de motores, consumo de combustible y emisiones en el transporte.

- Beneficios de la conducción eficiente sobre el vehículo y el conductor. o

Planificación de viaje y uso adecuado de componentes del vehículo. o

Elección de marcha durante el recorrido y uso de freno. o Conducción 
a Tabla 2 presenta algunos de los registros de variables y resultados obtenidos para las pruebas iales y después de la capacitación en conducción eficiente, cabe aclarar que para cada prueba zalizó un total de 20 ensayos.

Tabla 2.

insayos realizados durante la implementación de la estrategia

\begin{tabular}{|c|c|c|c|c|c|}
\hline \multirow[b]{2}{*}{ Ensayo } & \multirow{2}{*}{$\begin{array}{l}\text { Masa } \\
\text { isumida } \\
\text { [kg] }\end{array}$} & \multirow{2}{*}{$\begin{array}{l}\text { Isidad Distaı } \\
\text { bustible } \\
\text { y/m3] }\end{array}$} & $\begin{array}{l}\text { Condiciones } \\
\text { ambientales } \\
\end{array}$ & \multirow{2}{*}{$\begin{array}{l}\text { olumen } \\
\text { mbustible } \\
\text { nsumido }\end{array}$} & \multirow{2}{*}{$\begin{array}{l}\text { Rendimiento } \\
\text { le } \\
\text { ombustible } \\
\text { km/l] }\end{array}$} \\
\hline & & & $\begin{array}{cc}\operatorname{lamb} \text { ratm } & \varphi \\
{\left[{ }^{\circ} \mathrm{C}\right]} & {[\mathrm{hPa}]} \\
{[\%]}\end{array}$ & & \\
\hline
\end{tabular}

\begin{tabular}{|c|c|c|c|c|c|c|}
\hline 3 & 1,60 & 22,3 & 21,1 & 73,6 & 2,18 & $10 ., 22$ \\
\hline \multirow[t]{2}{*}{7} & 1,51 & 22,31 & 22,3 & 70,2 & 2,06 & 10,82 \\
\hline & & & & $\ldots$. & & \\
\hline 2 & 1,19 & $22,1:$ & 27 & 56,6 & 1,61 & 13,71 \\
\hline 6 & 1,40 & $22,3 i$ & 22,8 & 76,6 & 1,90 & 11,77 \\
\hline
\end{tabular}

ie realizaron pruebas estadísticas de los resultados obtenidos, con el fin de identificar si el odo empleado para la medición del consumo de combustible en ruta se encuentra dentro de una ibución aceptable. Para ello, se empleó el coeficiente de variación CV, o desviación estándar 
lecturas, tal como se presenta en la ec.(3) [45].

$$
\% C V=\begin{aligned}
& S \\
& X
\end{aligned} * 100
$$

donde,

$S:$ es la desviación estándar de las lecturas.

$X$ : es el promedio de la totalidad de las lecturas.

Un coeficiente de variación menor al $10 \%$, valida los resultados obtenidos en las pruebas ejecutadas [38].

El análisis estadístico para la validación de los resultados obtenidos en las pruebas realizadas en ruta se presenta en la Tabla 3. En este se identifica que, aunque las pruebas de ruta están dentro del rango aceptable de desviación estándar y que la desviación estándar es menor para las pruebas iniciales, sin embargo, el criterio de validez sigue estando dentro del rango de confiabilidad, puesto que el coeficiente de variación es de $8,29 \%$.

Tabla 3.

\begin{tabular}{|c|c|c|c|}
\hline \multicolumn{2}{|c|}{$\begin{array}{c}\text { Análisis estadistico en pruebas de ruta. } \\
\text { Pruebas sin conducción eficiente }\end{array}$} & \multicolumn{2}{c|}{ Pruebas en conducción eficiente } \\
\hline & & & \\
\hline & $0,1298 \mathrm{~km} / 1$ & $\mathrm{U}(\mathrm{R})$ & $0,1612 \mathrm{~km} / 1$ \\
\hline $\mathrm{U}(\mathrm{R})$ & $10,594 \leq \mathrm{R} \leq 10,854$ & $\begin{array}{c}\text { zndimiento de } \\
\text { mbustible } \\
{[\mathrm{km} / 1]}\end{array}$ & $75 \leq \mathrm{R} \leq 13,1$ । \\
\hline $\begin{array}{c}\text { Rendimiento de } \\
\text { combustible } \\
{[\mathrm{km} / 1]}\end{array}$ & \begin{tabular}{c}
$\mathrm{k}$ \\
\hline
\end{tabular}
\end{tabular}

En la Figura 7 se puede observar que los datos se mantienen por dentro de los criterios permitidos de la desviación estándar; 3 veces la desviación estándar por encima del promedio y menos 3 veces la desviación estándar por debajo del promedio, para una distribución normal de probabilidad. 
snsumo de combustible, puesto que, a medida que los conductores practican las técnicas ejecut s recomendaciones con mayor facilidad y el rendimiento del vehículo aumenta.

\section{igura 7.}

'ispersión de datos en pruebas de conducción eficiente en ruta

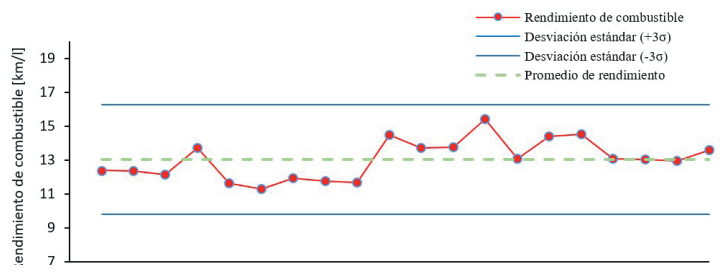

Con base en los resultados se puede determinar que la conducción eficiente es una estrateg lable para la reducción del consumo de combustible en los vehículos livianos. En la Figura 8, lede observar el porcentaje de aumento del rendimiento de combustible y el contraste con orcentaje de tiempo adicional invertido en la realización de las pruebas. ico.

a) Conducción eficiente en horas valle.

b) Conducción eficiente en horas 

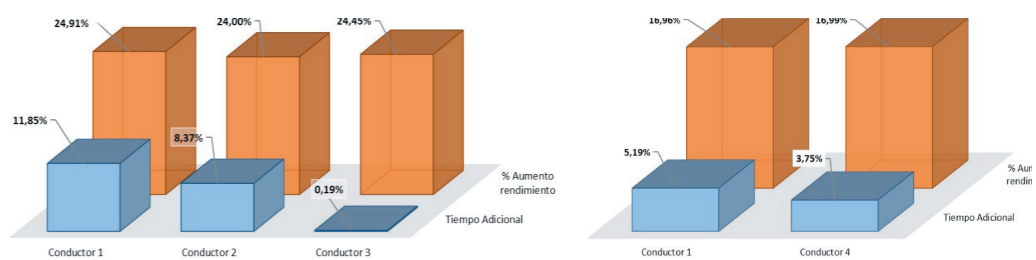

Se puede determinar que aun cuando se debe adicionar un tiempo para realizar conducción əficiente, este es mínimo en comparación con la notoria reducción del consumo de combustil ıdemás, se evidencia que el aprovechamiento de las técnicas va directamente relacionado col sersona que las practica, tal como lo demuestra el conductor 3 en la ejecución de las pruebas 1oras valle, el cual obtuvo el mismo porcentaje de aumento del rendimiento sin inversión de tien ıdicional. Además, los ensayos realizados indican que el efecto del tráfico en horas pico es elevante al implementar conducción eficiente, puesto que, se presenta un 7,48\% de reducción endimiento del combustible en comparación con los ensayos realizados en horas valle.

\section{Conclusiones}

A continuación, se presentan las conclusiones encontradas en la ejecución del proyecto:

Durante la revisión del estado del arte se identificó que existen estrategias tecnológicas y operacionales que pueden ser aplicables en vehículos livianos para mejorar la eficier energética. De igual forma, se identificó la metodología de consumo de combustible y el método de medición, que permiten evaluar las estrategias implementadas en ruta y definiı forma segura si la estrategia es efectiva considerando factores reales de las carreteras. anterior, permite identificar que estrategias pueden ser implementadas a gran escala en 
Colombia para impactar positivamente sobre la reducción del consumo de combustible y las emisiones vehiculares, lo cual aporta a las metas planteadas en los pactos gubernamentales.

Se identificó la conducción eficiente como una de las estrategias de eficiencia energética viable para ser implementada en el territorio colombiano, puesto que, su costo-beneficio es bajo, permite la reducción en el consumo de combustible, la tasa de accidentalidad y las emisiones de $\mathrm{CO}_{2}$, adicionalmente es una estrategia cómoda para aplicar, entender y con amplios canales de información.

Se definieron las especificaciones técnicas de los equipos, y el protocolo de pruebas para llevar a cabo la implementación de la medición del consumo de combustible en ruta bajo el método gravimétrico, tomando en consideración que las capacidades tecnológicas y de infraestructura de los laboratorios en Colombia favorecen su implementación. Adicionalmente, se establecieron los criterios de aseguramiento metrológico necesarios para garantizar la repetibilidad y confiabilidad en los resultados en la realización de pruebas de ruta.

Se determinó que la implementación de la conducción eficiente como estrategia de efíciencia energética en vehículos livianos permite reducir en el consumo de combustible. Las pruebas realizadas bajo las características de operación de los vehículos en

Pereira, se obtuvo una reducción general de hasta un $20 \%$ en el consumo. Conducir de forma eficiente puede aumentar de $4,47 \%$ a $6,8 \%$ el tiempo de un recorrido en la ciudad. Sin embargo, aun cuando se debe adicionar un tiempo para realizar conducción eficiente, este es mínimo en comparación con el notorio aumento del rendimiento de combustible, además, se evidencia que el aprovechamiento de las prácticas va directamente relacionado con la persona que las eiecuta. 


\section{Bibliografía}

[1] Icontec International, “Norma Técnica Colombiana - NTC ISO 50001,” no. 571. 2011.

[2] L. Michaelis and O. Davidson, "GHG mitigation in the transport sector," Energy Policy vol. 24 , no. 10-11, pp. 969-984,

Oct. 1996

[3] G. R. Timilsina and A. Shrestha, "Transport sector CO2 emissions growth in Asia: Underlying factors and policy

options," Energy Policy, vol. 37, no. 11, pp. 4523-4539, Nov. 2009.

[4] CTS Embarq México, "Documento base para la elaboración de la "Estrategia de Transición para promover el uso de Tecnologías y Combustibles más limpios" en el ten de ahorro de energía en transporte." 2015.

[5] Agencia Chilena de Eficiencia Energética, "Guía de Conducción Eficiente Vehículos particulares." 2013.

[6] J. B. Mariano and Superintendencia de Planificación e Investigación, "Eficiencia Energética en Brasil," 2012.

[7] C. Gavilán Labra and Agencia Chilena de Eficiencia Energética, "Etiquetado vehicular Chile y otras medidas de

eficiencia energtica para vehículos particulares," 2013.

[8] U.S. Department of Energy - Energy Efficiency and Renewable Energy, "Learn More About the Fuel Economy Label for

Gasoline Vehicles." [Online]. Available: https://www.fueleconomy.gov/feg/label/learn. more-gasoline-label.shtml.

[Accessed: 26-Dec-2016].

[9] M. Andrejić, N. Bojović, and M. Kilibarda, “A framework for measuring transport efficiency in distribution centers," Transp. Policy, vol. 45, pp. 99-106, Jan. 2016.

[10] J. Wu, Q. Zhu, J. Chu, H. Liu, and L. Liang, "Measuring energy and envis efficiency of transportation systems in China based on a parallel DEA approach," Transp. Res. Part D Transp. Environ., Sep 2015 . 
CO2 emissions reduction and welfare gains," Transp. Policy, vol. 42, pp. 144-155, Aug. 2015 .

F. B. Chaaban, I. Nuwayhid, and S. Djoundourian, "A study of social and economic implications of mobile sources on

air quality in Lebanon," Transp. Res. Part D Transp. Environ., vol. 6, no. 5, pp. 347-355, Sep. 2001.

A. Singh, S. Gangopadhyay, P. K. Nanda, S. Bhattacharya, C. Sharma, and C. Bhan, "Trends of greenhouse gas

emissions from the road transport sector in India," Sci. Total Environ., vol. 390, no. 1, pp. 124-31, Feb. 2008.

J. Pongthanaisawan and C. Sorapipatana, "Greenhouse gas emissions from Thailand's transport sector: Trends and

mitigation options," Appl. Energy, vol. 101, pp. 288-298, Jan. 2013.

J. P. Ribau, C. M. Silva, and J. M. C. Sousa, "Efficiency, cost and life cycle CO2 optimization of fuel cell hybrid and

plug-in hybrid urban buses," Appl. Energy, vol. 129, pp. 320-335, Sep. 2014.

Á. I. Cadena, O. V. González, O. Báez, and Unidad de Planeacion Minero Energética, "Eficiencia Energética En

Colombia Estrategias y metas," 2014.

Unidad de Planeación Minero-Energética, "EFICIENCIA ENERGÉTICA Y TRANSPORTE EN COLOMBIA,” 2015.

I. F. Okafor, G. O. Unachukwu, and A. O. Odukwe, "Measuring energy efficiency of the public passenger road transport

vehicles in Nigeria," Transp. Policy, vol. 35, pp. 319-325, 2014. 
Indicativo De Eficiencia

Energética 2017 - 2022,”p. 157, 2017.

[20] T. M. I. Mahlia, S. Tohno, and T. Tezuka, "A review on fuel economy test procedure $\mathrm{f}$ automobiles: Implementation

possibilities in Malaysia and lessons for other countries," Renew. Sustain. Energy Rev. vol. 16, no. 6, pp. 4029-4046, 2012.

[21] V. Ş. Ediger and Ü. Çamdali, "Energy and exergy efficiencies in Turkish transportatio. sector, 1988-2004," Energy Policy, vol. 35, no. 2, pp. 1238-1244, 2007.

[22] G. Ombach and J. Junak, "Weight and efficiency optimization of auxiliary drives used automobile," 19th Int. Conf.

Electr. Mach. ICEM 2010, 2010.

[23] S. Kobayashi, S. Plotkin, and S. K. Ribeiro, "Energy efficiency technologies for road vehicles," Energy Effic., vol. 2, no.

2, pp. 125-137, 2009.

[24] HM Treasury, The King Review of low-carbon cars - Part I: the potential por CO2 reduction, no. November. 2007.

[25] G. Fontaras and Z. Samaras, "On the way to $130 \mathrm{~g} \mathrm{CO} / \mathrm{km}$-Estimating the future characteristics of the average European

passenger car," Energy Policy, vol. 38, no. 4, pp. 1826-1833, 2010.

[26] J. Pandazis and A. Winder, "Study of Intelligent Transport Systems for reducing CO 2 emissions for passenger cars," Eur. Road Transp. Telemat. Implement. Coord. Organ., 1, no. 9, p. 49, 2015.

[27] R. Improvements, Making Cars More Fuel Efficient: Technology for real improvemen. the road, vol. 9789282103. 2005. 
G. Helfand et al., "Searching for hidden costs: A technology-based approach to the energy efficiency gap in light-duty

vehicles," Energy Policy, vol. 98, pp. 590-606, 2016.

R. A. Simmons, G. M. Shaver, W. E. Tyner, and S. V. Garimella, “A benefit-cost assessment of new vehicle

technologies and fuel economy in the U.S. market," Appl. Energy, vol. 157, pp. 940-952, 2015.

S. Skippon, S. Veeraraghavan, H. Ma, P. Gadd, and N. Tait, "Combining technology development and behaviour change

to meet $\mathrm{CO} 2$ cumulative emission budgets for road transport: Case studies for the USA

and Europe," Transp. Res. Part A Policy Pract., vol. 46, no. 9, pp. 1405-1423, 2012.

S. Birrell, J. Taylor, A. McGordon, J. Son, and P. Jennings, "Analysis of three independent real-world driving studies: A

data driven and expert analysis approach to determining parameters affecting fuel

economy," Transp. Res. Part D Transp. Environ., vol. 33, pp. 74-86, 2014.

I. Jeffreys, G. Graves, and M. Roth, "Evaluation of eco-driving training for vehicle fuel use and emission reduction: A

case study in Australia,” Transp. Res. Part D Transp. Environ., 2016.

S. H. Ho, Y. D. Wong, and V. W. C. Chang, "What can eco-driving do for sustainable road transport? Perspectives from

a city (Singapore) eco-driving programme,” Sustain. Cities Soc., vol. 14, no. 1, pp. 82-88, 2015.

M. Nesbit et al., "Comparative Study on the differences between the EU and US legislation on emissions in the

automotive sector,” Eur. Parliam. Com., 2016

Asociacao Brasileira de NormasTécnicas, “ABNT NBR 7024 - Veículos rodoviários automotores leves - Medicao do consumo de combustivel - Método de ensaio.” pp. 1-8, 201 
consumo de combustivel - Metodo de ensa1o." pp. 1--

[36] Organismos Nacionales de Normalización (ONN) de las Américas, "COPANT - Comi Panamericana de Normas

Técnicas.” [Online]. Available: http://www.copant.org/index.php/es/. [Accessed: 18-Jı $2017]$.

[37] U.S. Government Publishing Office, "CFR 40 - Code of Federal Regulations." [Onli1 Available:

https://www.ecfr.gov/cgi-bin/text-idx?tpl=/ecfrbrowse/Title40/40tab_02.tpl. [Accessec 18-Jul-2017].

[38] ABNT, "NBR 10312 - Veículos rodoviários automotores leves - Determinação da resistência ao deslocamento por desaceleração livre em pista de rolamento e simulação em dinamômetro," 2014.

[39] M. Kisan, S. Sangathan, J. Nehru, and S. G. Pitroda, "Automotive Vehicles Determination of Road-Load Constants by coast Down Test Method,” 2000.

[40] J. C. López et al., "Development of a fuel consumption measurement methodology for light duty vehicles in Colombia,

based on metrological principles," 30th Int. Conf. Effic. Cost, Optim. Simul. Environ. Impact Energy Syst. ECOS 2017, vol. 87, no. 212, pp. 47-56, 2017.

[41] Associacao Brasileira de Normas Técnicas, “ABNT NBR 6601 - Veículos rodoviários automotores leves -

Determinação de hidrocarbonetos, monóxido de carbono, óxidos de nitrogênio, dióxidı carbono y material particulado no gás de escapamento.” 2005.

[42] Senter Novem and IDAE - Instituto para la Diversificación y Ahorro de la Energía, "L Conducción Eficiente."

[43] IDAE - Instituto para la Diversificación y Ahorro de la Energía and Ministerio de Indu Turismo Comercio,

“Eficiencia en el Transporte: Manual de conducción Eficiente,” 2006.

[44] A. Hurtado Gómez, “'Desarrollo de ciclos de conduccion para el área metropolitana ce occidente - Amco,"” 2014.

[45] S. Sandoval, "Guía Técnica: Validación de métodos y determinación de la incertidumb de la medición,” Zhurnal Eksp.

i Teor. Fiz., p. 66, 2010. 


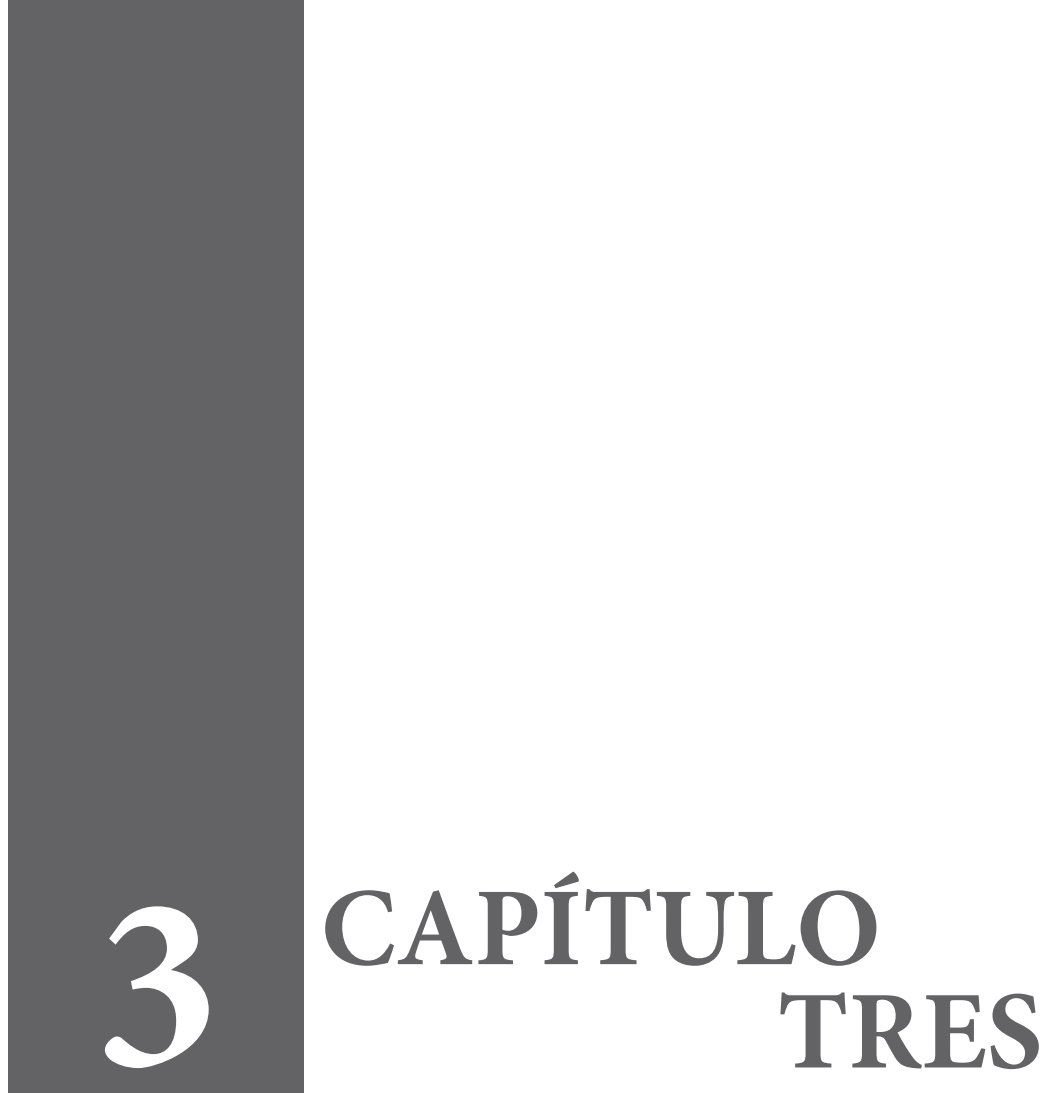





\title{
Caracterización De Señales Electrocardiográficas Para Identificación De Arritmias Cardiacas
}

\author{
Characterization of Electrocardiographic Signals for \\ Identification of Cardiac Arrhythmias
}

\author{
Ana María López Echeverry, Jovany Bedoya Guapacha, Sebastián López Flórez \\ Universidad Tecnológica de Pereira \\ anamayi@utp.edu.co,jovan@utp.edu.co, sebastianlopezflorez@utp.edu.co
}

\begin{abstract}
Resumen
Las enfermedades cardiovasculares son unas de las principales causas de muerte a nivel mun y entre estas enfermedades se encuentran las arritmias cardíacas. El proyecto tiene como propć identificar con la ayuda de un módulo de análisis inteligente diferentes tipos de arritmias permitan un diagnóstico oportuno por parte de los médicos tratantes. En este proyecto fue pos la caracterización de las señales tomadas por monitores ambulatorios externos, por medio di módulo de procesamiento de datos que hace uso de la TW (Transformada Wavelet) y fil digitales para la extracción y análisis de patrones naturales que se encuentran dentro d electrofisiología del corazón como son el complejo QRS, el segmento PR, el segmento QF segmento RS y el segmento ST, para luego pasar por una etapa de clasificación con base en máquinas de soporte vectorial. A través del proyecto fue posible demostrar que, mediante el mor propuesto, se puede generar una herramienta automática de detección de arritmias cardíacas cr un elemento de ayuda para la toma de decisiones de remisión de pacientes a valoración pc médico especialista
\end{abstract}

Palabras claves: Arritmia cardiaca, transformada wavelet, filtros, máquinas de soporte vector

\begin{abstract}
Cardiovascular diseases are one of the main causes of death worldwide, and among these dise are cardiac arrhythmias. The purpose of the project is to identify with the help of an intelli: analysis module different types of arrhythmias that allow a timely diagnosis by treating doctor: this project it was possible to characterize the signals taken by external ambulatory monitors means of a data processing module that makes use of the TW (Wavelet Transform) and dis filters for the extraction and analysis of natural patterns found within of the electrophysiolog the heart such as the QRS complex, the PR segment, the QR segment, the RS segment and the
\end{abstract}


ment, and then go through a classification stage based on vector support machines. Through the ject, it was possible to demonstrate that using the proposed model, an automatic cardiac tythmia detection tool can be generated as an aid to decision-making regarding the referral of ents for evaluation by the specialist physician.

Iwords: Cardiac arrhythmias, Wavelet Transform, filters, vector support machines.

\section{oducción}

a muerte súbita es una muerte natural, inesperada y rápida que se presenta dentro de la primera a después del inicio de síntomas [27]. La causa más común de la muerte súbita son las ərmedades Cardiovasculares (ECV), que además se constituyen en una de las principales causas nuerte en todo el mundo. En 2012, la Organización Mundial de la Salud (OMS) registró 17,5 lones de muertes por ECV, que representan el $31 \%$ de todas las muertes registradas en el mundc De acuerdo al segundo informe del observatorio nacional de salud, que incluyó en el análisis a mortalidad el período comprendido entre los años 1998 y 2011, la principal causa de muerte vel nacional es la enfermedad isquémica cardiaca [28]. Esto evidencia la necesidad de conta1 sistema de diagnóstico oportuno que permita la inclusión de los pacientes con problemas liacos en las rutas de atención integral.

_as diferentes características presentes en la señal ECG están asociadas con tipos específicos de . Por ejemplo, El bloqueo de rama izquierda (LBBB) se diagnostica mediante la morfología $\mathrm{S}$ distinta en las derivaciones I, aVL, V1, V2, V5 y V6, mientras que el bloqueo de rama derecha :BB) se diagnostica mediante el patrón rsR' en V1 y V2 [29]. Esto se puede observar en la gen 1, donde en el bloqueo de rama izquierda (LBBB), el patrón se detecta mejor en V6 donde un patrón "M", mientras que en V1 hay un patrón "W"「32]. Adicionalmente, en el bloqueo de 
rama derecha (RBBB), el patrón se detecta mejor en V1 donde hay un complejo RSR, mientra en V6 hay un complejo QRS. Para reconocer de manera confiable estas características comf de ECG asociadas con AC, es posible capacitar un sistema dotado de inteligencia. De hech estudios han demostrado que los internistas o cardiólogos a veces diagnostican erróneament tipos de Ac [30]. El crecimiento significativo del número de exámenes de ECG, que aumenta médicos su carga de trabajo, exacerba el problema. Esta situación podría aliviarse mediar desarrollo de algoritmos informáticos capaces de producir diagnósticos precisos y automáticos ayudar a los médicos. Aunque tal tarea sería difícil debido a la gran variación en las caracterís geométricas y fisiológicas de las señales de ECG [31, 10].

Figura 1.

Patrones de electrocardiograma de bloqueo de rama izquierda y bloqueo de rama derecha.

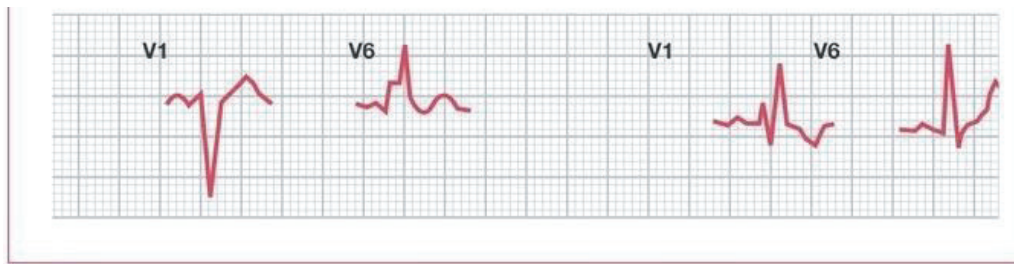

Fuente: [32]

El proyecto se inició con un estudio a nivel de estado del arte partiendo del problema identificando diferentes técnicas y herramientas de solución, se continuó con la etapa de diseí los módulos de caracterización, clasificación y visualización como se muestra en la imagen : permite tener una primera aproximación a los componentes del sistema, para posteriormente ] a la etapa de implementación y validación de funcionalidad. Por último, se realizó la validacis la solución mediante dos conjuntos de datos de prueba, uno a partir de la base de datos MIT 
, el segundo consistió en una base de 10 pacientes entregada por el médico especialista que Ió el desarrollo del proyecto, permitiendo esta segunda instancia de validación contar con ıos resultados a partir de datos de la región.

os resultados obtenidos por medio de la aplicación prototipo generada con el sistema integrado iitió la clasificación de las señales bloqueo de rama derecha (RBBB), bloqueo de rama ierda (LBBB) y latido NORMAL.

'on base en los resultados, se valida la hipótesis planteada, donde el sistema fue capaz de ficar diferentes arritmias a partir de una arquitectura simple identificando las arritmias ridas por el médico que más afectaban la región.

'igura 2.

squema general del proceso de prediagnóstico.
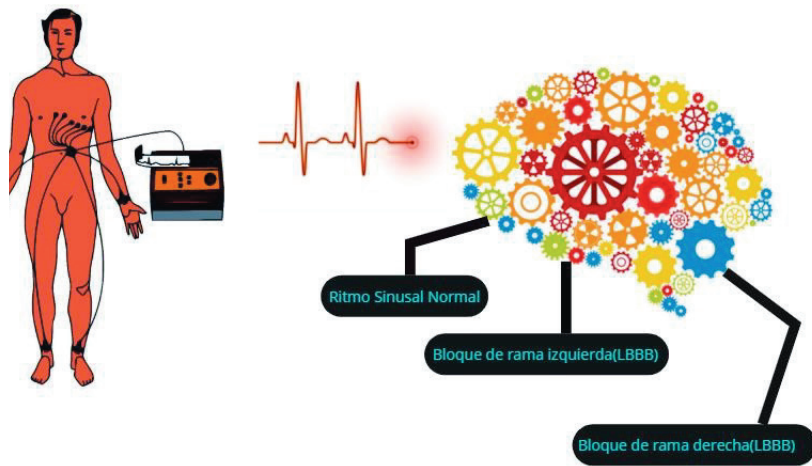

nte: Elaboración propia. 


\section{Planteamiento del problema y justificación}

En Colombia, la primera causa de muerte es la enfermedad coronaria en 25 departamentos, segunda causa en 7 departamentos (Arauca, Valle del Cauca, Guaviare, Cauca, La Guajira, Putumayo y Guainía) [2]. Las arritmias son una causa importante de morbilidad y mortalidad, $\epsilon$ las cuales se destacan las taquiarritmias ventriculares agudas que son la mayor causa de muє súbitas, a menudo provocadas por eventos coronarios agudos. Éstas pueden presentarse en persı sin enfermedad cardíaca conocida o en asociación con cardiopatía estructural. [4]. La Polític Atención Integral en Salud -PAIS adoptada mediante la resolución 429 de 2016, establece de de sus principios para la atención en salud, el compromiso con la persona, al considerar el conte entorno y cultura con un enfoque diferencial territorial bien sea urbano, de alta ruralidad, ó : rural dispersa, estableciendo un reto para las entidades prestadoras de servicios de salud, al t que garantizar procesos de atención primario en sitios alejados de los grandes centros urbanos. embargo, los pacientes en zonas apartadas no cuentan con fácil acceso a profesionales especial en las zonas de residencia. Es por ello que se hace necesario generar soluciones que ayud brindar acceso a procesos de diagnóstico oportuno a las personas sin importar su ubicación fj ó qué tan alejados se encuentren de los centros urbanos con servicios de mayor nivel.

Establecen los autores en [3] que la clasificación automática de latidos cardíacos se ha origir en ocasiones a partir de métodos de procesamiento de señales del complejo QRS, teniendı cuenta que este complejo QRS representa la característica más pronunciada de una señal ECG señal P, Q, R, S y T se refiere a diferentes ubicaciones y frecuencias de la actividad cardíaca les brinda a los médicos pistas para detectar daño [5]. 
ıdicionalmente, mediante la transformada discreta de wavelet (TDW) es posible realizar una omposición adaptativa de tiempo-frecuencia en un patrón correspondiente, lo que permite эer patrones naturales que se encuentran dentro de la electrofisiología del corazón como lo son smplejo QRS, el segmento PR, el segmento QR, el segmento RS y el segmento ST según Jlecen los autores en [6]. Teniendo en cuenta que estos patrones se ven modificados por el o proveniente de la muestra ECG por medio de la filtración es posible eliminar las señales no adas que modifican el patrón de comportamiento de la señal original. [7]

a razón principal de este estudio es aportar a los profesionales en el área una herramienta de ıo para el diagnóstico de enfermedades cardiacas con base en el análisis del electrocardiograma. tecnologías de la información y las comunicaciones aplicadas a la salud posibilitan un gran ero de soluciones a las problemáticas de este sector, brindando opciones para optimizar los mas integrales de salud en países en vía de desarrollo como el nuestro. Se busca implementar Itegias que beneficien un gran número integrantes de la sociedad por medio de sistemas znibles económicamente, de fácil aceptación y buenos resultados, teniendo en cuenta las dades sociales y económicas del país.

\section{etivos}

arrollar un sistema de diagnóstico automático que apoye la detección de algunas enfermedades corazón, mediante la caracterización y clasificación de señales por medio de herramientas zmáticas como la transformada Wavelet y de algoritmos de clasificación inteligentes. 
características de la señal electrocardiográfica y sobre los métodos matemáticos para la identificación y análisis de señales biológicas.

Diseñar un módulo de caracterización de las ondas de señal que hacen parte del electrocardiogr

Diseñar un módulo de clasificación a partir de las características de la señal ECG que pe] identificar tanto arritmias como señales normales.

Desarrollar un prototipo de aplicación web que integre los módulos de caracterización y clasificación que permita la visualización del diagnóstico a partir de la señal ECG de entrada.

\section{Referente teórico}

La solución de problemáticas de diferentes sectores requiere una mirada interdisciplinaria. por esto que en este proyecto se abordan elementos de la salud, específicamente del corazór posibilidad de identificar enfermedades cardiovasculares a partir del análisis de señales, para l se requiere integrar conocimientos de las áreas de ingeniería y salud. Se describen algunos conceptos que validan teóricamente la posibilidad de generar diagnósticos a partir del anális señales.

El aparato circulatorio tiene como órgano principal el corazón, es un órgano muscular hur contráctil, dividido en 4 cavidades por medio de tabiques interiores, internamente puede divi 
ventrículos (cavidades inferiores) y aurículas (cavidades superiores). Existen una serie de vulas que controlan el flujo sanguíneo en el corazón, estas están ubicadas en la unión entre e Itrículo y las arterias de salida (unión auriculoventricular), para el lado izquierdo correspondel válvulas mitral y aórtica, y en el lado derecho están las válvulas tricúspides y la pulmonar. [8]

La electrocardiografía es el estudio de la actividad eléctrica del corazón que representa los nbios en el potencial de acción ocurridos durante el ciclo cardiaco; estos cambios son descritos no una serie de vectores que indican la dirección de la despolarización celular en cada una de cavidades cardiacas; por ello, el análisis de la secuencia de propagación del impulso hace tible la deducción del comportamiento electrofisiológico de las estructuras del corazón y de ;ibles anormalidades. El registro de dicha actividad se ve representado en una gráfica que estra una serie de deflexiones en la medida en la que el impulso cardiaco se propaga, pudiendo obtenida a través de aparatos llamados electrocardiógrafos, los cuales, son conectados al :iente mediante cables unidos a electrodos de superficie ubicados sobre el cuerpo según normas ablecidas llamadas derivaciones. La señal electrocardiográfica puede interpretarse de acuerdo I derivación con la que es captada, ya que cada una de estas, representa la lectura de la magnitud irección de los vectores del potencial de acción desde distintos lugares de referencia [9].

Un electrocardiograma (ECG - EKG) es un examen que muestra por medio de una gráfica de li ividad eléctrica del corazón, la cual es adquirida a través del electrocardiógrafo. El ECG S liza básicamente para diagnosticar enfermedades cardiacas como infartos, medir el ritmo y li ularidad de los latidos, así como la posición y el tamaño de las cámaras cardiacas, la señal se iene a través de una serie de electrodos ubicados en diferentes partes del cuerpo llamado ivaciones, por lo tanto la causa principal para la realización de un electrocardiograma se debe : 
fue este examen es de gran utilidad para determinar si una persona padece de dolencias cardia J no [10][11].

Durante las fases de despolarización y polarización del corazón, se registran en el ECG nor] ına serie de ondas como son la P, el complejo QRS, la onda T, la onda U, los segmentos P-R J $\Gamma$ y el intervalo Q-T [12][13].

\section{Figura 3.}

\section{Señal Electromiográfica}

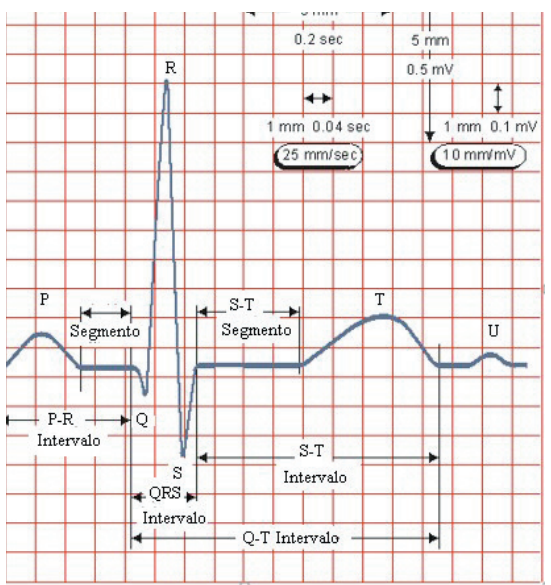

Fuente: www.fi.uba.ar/materias/6643/u3_cardiologia.pdf. (2006)

La imagen 3 muestra las diferentes ondas. La onda P: es una pequeña onda que corresponc la despolarización de las aurículas (Contracción o sístole auricular), la anchura de una ond Jetermina el tiempo que demora un impulso en pasar del nodo SA al nodo AV con una durac náxima de 0,10 s. 
entrículos (despolarización ventricular). Es el componente más característico del ECG.

: inicia con una onda descendente, continúa con una onda rápida triangular ascendente y za con una pequeña deflexión. Está constituido por la sucesión de las ondas Q, R, S. Duración 60-100ms.

nda Q: representa la deflexión negativa inicial resultante de la despolarización ventricular, que :de a la onda R, con una duración habitual de $40 \mathrm{~ms}$.

nda R: es la primera deflexión positiva que aparece durante la despolarización ventricular.

nda S: es la segunda deflexión negativa que se obtiene durante la despolarización ventricular al en ocasiones puede no visualizarse.

nda T: es la onda positiva ascendente y suave que aparece después del complejo QRS y senta la repolarización ventricular (relajación o diástole ventricular). Tiene una duración de rimadamente $200 \mathrm{~ms}$ o menos.

nda U: Esta onda no es constante, tiene una dirección positiva, aunque puede ser negativa, su 
Segmento S-T: representa el intervalo entre el final del complejo QRS y el inicio de la ond Este segmento se asocia con el proceso de recuperación o repolarización ventricular. Durar típica: $240 \mathrm{~ms}$.

Segmento P-R: corresponde a la línea isoeléctrica definida desde el comienzo de la onda $\mathrm{P} \mathrm{h}$ la deflexión inicial del complejo QRS. La duración normal de este segmento está entre los 0 , $\operatorname{los} 0,21 \mathrm{~s}$.

Intervalo R-R: equivale a la distancia entre dos ondas $\mathrm{R}$ sucesivas, con una duración típica e $600-1000 \mathrm{~ms}$

Intervalo Q-T: es la distancia desde el inicio de la onda Q hasta el final de la onda T. Repres el principio de la despolarización ventricular hasta el final de la repolarización ventricular intervalo Q-T depende la frecuencia cardíaca. Duración típica: 300-400ms.

Intervalo P-P: es la distancia entre dos ondas P sucesivas; sí el ritmo es regular, debe med: mismo que el intervalo RR.

Intervalo P-R: mide la distancia desde el comienzo de la onda P hasta el inicio del comp QRS. Determina el tiempo en el que el impulso eléctrico está viajando del nodo SA, (a través nodo AV) hacia los ventrículos. Duración típica: 120-200ms.

Las arritmias cardíacas se definen como la irregularidad en el ritmo natural del corazón. É

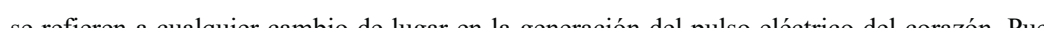


triculares [14].

Las arritmias supraventriculares se producen generalmente en las aurículas, mientas que las tmias ventriculares se producen en los ventrículos. Las arritmias también se definen según la scidad de los latidos [15]:

La bradicardia: es la disminución de la frecuencia cardíaca por debajo de 60 lpm.

Taquicardia: es el aumento de la frecuencia cardíaca por encima de $100 \mathrm{lpm}$.

Existen estudios que presentan resúmenes de los métodos de procesamiento de señales puestos para el filtrado, extracción de características y clasificación de arritmias de una señal G desde el año 1979 hasta el año 2014, dentro de los que se encuentran filtros digitales, análisis ımplitud, ancho de señales y uso de filtros pasa banda y digitales con respecto al método Okada nsformada Wavelet Dyadic, Wavelet spline cuadrática con clasificación por inferencia con ica difusa, Wavelet sombrero mejicano, la función wavelet compleja de Morlet, redes ronales, wavelet spline cuadrática, wavelet Haar, entre otras, denotándose que el análisis diante wavelet es el más usado en el ámbito investigativo hasta ahora para el análisis de señales G.[6]

La transformada Wavelet es una herramienta matemática usada en múltiples aplicaciones en el cesamiento de señales y en Control de Procesos y detección de anomalías sintomáticas en 
de una señal, bloques que son generados desde una única función fija denominada wavelet $\mathrm{n}$ $\psi(t)$ [17], mediante operaciones de traslación y dilatación, a través de la siguiente expresión:

$x-b$

$$
\begin{gathered}
w(\quad) \\
\psi a, b=\sqrt{\mid \overline{|a|}}, a, b \in R, a \neq 0
\end{gathered}
$$

Donde, a y $\mathbf{b}$ son escalares reales, a permite hacer las dilataciones y contracciones de la s y b permite cambiar la posición de la señal en el tiempo. La transformada wavelet proporcion: localización tiempo-frecuencia adaptativa. Si se tiene un nivel de escala baja se obtiene una b resolución en tiempo, pero si se tiene un nivel de escala grande se obtiene buena resolucić frecuencia. Las wavelets están clasificadas por familias, donde el uso de una de ellas depen la aplicación y las características a extraer, algunas familias son: Daubechies, Symlets, Biortogonales.

En el procesamiento de las señales también se usan filtros, estos permiten la discriminaci señales con relación a su contenido espectral, es decir, son sistemas que están diseñados transmitir o bloquear señales dentro de un cierto rango o intervalo de frecuencias. Así, al ran frecuencias dentro del cual las señales pasan inalteradas se conoce como banda de paso, y al intervalo de frecuencias donde las señales son bloqueadas se le llama banda de rechazo. Los $f$ pueden estar conformados por componentes puramente pasivos (resistencias, capacitores e inductores), activos (con amplificadores operacionales) o digitales (implementados con circu digital o programados en una computadora). Existen dos grandes divisiones dentro de 
smas: IOS Intros anaıgıcos que son empıeados para tratamıento de senaies contınuas en eı ıpo, y los filtros digitales que trabajan con señales discretas en el dominio del tiempo [18] [19].

'ara la etapa de clasificación es necesario considerar que existen algoritmos que permiten :nder patrones y luego usar estos para resolver nuevos problemas. Existen dos grandes grupos técnicas para este aprendizaje, aprendizaje supervisado que corresponde a las tareas de ificación y regresión y, aprendizaje no supervisado que corresponde a tareas de agrupamientos rrelaciones. Los algoritmos de aprendizaje supervisado [20] son usados como técnica de :ndizaje de patrones y disminución de la dimensionalidad. Requieren un etiquetado de cada uno os patrones de entrada. El objetivo de los algoritmos de aprendizaje supervisado es construir función a partir de datos de aprendizaje y transformarlos en salidas deseadas. Los algoritmos ıprendizaje no supervisado [21] son unas técnicas de aprendizaje automático en el cual un lelo es ajustado a las observaciones. Se diferencian del aprendizaje supervisado en que no hay prendizaje a priori.

as máquinas de soporte vectorial SVM pertenecen al aprendizaje supervisado, estas construyen liperplano para discriminar entre diferentes tipos de clases y tiende a maximizar el margen y uir cualquier punto de datos mal clasificado en este margen. Se pueden aplicar múltiples :iones de kernel: kernel polinomial, kernel de la función de base radial y Sigmoid [5].

)esde un enfoque bayesiano, el problema de clasificación supervisada consiste en asignar a un :to descrito por un conjunto de atributos o características, $\mathrm{X} 1, \mathrm{X} 2, \ldots, \mathrm{Xn}$, a una de $\mathrm{m}$ clases bles, c1, c2, ..., cm, tal que la probabilidad de la clase dados los atributos se maximiza[22]: 
La formulación del clasificador bayesiano se basa en utilizar la regla de Bayes (compacta) calcular la probabilidad posterior de una clase a partir de sus atributos.

$$
\boldsymbol{P}(\boldsymbol{C} \mid \boldsymbol{X})=\boldsymbol{P}(\boldsymbol{C}) \boldsymbol{P}(\boldsymbol{X} \mid \boldsymbol{C}) / \boldsymbol{P}(\boldsymbol{x})
$$

El algoritmo K vecinos más cercanos (KNN, por sus siglas en inglés) es un método simple, a la vez de alto rendimiento en clasificación. Este se ha usado para diagnosticar algunas enfermedades del corazón de forma automática. El algoritmo KNN clasifica un nuevo vє aplicando un conjunto de entrenamiento sin necesidad de aprender parámetros, a diferencia de c algoritmos que aplicando un conjunto de entrenamiento aprende algunos parámetros y luego utilizando estos últimos clasifica un nuevo vector [23]

Los autores en [24] proponen un sistema AIoT (Artificial IoT) que incluye un dispositivo fr end, una interfaz de usuario de la aplicación y un servidor en la nube para los procesos de Demostrando esto la posibilidad de integrar procesos de análisis de señales, inteligencia artif y sistemas de procesamiento web en una única solución.

Teniendo en cuenta los elementos que se mencionaron en este apartado, en el siguiente pun indica la metodología de desarrollo llevada a cabo en el proyecto. 
$\exists 1$ proyecto se desarrolló utilizando el método de cascada, en el que se llevan a cabo las vidades de manera secuencial, iniciando con una etapa de investigación del estado del arte quє mitió establecer el conjunto de herramientas y algoritmos específicos a utilizar. Luego se tinuó con la etapa de diseño de los módulos de caracterización, clasificación y visualizaciór a posteriormente pasar a la etapa de implementación y validación de funcionalidad. Por último. ealizó la validación de la solución mediante dos conjuntos de datos de prueba, uno a partir d€ ase de datos MIT-BIH y otro a partir de datos anonimizados de pacientes entregados por el lico especialista que apoyó el desarrollo del proyecto.

-a etapa de investigación consistió en búsquedas de bibliografía especializada a nivel de culos en los que se aplican técnicas de inteligencia artificial para el análisis de señales de pruebas కnósticas. Además, se incluyó en esta etapa el análisis de la base de datos de arritmias MITI, la cual fue seleccionada para llevar a cabo los procesos de entrenamiento y validación de le ıción.

-a base de datos de arritmias MIT-BIH es un conjunto de más de 4000 registros Holter a largc zo obtenidos por el Laboratorio de Arritmia del Hospital Beth Israel. El 60\% de los registros s€ uvieron de pacientes hospitalizados. Cada registro de Holter tiene alrededor de 30 minutos d€ ación. La base de datos cuenta con dos grupos de registros el primero de 23 registros y el undo con 25 registros. El primero de los grupos sirve como muestra representativa de la variedac 
Los sujetos objeto de muestra fueron 25 hombres de 32 a 99 años y 22 mujeres de 23 a 89 a [25].

En la etapa de diseño se definió la forma de articular las diferentes técnicas y herrami seleccionadas para la generación de la solución. Para la caracterización de las señales se utili: transformada wavelet con las funciones Sym y Daubechies para la identificación de señale: ECG, con base en las cuales es posible obtener los vectores de características de cada seña incluyó además en el diseño una fase de filtrado que permita adecuar la señal para el post proceso de clasificación, el mecanismo de filtrado se basó en los filtros Chebyshev y Notch.

Seguidamente, para la fase de clasificación se estableció aplicar el algoritmo de aprend supervisado SVM que es usado de manera regular para resolver problemas de clasificaci regresión logística [26]. La visualización de resultados se definió a través de una aplicación w nivel de prototipo que además serviría de integradora de los diferentes módulos.

Posteriormente, se realizó la implementación de la cada uno de los módulos de acuerdo definiciones del diseño, realizando pruebas de concepto a cada uno de los componentes, proceder a la integración de los mismos en un solo sistema mediante el prototipo web.

Una vez verificada la funcionalidad del sistema desarrollado, se procedió a realizar la valida del mismo con datos de prueba a partir del de la base de datos MIT-BIH y con los datos etiquet 
el proceso de caracterización de las señales se utilizó la transformada wavelet con las funcione m y Daubechies para la identificación de señales del ECG, con base en las cuales se obtuviero vectores de características de cada señal como se observa en la figura 1.

\section{sura 1.}

racterización del Complejo QRS.

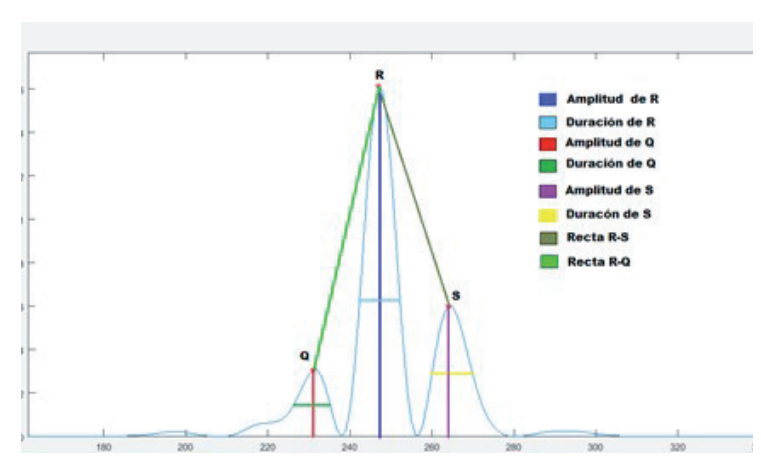

ego se pasó a la fase de filtrado de la señal mediante la discriminación de esta con relación a s ıtenido espectral permitiendo su adecuación para el proceso de clasificación, el mecanismo d rado se basó en los filtros Chebyshev y Notch, En la figura 2 se muestra un esquema del proces 
Figura 2.

Filtrado de la señal

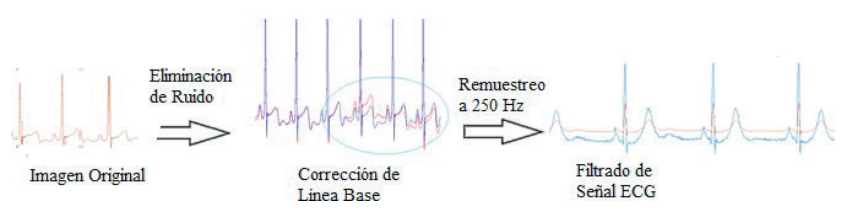

Figura 3.

Detección del complejo QRS, pico P y T desde TW y filtro adaptativo gaussiano

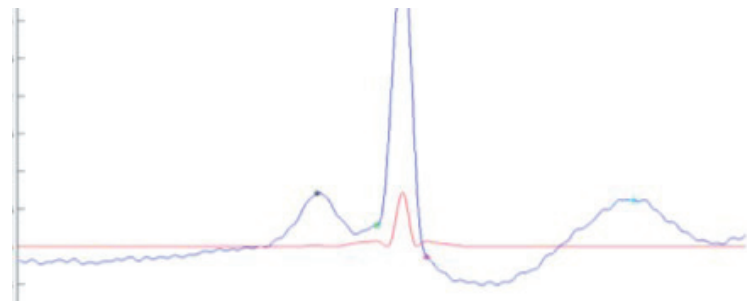

Una vez la señal es pre-procesada y caracterizada, se procedió a aplicar el algoritmo de aprendizaje supervisado Máquina de Soporte Vectorial (SVM) donde, los vectores usados pc algoritmo SVM, permitieron ajustar los límites de decisión y así, reducir la dimensionalidad conjunto de datos que está compuesto de muchas variables correlacionadas entre sí, coincidie con lo afirmado en [5]. Adicionalmente, se utilizó la técnica PCA para la extracción características más relevantes y reducción de dimensionalidad sin pérdida de informar fundamental. En la figura 4, se muestra la varianza según los clasificadores y la relevancia d $\epsilon$ características según PCA, que permite observar que el proceso no se sesga a ninguna clase. 
iigura 4.

'arianza según los clasificadores y la relevancia de las características según PCA

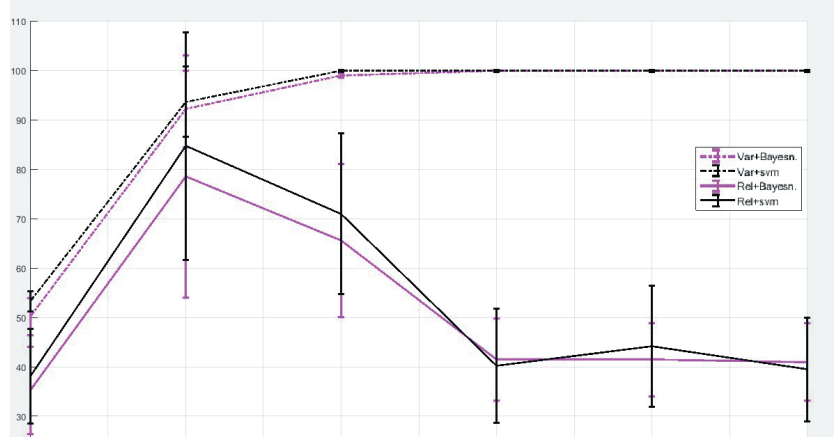

El proceso de clasificación mediante SVM construye un hiperplano para discriminar entre erentes tipos de clases, al que se le aplicó un kernel gaussiano lineal cuadrático para exclu alquier punto de datos mal clasificado en el margen de las clases. El resultado se puede observa la figura 5 que se muestra a continuación.

\section{Figura 5.}

Clasificación SVM - Kernel Gaussiano.

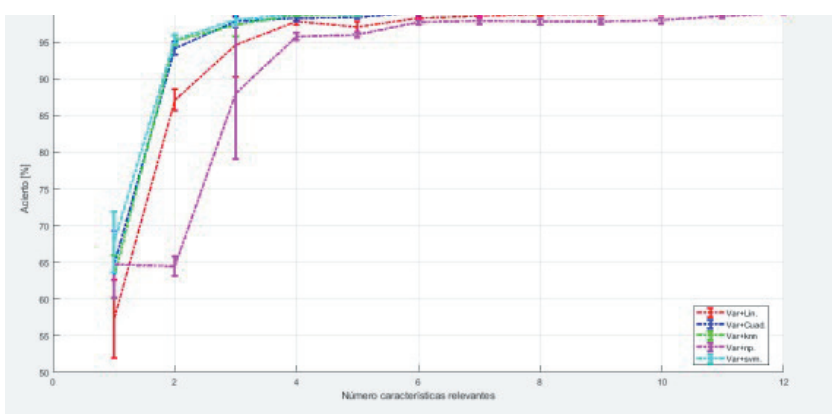


nismo, un prototipo web desarrollado mediante el framework Ruby on Rails con base en un moc vista controlador MVC. Este prototipo cuenta con un módulo de usuarios que gestiona desdi ıutenticación hasta el almacenamiento de datos de los diferentes actores del sistema (pacientє loctores). Posee además un módulo de gestión que permite la gestión de los pacientes que pern srear, actualizar, eliminar o visualizar información básica de los usuarios. También permit‘ zestión de electrocardiogramas ECG, donde el profesional puede consultar la totalidad de la se: sermitiendo explorar zonas específicas de la misma. En un panel de hallazgos se define do ıparece la arritmia encontrada por la SVM de forma que el profesional en el área de la salud obti ın prediagnóstico de la enfermedad.

Los resultados obtenidos por medio de la aplicación con el sistema integrado para el procesc slasificación de las señales bloqueo de rama derecha (RBBB), bloqueo de rama izquierda (LBI y latido NORMAL del ECG corresponden a los presentados en la Fig. 5. Adicionalmente, el abla 1 se muestran los resultados de los diferentes clasificadores para la identificación de señ: 1ormales, LBBB y RBBB.

Tabla 1.

Resultados de clasificadores para las señales del corazón.

\begin{tabular}{l|l|l|l|}
\hline & $\begin{array}{l}\text { Ritmo sinusal } \\
\text { normal }\end{array}$ & LBBB & RBBB \\
\hline & & & \\
\hline & & & \\
\hline & & & 0.963 \\
\hline cuadrático & 0.933 & 0.943 & \\
\hline
\end{tabular}


Con base en los resultados, se valida la hipótesis planteada, siendo posible la caracterización de ales electrocardiográficas para identificación de arritmias cardiacas, a partir de una muestrc lacional de la región, permitiendo obtener niveles de precisión en el diagnóstico de acuerdo cor resultados que se encuentran en el estado del arte.

\section{nclusiones}

Mediante el presente proyecto se pudo validar la posibilidad de implementar un sistema que :gra procesos relacionados con el tratamiento de las señales ECG, mediante los cuales se realiz: acción de características, filtrado, clasificación y corrección de clasificación por medio de la icación de la transformada Wavelet, filtros Chebyshev y Notch, análisis de componentes ıcipales PCA y kernel gaussiano en conjunto con máquinas de soporte vectorial SVM.

Se logró el desarrollo de un sistema de diagnóstico automático capaz de apoyar la detección de ınas enfermedades del corazón, mediante la caracterización y clasificación de señales por medic herramientas matemáticas como la transformada Wavelet y del algoritmo de clasificaciór ado en máquinas de soporte vectorial SVM.

Entregar un prediagnóstico de las arritmias otorga a los profesionales un insumo para toma isiones con respecto a electrocardiogramas largos, que pueden ser difíciles de leer y por tant den producir ocasionalmente diagnósticos errados por una mala lectura. El prediagnóstico 1 da al profesional a identificar dónde se encuentran puntos críticos de los ECG y poder as ıdiar en detalle la señal ECG para corroborar el resultado. A lo largo de este trabajo se demostr : la efectividad del sistema depende del buen proceso de entrenamiento mediante la extracció 
de características dotadas de criterio médico quien basado en su experticia etiqueta los difer tipos de arritmias presentes en las señales ECG utilizadas como conjunto de entrenamiento.

Fue posible demostrar que la integración de varias ramas del conocimiento permite generar soluciones a problemáticas sociales que afectan a población en condición de vulnerabilidad, es este caso por su ubicación geográfica alejada de los grandes centros urbanos que cuentan con servicios de atención en salud de mayor nivel.

El grupo de investigación logró mediante este proyecto consolidar un área de investigación conjunta que integra las tecnologías de la información y las comunicaciones con el sector salu

\section{Reconocimientos}

El presente trabajo fue desarrollado gracias al apoyo obtenido mediante la convocatori: proyectos de innovación de la vicerrectoría de investigación, innovación y extensión d Universidad Tecnológica de Pereira con código de proyecto "6-1810", además del apoyo de Ja Gustavo Martínez Aroca médico especialista en cardiología.

\section{Bibliografía}

[1]Özal Yıldırım, Paweł Pławiak, Ru-San Tan, U. Rajendra Acharya,"Arrhythmia detection u deep convolutional neural network with long duration ECG signals"Computers in Biology Medicine Volume 102, 1 November 2018, Pages 411-420, EL Sevier.

[2]Equipo Técnico ministerio de salud y proteccion social, "Aspectos relacionados con la frecuencia de uso de los servicios de salud, mortalidad y discapacidad en Colombia". Min salı instituto nacional de salud, 2010.

[3] B.-U. Köhler, C. Hennig, R. Orglmeister, “The principles of software QRS detection”, IEF Eng. Med. Biol. Mag. 21 (January- February (1)) (2002)42-57

[4] Christine M. Albert, M.D. and William G. Stevenson, M.D. "The Future of Arrhythmias a Electrophysiology". American Heart Association/ahajournals.org (2016). 
3rahim Ibrahim Abou Ghaleb and Mohamed Ismail Owis. "Automatic Arrhythmia Detection Jsing Support Vector Machine Based on Discrete Wavelet Transform”, American Scientific 'ublishers, Vol. 6, 1-6 (2016).

Jutiérrez-Gnecchi Jose Antonio, Rodrigo Morfin-Magana, Daniel Lorias-Espinoza b, łdriana del Carmen Tellez-Anguiano, Enrique Reyes-Archundia, Arturo Méndez-Patiño and Rodrigo Castañeda-Miranda. "DSP-based arrhythmia classification using wavelet transform nd probabilistic neural network”, ELSEVIER: Biomedical Signal Processing and Control. Jolume 32, February

', Pages 44-56

M.E. Herbert, S.R. Votey, M.T. Morgan, P. Cameron, L. Dziukas. "Failure to agree on the :lectrocardiographic diagnosis of ventricular tachycardia". Annals of Internal Medicine. DOI: 0.1016/s0196-0644(96)70293-7

\TLAS DE ANATOMIA ORDENADA Adermicina.com.ar [en línea]. [consulta: :1/11/2017]

onible en: $\underline{\text { http://ar.geocities.com/argenvista/corazon2.bmp }}$

J. D. Clifford, F. Azuaje, and P. E. McSharry, Advanced Methods and Tools for ECG Data tnalysis. Artech House, Inc., 2006.

J. D. Clifford, F. Azuaje, and P. E. McSharry, Advanced Methods and Tools for ECG Data tnalysis. Artech House, Inc., 2006.

. Sotos, "Aplicación de redes neuronales artificiales en el procesado versátil de señales :lectrocardiográficas,” 2012.

Irupo de Señales e imágenes médicas Kiron [en línea]. [consulta: 20/11/2017] Disponible en: //bioinstrumentacion.eia.edu.co/WebEstudiantes/2005II/marcapasos/imagenes/imag.jpg

MATIZ, Hernando. , GUTIÉRREZ, Oscar. y TORRES, Adriana. Electrocardiografía Básica, 'olumen I. Universidad del Bosque, primera edición, 1999.

2. Oter Rodríguez, J. de Juan Montiel, T. Roldán Pascual, A. Bardají Ruiz, and E. Molinero le Miguel, "Guías de práctica clínica de la Sociedad Española de Cardiología en narcapasos,” Rev. Esp. Cardiol., vol. 53, no. 7, pp. 947-966, 2000.

MEDLIBRES Online Medical Library [en línea]. [consulta: 25/11/2017] Disponible en:< Ittn://medlibes.com/entrv/nremature-ventricular-contractions>. 
16] A. Grossmann \& J. Morlet. Decomposition of Hardy functions into square integrable wavelets of constant shape, Soc. Int. Am. Math. (SIAM), J. Math. Analisys., 15, 723-736. (1984).

17] Ruch David K. and Patrick J. Van Fleet, "Wavelet Theory An Elementary Approach with Applications", Wiley, 2009.

18] Van Valkenburg, M. (1982). Analog Filter Design. New York: CBS College Publishing.

19] William, A., \& Taylors, F. (1988). Electronic Filter Design Handbook. New York: McGrav Hill.

20] O. Chapelle, B. Scholkopf, and A. Zien, "Semi-supervised learning (chapelle, o. et al., eds.2006)[book reviews]," IEEE Trans. Neural Networks, vol. 20, no. 3, p. 542, 2009.

21] M. Celebi and K. Aydin, “Unsupervised Learning Algorithms,” Springer, 2016.

22] Bielza C., G. Li, and P. Larranaga. Multi-dimensional classification with bayesian networ: International Journal of Approximate Reasoning, 2011.

23] R. Saini, N. Bindal, and P. Bansal, "Classification of heart diseases from ECG signals usin६ wavelet transform and kNN classifier," in Computing, Communication $\backslash \&$ Automation (ICCCA), 2015 International Conference on, IEEE, 2015, pp. 1208- 1215.

24] Yu-Jin Lin, Chen-Wei Chuang, Chun-Yueh Y, Sheng-Hsin Huang, Ju-Yi Chen and Shuenn Yuh Lee, "An AIoT Wearable

iCG Patch with Decision Tree for Arrhythmia Analysis" 2019 IEEE Biomedical Circuits and iystems Conference (BioCAS)

25]Database: https://physionet.org/physiobank/database/html/mitdbdir/intro.htm - visitado en nayo de 2019.

26] Vapnik, V.N. (2000). The Nature of Statistical Learning Theory. 2nd edn, Springer. pp 15, . L. Doobet. Stochastic Processes. Wiley, New York, 1953

27]Bayes de Luna Antonio, Elosura Roberto, “Muerte Súbita” Revista Española de Cardiologí Iol 65. Núm 11. noviembre 2012.

28] Ministerio de Salud y Protección Social. Instituto Nacional de Salud. Observatorio Naciona de Salud. Segundo informe ons observatorio nacional de salud: mortalidad 1998-2011 y situación de salud en los municipios de frontera terrestre en Colombia. Carlos Andrés Castañeda Orjuela, director ONS. Bogotá: INS, 2013. 237p

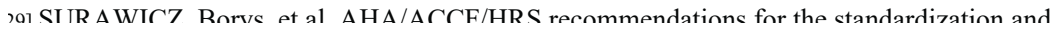

zlectrocardiogram: part III: intraventricular conduction disturbances a scientific statement from the American Heart Association Electrocardiography and Arrhythmias Committee, Council on Clinical Cardiology; the American College of Cardiology Foundation; and the Heart Rhythm 
srican College of Cardiology, 2009, vol. 53, no 11, p. 976-981.

IANNUN, Awni Y., et al. Cardiologist-level arrhythmia detection and classification in Imbulatory electrocardiograms using a deep neural network. Nature medicine, 2019, vol. 25, 10 1, p. 65 .

Hoekema, R., Uijen, G.J., and Van Oosterom, A. (2001). Geometrical aspects of the nterindividual variability of multilead ECG recordings. IEEE Trans. Biomed. Eng. 48, 551;59.

Ashley EA, Niebauer J. Cardiology Explained. Chapter 8. Arrhythmia. London: Remedica; 2004. 


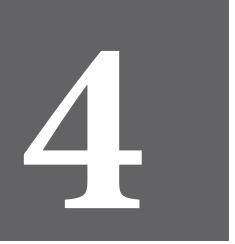

CAPÍTULO CUATRO 



\title{
Landfill biogas models
}

\author{
Ángel Andrade, Álvaro Restrepo \\ Universidad Tecnológica de Pereira \\ aaandrade@utp.edu.co, arestrep@utp.edu.co
}

\section{Resumen}

Ja población mundial está en constante crecimiento y para sobrevivir como especie se neces: ecursos y energía. A medida que se acelera el crecimiento poblacional, se acelera tambiét zonsumo de recursos y materias primas, lo cual contribuye con una mayor producción de resid sólidos. La producción de residuos ocasiona problemas al planeta en diversas áreas, principalme ıquellos asociados con la disposición final. Entre los problemas asociados a las malas prácti elacionadas con la disposición final de los residuos se destacan: el impacto ambiental causado a emisión de Gases de Efecto Invernadero - GEI, la filtración de lixiviados a las aguas subterránı os vectores endémicos, las plagas, la generación de malos olores, los problemas soci: elacionados con actividades de recolección y reciclado en rellenos sanitarios no controlados, e1 stros. Debido a ello, la temática asociada con la gestión y manejo de residuos sólidos es ampl nterdisciplinar. Abarca campos del conocimiento tales como la administración de políti úblicas, ambiental, social, antropológica, económica y en el área de ingenierías, entre otras. sste documento, se presentan los modelos teóricos para simular la generación de biogás en relle janitarios, las variables asociadas al fenómeno de generación de biogás, la evaluación de difereı nodelos y la valorización energética mediante aplicaciones de motogeneradores. En gene zxisten dos métodos para estimar la cantidad de biogás generado en rellenos. El primero de el ss mediante el uso de modelos teóricos que representan matemáticamente los fenómenos químis ĩsicos o biológicos que se llevan a cabo en la degradación del material orgánico para gen jiogás. El segundo de ellos es mediante la medición directa en rellenos que dispongan de una 
rchas, o para el aprovechamiento energético mediante aplicaciones en motogeneradores, lucción de frio o calor, cogeneración, entre otras.

ıbras claves: biogás, relleno sanitario, aprovechamiento de energía.

\section{tract}

world population is constantly growing and resources and energy are needed to survive as a ies. As population growth accelerates, consumption of resources and raw materials also lerates, which contributes to greater production of solid waste. Waste production causes lems for the planet in various areas, mainly those associated with final disposal. Among the lems associated with bad practices related to the final disposal of waste, the following stand the environmental impact caused by the emission of greenhouse gases-GHG and climate Ige, the leachate leaking into groundwater, endemic vectors, pests, the generation of bad odors, al problems related to collection and recycling activities in uncontrolled sanitary landfills, nng others. Due to this, the subject associated with solid waste management and handling is Id and interdisciplinary. It covers fields of knowledge such as the administration of public, ronmental, social, anthropological, economic policies and in the area of engineering, among :rs. In this document, the theoretical models are presented to simulate the generation of biogas Indfills, the variables associated with the phenomenon of biogas generation, the evaluation of zrent models and the energy recovery by means of motor-generator applications. In general, e are two methods to estimate the amount of biogas generated in landfills. The first of these is ugh the use of theoretical models that mathematically represent the chemical, physical or ogical phenomena that take place in the degradation of organic material to generate biogas. The Ind of them is through direct measurement in landfills that have a biogas collection network, ar to be directly emitted into the atmosphere, for burning in torches, or for energy use through ications in motor-generators, production of cold or heat, cogeneration, among others.

words: landfill, biogas, waste to energy.

\section{oducción}

os modelos teóricos para la estimación de la generación de biogás en rellenos sanitarios son ccionados a partir de la precisión de los resultados comparado con mediciones en sitio 


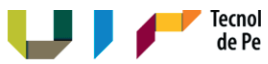

previamente realizadas; la disponibilidad de datos y variables asociadas al proceso. Existen modelos teóricos de primer y segundo orden. En la práctica los modelos de generación de primer orden son los más utilizados. La estimación de las emisiones de biogás de los rellenos sanitarios resulta compleja, debido a que se trata de múltiples fuentes con una alta variabilidad espacial y temporal. Las principales variables asociadas a todos los modelos son la composición de los Residuos Sólidos Urbanos- RSU y el nivel de lluvia en la región. La capacidad máxima de emisión de metano se alcanza cuando el relleno sanitario aún no ha sido clausurado, esto se debe a que la degradación de la materia orgánica (residuos de degradación rápida) ocurre en su mayoría en los primeros años. [1-2]

Después de clausurado el relleno sanitario continua con las emisiones de biogás, ya que residuos como el papel y el cartón son de degradación lenta y algunos pueden tardar en degradarse hasta 30 años, esto si las condiciones pluviales en el relleno son bajas y la región sea predominantemente seca. Algunos de los modelos de estimación de la generación de biogás en rellenos sanitarios, se presentan en la tabla 1.[3-4]

Tabla 1.

Climate Chan $\quad(\quad \times \quad \times$

Modelos de generación de biogás en rellenos sanitarios.

Es un modelo que utiliza dos enfoques basados en el método de Montecarlo y aproximaciones

GasSim estadísticas.

W S

$$
\left.M^{\mathrm{MNOPQR}}\right)(M C F)(F)
$$

Modelo Colombiano de biogás $Q_{\mathrm{X} 9 \mathrm{Y}}=\mathrm{I}$ I $2 k L_{\mathrm{L}} \mathrm{Z} 10[$ ( $e$

PUS TUL,S 
jetivos

arrollar una metodología para el aprovechamiento energético de los RSU considerando la sración energética del biogás captado del relleno sanitario.

- Caracterizar la composición elemental de los residuos sólidos de una ciudad, mediante la aplicación de la metodología propuesta.

- Implementar el uso de varios modelos teóricos para la estimación del biogás generado en un relleno sanitario.

- Evaluar la coherencia en los resultados según los valores reportados en la literatura.

- Realizar recomendaciones para el uso adecuado del biogás como combustible en aplicaciones de motogeneradores.

\section{erente teórico}

$\exists$ l biogás es un gas combustible que se genera por la descomposición microbiológica de la eria orgánica en un proceso natural que tiene lugar en un entorno húmedo y en ausencia d€ geno. A este proceso de descomposición se le denomina digestión anaeróbica. La digestiór eróbica convierte los compuestos complejos en compuestos simples, dando como resultado fina iberación de una mezcla de gases. De esa mezcla, el gas que representa el mayor porcentaje es ıetano con una proporción entre el 50 y $60 \%$, mientras que el porcentaje restante se atribuye er n medida al dióxido de carbono. La composición estimada del biogás de relleno sanitario sє estra en la Tabla 2.

Ja 2.

nposición química promedio del biogás, adaptado de [5].
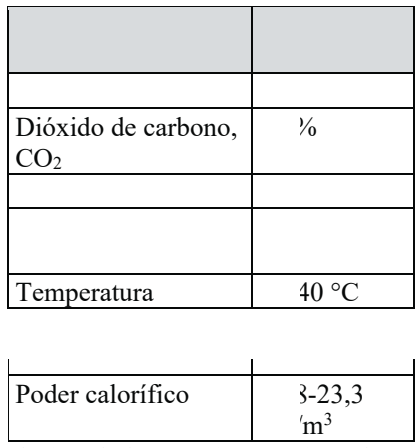

¿dación de la materia orgánica, el gas mı sorolmanta as amitidn o 1s otmónfaro $I$ o 
Debido al proceso de degradación de la materia orgánica, el gas metano es un producto d rellenos sanitarios, el cual generalmente es emitido a la atmósfera. La cantidad de metano obtє varía en función de los siguientes factores:

- La composición de los residuos;

- El tiempo de funcionamiento del relleno sanitario;

- Las condiciones ambientales.

Uno de los principales factores en consideración para la generación de biogás, es el cont de humedad de los RSU, el cual puede estar contenido en fracciones de volumen entre el 3( $70 \%$. La cantidad de residuos inorgánicos no contribuyen con la generación de biogás debido : no se degradan anaeróbicamente. En algunos rellenos sanitarios regulados se captura y utili biogás, para producir calor o electricidad. Según el estado del arte, desde el año 2001 se cc información estimada de mil rellenos sanitarios que capturaban biogás en todo el mundc Estados Unidos se capturan aproximadamente 2,6 millones de toneladas de metano anualment 6]

Los estudios teóricos y experimentales desarrollados en laboratorios con condiciones controladas indican que la completa biodegradación anaeróbica de los RSU genera cerca d $\epsilon$ $\mathrm{Nm}^{3}$ de metano por tonelada seca de biomasa contenida. Sin embargo, la tasa de generacić metano reportada en los reactores anaeróbicos industriales oscila entre 40 a $80 \mathrm{Nm}^{3}$ por ton de residuos orgánicos. Algunos rellenos en los Estados Unidos reportan que capturan hastc $\mathrm{Nm}^{3}$ de metano por tonelada de RSU. Estos resultados arrojan un estimado conservativo de generación de metano alrededor de $50 \mathrm{Nm}^{3}$ por tonelada de RSU.[5]

Se estima que la cantidad de RSU depositados en los rellenos de todo el mundo aproximadamente 1,5 billones de toneladas anualmente. La tasa correspondiente de generacir metano en los rellenos estimada es de 75 billones $\mathrm{Nm}^{3}$. Menos del $10 \%$ de este combustib 
e contribuye con el calentamiento global.

Existen algunas diferencias de un país a otro en las normativas asociadas con la gestión y mane egral de los RSU. No obstante, la tendencia mundial es disminuir la cantidad de RSU dispuestc los rellenos sanitarios. En algunos países como Alemania, Austria, Holanda, Dinamarc Slgica, Japón y Suecia, predomina el reciclaje y la recuperación energética en plantas (Waste : lergy $-W t E$ ), antes que la disposición final en rellenos. Países como Suecia y Japón se han trazac objetivo de eliminar los rellenos sanitarios. Mientras los rellenos proporcionan una solucić nple y económica para el problema asociado a la disposición final de los residuos, éstos cause pactos ambientales incluidos la filtración de lixiviados y emisiones de GEI. Con la plementación de los sistemas de recuperación de biogás, los rellenos sanitarios generan $\mathrm{\imath}$ zurso potencial de metano como gas combustible. La captura y aprovechamiento de biogás en le llenos sanitarios y el incremento de la vegetación son prácticas tradicionalmente aplicadas en stión de residuos con el fin de mitigar la degradación del ambiente circundante, lo cual adem: oporciona un recurso de biomasa para la producción de energía. [7]

La capacidad de los motogeneradores que funcionan con combustible a partir de biogás de lleno sanitario, van desde 0,3 a $4 \mathrm{MW}$. Actualmente la planta más grande se encuentra ubicac el relleno sanitario Puente Hills cerca a los Ángeles California, donde el biogás es aprovechac un generador de vapor para obtener una potencia de $50 \mathrm{MW}$. Algunos países de la Unión Europs mo Suiza, Alemania, Holanda, Suecia, Austria, Dinamarca y Bélgica han reportado ur sminución en la cantidad de rellenos sanitarios abiertos, cercana al 5\% desde el año 2009 debic aumento de las tasas de impuestos asociados a la práctica. Las emisiones de metano a niv undial asociadas al vertido de residuos han sido estimadas por la Environmental Protectic rency - EPA con una media de 8,7E6 t/año. Las emisiones de metano de rellenos sanitarios es ur las causas del alarmante incremento de la concentración de metano en la atmósfera, las cualı sde 1990 son de aproximadamente $1,72 \mathrm{ppm}$ en volumen, ligeramente más del doble de $\mathrm{k}$ lores estimados en el año 1750. Según la $E P A$, estas emisiones corresponden entre un 6 y un $13^{\prime}$ las emisiones totales mundiales antropogénicas y no antropogénicas. El ritmo de crecimien ual de las emisiones de gases efecto invernadero producto de los rellenos sanitarios es estimac $0,9 \%$. Este crecimiento es debido fundamentalmente a emisiones de origen 
atmósfera. [8]

\section{Modelos de estudio}

Se seleccionó como caso de estudio la ciudad Pereira- Risaralda y su relleno sanitario. P€ es una ciudad ubicada a 1400 metros sobre el nivel del mar y una población aproximada 700000 habitantes, teniendo en cuenta su zona metropolitana. Los niveles de pluviosidac aproximadamente $2100 \mathrm{~mm}$ por año. La ciudad de Pereira dispone sus residuos en el re sanitario regional La Glorita, que cuenta con 327 hectáreas, y está localizado en el corregim de Combia Baja, a $14 \mathrm{~km}$ del casco urbano de la ciudad. En éste, un total de 17 municipios descargan sus residuos, y la ciudad aporta alrededor de 280 de las 650 t/día que se disponen relleno sanitario. La apertura del relleno sanitario data del año 1997 y se proyecta el año de claı para el 2033. En promedio, los residuos que ingresan al relleno sanitario presentan una hum de $76 \%$ asociado con la fracción orgánica. La caracterización de los RSU se presenta en la F 1. La densidad promedio de los RSU medidos se estableció en $335 \mathrm{~kg} / \mathrm{m}^{3}$, y el peso específi $5341 \mathrm{~N} / \mathrm{m}^{3}$. [9]

\section{Figura 1.}

Caracterización RSU del relleno sanitario La Glorita. [10]

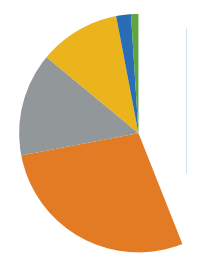

Otros (textil, caucho, cuero)

-

Metales

La caracterización de los RSU que se presenta en la Figura 1, fue utilizada como datos de en para los modelos seleccionados a estudiar. Se seleccionaron tres modelos. El modelo LandGE 
zcionó debido a que es el más utilizado a nivel mundial. El modelo colombiano se seleccionó do a que está reconocido por la Agencia de Protección Ambiental de los Estados Unidos ited States Environmental Protection Agency - US EPA), modificado para tener en cuenta las cterísticas climatológicas de la región de estudio. Finalmente se seleccionó el modelo GasSim do a que es ampliamente utilizado en la comunidad europea.

\section{lelo LandGEM}

1 modelo LandGEM es utilizado para estimar la cantidad de biogás generado en los rellenos tarios. Este modelo se basa en una ecuación de descomposición cinética de primer orden para ttificar las emisiones derivadas de la descomposición de los residuos orgánicos presentes en los J. El modelo LandGEM se presenta en la (Ec. 1).

$$
\begin{gathered}
n 1 \\
3 H 4=\mathrm{I} \mathrm{I}_{i=1} k 0^{\wedge} \mathrm{HO} i_{-} e^{-k t i j}
\end{gathered}
$$

le:

ıma desde el año de apertura +1 (i=1) hasta el año de proyección (n);

: tiempo de incremento de cada año;

1,1: tiempo de incremento para cada año;

¡: generación máxima de metano $\left[\mathrm{m}^{3} / \mathrm{año}\right]$;

dice de generación de metano [1/año];

šneración potencial de metano $\left[\mathrm{m}^{3} / \mathrm{Mg}\right]$;

masa de residuos sólidos dispuestos en el año $i[\mathrm{Mg}]$;

periodo en que los RSU totales $M_{\mathrm{M}}$ : dispuestos en el año $i$, con incrementos $j$.

le la tasa de RSU depositados en un relleno sanitario, las emisiones de metano pueden ser nadas suponiendo que de $L_{\mathrm{L}}$ es $170 \mathrm{~m}^{3} / \mathrm{Mg}$ y $k$ es 0,05 [1/año]. Estos valores son recomendados países en vía de desarrollo en los cuales la composición de los RSU corresponde con una sión alta de residuos orgánicos. Para rellenos sanitarios a cielo abierto, el potencial de emisión retano puede asumirse como el $50 \%$ del valor de rellenos sanitarios controlados y cubiertos, o 
el promedio equivalente a $85 \mathrm{~m}^{3} / \mathrm{Mg}$. El índice de generación de metano $k$, representa la tas biodegradación de los residuos orgánicos de primer orden en la cual el metano es generado lı de disponer finalmente los RSU en el relleno. Este parámetro depende del contenido de hume de la disponibilidad de nutrientes, el pH y la temperatura. El contenido de humedad es import ya que funciona como transporte de nutrientes y bacterias. [11]

La humedad en el relleno depende de la infiltración de las lluvias, la cobertura, el tipo de impermeabilización de la base del sistema, la recirculación de lixiviados y la profundidad vertido [12]. Las tasas de degradación más rápidas (de 3 años aproximadamente) están asociac condiciones de alta humedad y de residuos de degradación muy rápida como los alimentos. tasas más lentas, están asociadas a residuos como el papel y el cartón de degradación lenta, co periodo de degradación cercano a 35 años. [13]

El parámetro $L_{\mathrm{L}}$, llamado potencial de generación de metano estima la cantidad de me potencialmente producida por un kilogramo de RSU cuando son degradados, por lo cual depr de la caracterización física-química de los RSU en porcentaje en pesos y masas. Este parámetı presenta en la (Ec. 2). [14]

$$
L 0=(M C F) \cdot(D O C) \cdot(D O C F)
$$

donde:

$M C F$ : factor de corrección para el metano;

DOC fracción de carbono orgánico degradable;

$D O C_{9}$ : fracción de carbono orgánico degradable asimilado;

$F$ : fracción de metano en el biogás;

$\mathrm{Sh}$

_.: constante estequiométrica.

$\mathrm{Si}$

El factor de corrección para el metano $M C F$ es un ajuste para estimar la generación de bi que el modelo toma en cuenta ya que depende del grado de degradación anaeróbica de los $\mathrm{R}$ Este valor depende de la profundidad y el tipo de relleno sanitario (controlado, no controlac 
abierto, etc) y las prácticas de gestión y manejo asociadas. La Tabla 3 expone los valores os del parámetro $M C F$.

\section{a 3.}

res estimados del parámetro $M C F$. Adaptado de [14].

\begin{tabular}{|l|l|l|}
\hline & & \\
\hline & & \\
\hline Controlado & $;$ & 1,0 \\
\hline $\begin{array}{l}\text { Condición } \\
\text { desconocida }\end{array}$ & + & 0,8 \\
\hline
\end{tabular}

os valores estimados del factor de carbono orgánico degradable $D O C$ depende de la josición de los RSU, por lo cual varía de acuerdo a cada relleno sanitario y cada país. Este netro se estima según la Ec.3 [14-15].

$$
D O C=0,40(A)+0,17(B)+0,15(C)+0,30(D)
$$

e:

rrcentaje de los residuos que corresponde al papel, cartón y los textiles;

srcentaje de los residuos que corresponde a los desechos de jardín y de los parques u otros chos orgánicos putrescibles (excluidos los alimentos);

rrcentaje de los residuos que corresponde a los restos

llimentos; $D$ : porcentaje de los residuos que

ssponde a madera.

trámetro fracción de carbono orgánico degradable asimilado $D O C_{9}$, se calcula mediante la ción (Ec. 4).

$$
\text { DOC }_{9}=0,014 T+0,28
$$

e: 
$T$ : temperatura. $\left[{ }^{\circ} \mathrm{C}\right]$.

La Ec. 4 está basada en el modelo teórico que varía sólo con la temperatura en la zona anae del relleno sanitario. El valor predeterminado utilizado por la IPCC es de 0,77 . No obstante factor puede variar desde 0,42 para $10{ }^{\circ} \mathrm{C}$ hasta 0,98 para $50{ }^{\circ} \mathrm{C}$. De hecho, en muchos rel sanitarios profundos $(>20 \mathrm{~m})$ las temperaturas que se han registrado son mayores a $50{ }^{\circ} \mathrm{C}$, lk implica condiciones claramente anaerobias.

\section{Modelo GasSim}

Este modelo se encuentra integrado mediante un software de libre licencia en su versión b€ cual modela el impacto ambiental provocado por los rellenos sanitarios. Tiene como objetiv una herramienta para estimar las emisiones anuales de biogás, diferentes especies tóxicas y sustancias generadas en un relleno sanitario. Este modelo es aceptado desde 1998 como refer por la agencia de medio ambiente británica para la evaluación de emisiones en rellenos sanit: el uso de otros modelos debe ser justificado, mientras que los resultados obtenidos por GasSir aceptados directamente. El modelo entrega un reporte de 45 especies diferentes las cuale listadas en un reporte de 25,50 y 75 percentiles. Los resultados del 50 percentil pueden ser utilizados para analizar las emisiones en escenarios no controlados. El modelo se divide es módulos. El primer módulo define el tipo de residuos a analizar y el segundo se refiere a las emisiones generadas por el relleno sanitario. El biogás generado se calcula mediante el anális tipo de residuos depositados y su caracterización elemental. [16]

El modelo GasSim estima la generación del biogás y otras especies, a partir de la compos de los RSU y el tiempo de llenado de la celda en uso del relleno sanitario. También estima med modelos de dispersión, el impacto en los alrededores cuando se implementan medidas de ge como antorchas y motores de combustión interna. La representación de la incertidumbre (estadísticamente) es determinada mediante el método de Montecarlo.

\section{Modelo colombiano de biogás}

El Modelo está basado en una ecuación de degradación de primer orden. Este modelo req que el usuario suministre datos relacionados con el relleno sanitario tales como: el año de ape año de clausura, índices de disposición anual, ubicación del sitio y contestar algunas preg 
zrentes a Ias conaiciones Iisicas pasadas y presentes deı sitıo. Eı modeı provee automaticament ores para cada uno de los 33 departamentos en Colombia. Los parámetros utilizados por e delo fueron desarrollados usando datos específicos de clima, caracterización de residuos y cticas de disposición de residuos de Colombia y estima el efecto de estas condiciones en la tidades e índices de generación de biogás. El Modelo colombiano se presenta en la Ec. 5. Fur arrollado con el objetivo de proveer proyecciones de generación y recuperación de biogá ıservadoras aplicadas al caso colombiano; el mismo se basa en el modelo mexicano de biogá ssión 2.0, y el modelo de residuos 2006 del IPCC.

10

Ide:

ı: flujo de biogás máximo esperado $\left[\mathrm{m}^{3} / \mathrm{año}\right]$;

ıcremento en tiempo de 1 año;

ıño del cálculo- año inicial de disposición de residuos;

ıcremento de tiempo en 0,1 años;

ndice de generación de metano [1/año];

generación potencial de metano $\left[\mathrm{m}^{3} / \mathrm{Mg}\right]$;

$:$ masa de residuos dispuestos en el año $i[\mathrm{Mg}]$;

: edad de la sección j de la masa de residuos Mi dispuesta en el año $i$;

' $F$ : factor de corrección de

$\operatorname{tano} ; F$ : factor de ajuste por

endios.

\section{;ultados modelo LandGEM}

Las condiciones que se utilizaron para realizar la simulación de generación de biogás del rellenc itario La Glorita, se presentan en la Tabla 4. Las condiciones iniciales fueron determinada: 
Tabla 4.

Condiciones iniciales para la estimación del biogás mediante el modelo LandGEM.

\begin{tabular}{|l|l|}
\hline & \\
\hline Nombre del relleno sanitari & La Glorita \\
\hline & \\
\hline $\begin{array}{l}\text { Capacidad del relleno } \\
\text { proyectada }\end{array}$ & $10736[\mathrm{Mg}]$ \\
\hline & \\
\hline $\begin{array}{l}\text { Concentración de } \\
\text { componentes volátiles } \\
\text { nrróninns nn motanns }\end{array}$ & $600[\mathrm{ppmv}]$ como hexanos \\
\hline Contenido de metano estim & $54 \%$ \\
\hline & \\
\hline
\end{tabular}

Los resultados de la simulación del modelo LandGEM se presentan en la Figura 2.

\section{Figura 2.}

Resultados del modelo LandGEM.

40

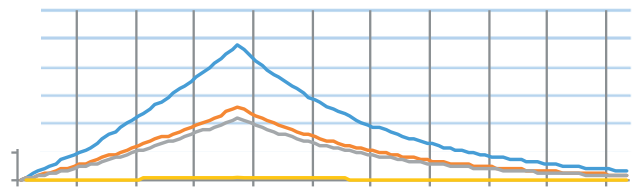

Años

Biogás generado Metano Dióxido de carbono

NMOCs

Según los resultados presentados en la Figura 2, la curva de generación crece hasta obtene valor máximo de biogás de 47,78E6 m³ /año proyectado para el año 2034, un año después del tieı proyectado para la clausura del relleno sanitario. Así mismo, la cantidad máxima de me1 obtenida es de 25,8E6 m³ /año y el dióxido de carbono generado es $22 \mathrm{E} 6 \mathrm{~m}^{3} / \mathrm{año}$. Como 
rva en la curva de generación, la fracción correspondiente a los compuestos orgánicos no inos (Non methane organic compounds - NMOCs) es baja.

- partir de los resultados se concluye que la generación de metano empieza a disminuir ledor del tiempo proyectado para el cierre del relleno sanitario, no obstante, la emisión de gases oyecta hasta casi el año 2100 ya que los elementos como el papel y el cartón son de degradación 1. La generación de lixiviados y el modelado no se tuvo en cuenta en esta simulación debido a :scases en la información recopilada y las dificultades de las mediciones in situ. Así mismo, el meno de migración de biogás por los costados no se tuvo en cuenta.

\section{Iltados modelo GasSim}

imulación de generación de biogás del relleno La Glorita según el modelo GasSim se realizó sndo en cuenta las condiciones iniciales presentadas en la Tabla 5.

la 5.

diciones iniciales para la estimación del biogás mediante el modelo GasSim.

\begin{tabular}{l|l|}
\hline & \\
\hline & \\
\hline iodo de simulación & nos (hasta el 2100) \\
\hline & \\
\hline & \\
\hline tenido de metano estimado & \\
\hline o de aislamiento de la celda con & $\begin{array}{l}\text { la de 1m de espesor y recubrimiento plástico de } \\
\text { ierra }\end{array}$ \\
\hline & \\
\hline itidad de RSU depositados & $\begin{array}{l}\text { ftware se modificó para tener en cuenta las } \\
\text { ciones del caso de estudio. }\end{array}$ \\
\hline
\end{tabular}

resultados de la simulación del modelo GasSim se resumen en la Figura 3. 
Figura 3.

Resultados del modelo GasSim.

40

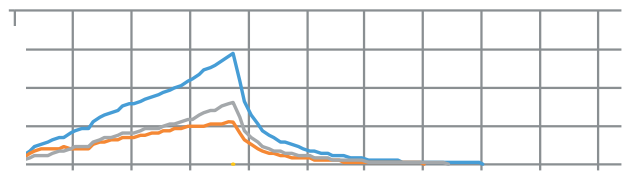

Años

Biogás generado __ Metano___ Dióxido de carbono__ NMOCs

Según los resultados presentados en la Figura 3, la curva de generación de biogás crece alcanzar un valor máximo estimado en 57,7E6 $\mathrm{m}^{3}$ /año proyectado para el año 2034, ur después de la clausura del relleno sanitario. La cantidad máxima de metano obtenida es de $\mathrm{m}^{3}$ /año y el dióxido de carbono generado es en 32,1E6 $\mathrm{m}^{3}$ /año. Como se observa en la cur generación, la fracción correspondiente a los NMOCs es baja, siendo los resultados coheren ser comparados con los obtenidos mediante el modelo LandGEM. Los parámetros relacionado la generación de lixiviados, las migraciones laterales de biogás y el aprovechamiento energéti antorchas o motores de combustión interna, no se tuvieron en cuenta en este análisis a pesar d el software permite modelar estas condiciones. Esto debido a la poca disponibilidad , información relacionada con el relleno sanitario.

\section{Resultados modelo colombiano}

La simulación se realizó con los parámetros iniciales que se presentan en la Tabla 6. Los resultados gráficos de la simulación del modelo colombiano se presentan en la Figura 4.

\section{Tabla 6.}

Condiciones iniciales para la estimación del biogás mediante el modelo colombiano.

\begin{tabular}{|l|l|}
\hline & \\
\hline ión & 2-Andina \\
\hline \multicolumn{2}{|l|}{} \\
\cline { 1 - 2 }
\end{tabular}

\begin{tabular}{|l|l|}
\hline & \\
\hline oosición anual del año más reciente & $292000[\mathrm{Mg}]$ \\
\hline & \\
\hline & \\
\hline & $\begin{array}{l}\text { Biogás, metano, dióxido de carbono } \\
\text { y NOCs }\end{array}$ \\
\hline scies de estudio & \\
\hline & \\
\hline
\end{tabular}

Figura 4. 
ra 4 .

ltados del modelo colombiano.

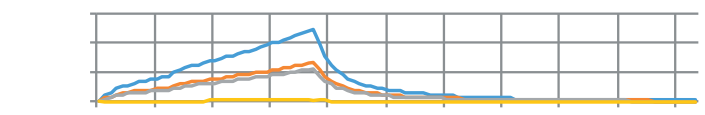

Años

__ Biogás generado Metano Dióxido de carbono

NMOCs

əgún los resultados presentados en la Figura 4, la curva de generación crece hasta obtener un : máximo de biogás generado de 49,19E6 $\mathrm{m}^{3}$ /año para el año 2034, un año posterior al e del relleno sanitario. Así mismo, la cantidad máxima de metano estimada para este año es de $\mathrm{E} 6 \mathrm{~m}^{3} /$ año y el dióxido de carbono generado es $22,1 \mathrm{E} 6 \mathrm{~m}^{3} / \mathrm{año}$. Como se observa en la curva sneración, la fracción correspondiente a los NMOCs es baja. Estos resultados son muy cercanos obtenidos con el modelo GasSim.

\section{caciones del biogás}

partir de la cantidad estimada de biogás generado en el relleno La Glorita, se procede a llar el poder calorífico del combustible para posteriormente ser utilizado en aplicaciones de

mediante la diferencia de entalpías $\Delta H_{\{}$de los reactivos $\left.h\right\}_{\sim,}$ y los productos de la combustión $\left.h\right\}_{\sim}$ , tal como se presenta en la (Ec.6), siendo $n_{\mathrm{T}}, \mathrm{y} n_{\mathrm{T}}$, las fracciones molares de los reactivos y productos de la combustión.

$$
\begin{gathered}
\text { TUS } \\
\text { TUS }
\end{gathered}
$$

Para realizar la simulación de combustión, se utilizó el software Gaseq el cual es de carácter oratuito I ac condicinnec de la cimularión ce nrecentan en la Tahla 7 
Tabla 7.

Condiciones iniciales para la simulación de combustión en el software Gaseq.

\begin{tabular}{|l|l|}
\hline & \\
\hline & \\
\hline $\begin{array}{l}\text { Temperatura de entrada de los } \\
\text { reactivos }\end{array}$ & $98[\mathrm{~K}]$ \\
\hline & $\ldots \ldots \ldots \ldots$ \\
\hline Presión del reactor & {$[\mathrm{atm}]$} \\
\hline & \\
\hline & \\
\hline
\end{tabular}

Tabla 8.

Reactivos y productos generados en la reacción de combustión del biogás del relleno sanitaric Glorita.

\begin{tabular}{|c|c|}
\hline $\begin{array}{c}\text { Reactivos [moles } \\
]\end{array}$ & $\begin{array}{c}\text { uctos [moles } \\
\text { ] }\end{array}$ \\
\hline & \\
\hline & \\
\hline & \\
\hline $\mathrm{CO}=3,4 \cdot 10^{\mathrm{N} \#}$ & 0,0060 \\
\hline & \\
\hline & \\
\hline- & $: 0,0169$ \\
\hline & \\
\hline
\end{tabular}

Reemplazando los valores obtenidos de la simulación de combustión que se presenta en la Tab] se obtiene la (Ec. 7)

$$
\begin{gathered}
P C I=0,53768\} h\}\} \sim\}, \mathrm{F} \#+0,41791\} h\}\} \sim\}, \mathrm{Fi}+0,000342\} h\}\} \sim\}, \mathrm{F} \\
-0,94984\} h\{\} \sim\}, \mathrm{Fi}+1,06896\} h\}\} \sim\}, \mathrm{Gi}+0,00601\} h\}\} \sim\}, \mathrm{F}
\end{gathered}
$$

De los valores de las tablas termodinámicas, las entalpías de formación de las especies considerc en la simulación a $\mathrm{T}=298 \mathrm{~K}$ son:

$$
\begin{aligned}
& \{h\}\} \sim\}, \mathrm{F}=-110,54[\mathrm{MJ} / \mathrm{kmol}] \quad h\}\}\} \sim\}, \mathrm{Gi}=0[\mathrm{MJ} / \mathrm{kmol}] \\
& h\}\}\} \sim\}, \mathrm{i}=0[\mathrm{MJ} / \mathrm{kmol}] \\
& h\}\}\} \sim\}, \& \mathrm{i}=0[\mathrm{MJ} / \mathrm{kmol}] \quad\{h\}\} \sim\}, \mathrm{F} \quad \mathrm{i}=\quad-393,52[\mathrm{MJ} / \mathrm{kmol}] h\}\}\} \sim\}, \mathrm{Gi}= \\
& -241,83[\mathrm{MJ} / \mathrm{kmol}]
\end{aligned}
$$

Finalmente reemplazando los valores de las entalpías de formación, se obtiene el

$$
\text { valor del poder calorífico. } P C I=428,2015
$$


$[\mathrm{MJ} / \mathrm{kmol}]$

Lo que es igual a:

$$
P C I=15,86[\mathrm{MJ} / \mathrm{kg}]=20,22\left[\mathrm{MJ} / \mathrm{m}^{\mathfrak{f}}\right]
$$

El poder calorífico estimado es coherente con los resultados presentados en [15] los cuales reportan un PCI del biogás captado de un relleno sanitario en España equivalente a $16 \mathrm{MJ} / \mathrm{m}^{3}$ siendo un poco menor ya que el contenido de metano estimado en el artículo fue determinado en $46 \%$ a diferencia del contenido de metano estimado en este proyecto equivalente a $54 \%$. Valores equivalentes a los registrados en la literatura en donde se reporta que el PCI del biogás de relleno oscila entre 13 y $23 \mathrm{MJ} / \mathrm{m}^{3}$ con un contenido de metano del $50 \%$ aproximadamente [11]. La cantidad estimada de biogás captado del relleno La Glorita fue presentada y el cálculo de su poder calorífico muestra que se puede aprovechar en aplicaciones de motogeneradores con el fin de

os resultados que se presentan a continuación corresponden a una adaptación del proyecto de stigación con desarrollado en Brasil titulado: "Desenvolvimento de soluções tecnológicas a ir do biogás produzido em sistemas de tratamento de esgotos e aterros sanitários para a 'ção de energia elétrica. Rede Biogás (Edital FINEL 06/2010- Saneamento Ambiental e itação). Convênio FINEP: 23076.032233/2011-54”. Este proyecto consistió en diseñar un :o de purificación y filtración de biogás captado del relleno sanitario de la ciudad de Brusque, un motor de ciclo Otto en V8 de 5,7 litros marca General Motors de $116 \mathrm{~kW}$ a $3000 \mathrm{rpm}$, el es acoplado a un generador eléctrico marca WEG modelo $200 \mathrm{SI} 17$ de $59 \mathrm{~kW}$ a $1800 \mathrm{rpm}$. Se ıló un panel de control para realizar las mediciones del sistema de generación entre 10 y 60 El diagrama de flujo del proyecto diseñado se muestra en la Figura 5.

\section{Ira 5.}

zrama de flujo de los diferentes sistemas para el aprovechamiento de biogás de relleno tario.

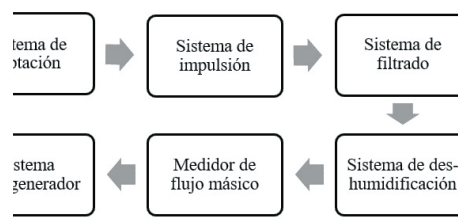

11 sistema de purificación se diseñó con dos filtros de carbono activado y dos filtros de óxido sso, con el fin de limpiar las impurezas presentes en el biogás y evitar posibles daños en el ma motogenerador. 
Sanitarı recibe aproximadamente 800 toneladas de residuos solidos diariamente, siendo un valı aproximado con el del relleno La Glorita. La Figura 6 muestra el panel móvil del banco de filtrc y purificación de biogás construido.

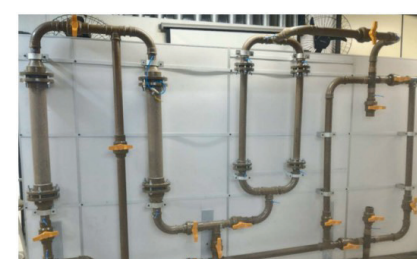

Figura 6. Banco de filtrado y purificación de biogás de relleno sanitario.

A partir de los resultados obtenidos del poder calorífico del biogás, se procede a calcular la potencia eléctrica generada por el sistema. La electricidad anual generada fue estimada mediante la (Ec. 8). [11]

donde:

$A E$ : electricidad anual generada $[\mathrm{kWh} / \mathrm{año}]$;

$C L B$ : volumen de biogás captado del relleno sanitario $\left[\mathrm{m}^{3} / \mathrm{año}\right]$;

$L H V$ : poder calorífico inferior del biogás captado [MJ/año];

$H R$ : potencia utilizada por el motor de combustión interna para generar un kilovatio hora de electricidad, los rangos están entre 9,5 y $12,5[\mathrm{MJ} / \mathrm{kWh}]$;

$P L$ : carga parasita, y representa la cantidad de electricidad utilizada por el compresor y otros elementos utilizados en el sistema de generación, normalmente están entre 0,04 a 0,08;

$A F$ : eficiencia del motor, normalmente se asume entre 0,92 y 0,96 , de acuerdo al equipo seleccionado y al mantenimiento.

Otro modelo propuesto para estimar la potencia eléctrica generada a partir del biogás captado del relleno sanitario es presentado en [7], como se muestra en la (Ec. 9)

$$
W_{\S}=\left(L F G_{\mathrm{FG} \#)}, 20^{100}, 221 Z^{G W} G g^{h}[\right.
$$

donde:

$W_{\S}$ : potencia eléctrica generada [GWh/año]

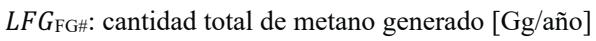


La potencia eléctrica total generada también puede ser determinada mediante el modelo colombiano el cual arroja una eficiencia en la captura estimada en $77 \%$. Los valores del metano captado hacen referencia a un promedio de los modelos de estimación de biogás presentados. Los resultados generales de la potencia eléctrica total generada, se presentan en la Figura 7.

\section{Potencia eléctrica generada}

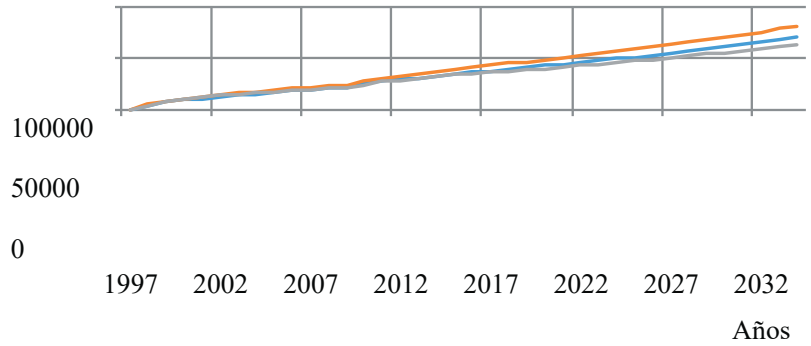

Ec. 8 Ec. $9 \_$Modelo Colombiano

Figura 7. Potencia eléctrica generada por el biogás del relleno La Glorita.

\section{Conclusiones}

Se presentaron tres modelos de estimación de biogás a partir de la degradación de los RSU en el relleno sanitario La Glorita. Los resultados generales del biogás estimado de los modelos evaluados se presentan en la Figura 8.

\section{Figura 8.}

Modelos de generación de biogás del relleno sanitario La Glorita.

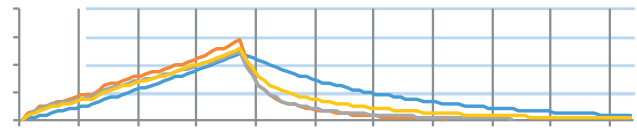

Años

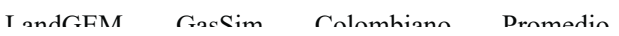


Para que un proyecto de generación de electricidad mediante motogeneradores con capacidades entre $800 \mathrm{~kW}$ y $3 \mathrm{MW}$ sea viable, el relleno sanitario debe captar biogás con una composición de $50 \%$ de metano y con caudales entre $4,4 \sim 16,5 \mathrm{E} 6 \mathrm{~m}^{3} / \mathrm{año}$. Se concluye que el relleno sanitario La Glorita tiene el potencial para generar electricidad como energía renovable del biogás captado de relleno sanitario. Esto es corroborado al analizar la Figura 8 al obtenerse capacidades coherentes. Como se observa en la Figura 8, a pesar de que la cantidad de biogás se estimó mediante tres modelos completamente diferentes, los resultados son similares y se puede concluir que convergen.

Por otro lado, al analizar las ventajas de cada modelo evaluado, se concluye que a pesar de que todos los tienden a valores similares, los modelos que representan mejor el fenómeno son el modelo colombiano y el modelo GasSim.

El modelo colombiano tiene la ventaja de que fue desarrollado teniendo en cuenta las condiciones del país y estima automáticamente los diferentes parámetros asociados como lo son el índice de generación de metano $k$ y el factor de generación potencial de metano $L_{\mathrm{L}}$, de acuerdo a la región de análisis del país. Así mismo permite obtener estimado de la capacidad de generación de electricidad en aplicaciones de motogeneradores según las proyecciones de captaciones simuladas. El modelo presenta la desventaja de que no permite caracterizar los RSU para cada caso específico de tal forma que el usuario los ingrese manualmente ya que el software está protegido y no permite realizar modificaciones al código. El modelo colombiano tampoco permite simular las condiciones del relleno como el nivel de compactación de residuos, el aislamiento superficial de los RSU y con los suelos, la generación de lixiviados, las migraciones laterales y otros factores asociados al fenómeno.

El software GasSim es completo y de los modelos evaluados es el que mejor resultados ofrece ya que permite analizar diversas especies generadas en el proceso de degradación anaeróbica y analizar los fenómenos de dispersión y aprovechamiento energético, sea simplemente quemando el biogás captado en antorchas o en aplicaciones de generación eléctrica como motogeneradores. Así mismo permite estimar el impacto ambiental causado por la liberación de dióxido de carbono de la planta de aprovechamiento del biogás captado. Por contras, el modelo GasSim necesita ser 
ıentado por muchos parámetros iniciales que en la mayoría de los casos son desconocidos por speradores de los rellenos sanitarios en Colombia y demandan de investigaciones para ser rminados. La escasa información referente al tema hace que aplicar el modelo sea complejo, jién porque se necesita tener un conocimiento avanzado para obtener resultados coherentes software ya que su uso no es tan intuitivo.

ıdelo LandGEM a pesar de que es uno de los más aplicados, no permite caracterizar los RSU . casos específicos y tampoco tiene en cuenta las características como el tipo de celda, nivel ompactación, generación de lixiviados, migraciones laterales, entre otros. No obstante, la aja del modelo LandGEM radica en que es un modelo de primer orden simple y esto lo hace I de implementar ya que no requiere conocer muchos parámetros para realizar la simulación y esultados obtenidos corresponden con una buena aproximación del fenómeno real.

oncluye que la disminución del impacto ambiental por la mitigación en la liberación de ano a la atmósfera, como se presenta en la Figura 9, es de aproximadamente 60 t. Teniendo en ta que el metano tiene un índice de calentamiento global 33 veces mayor que el dióxido de ono según cifras del IPCC, esto equivale aproximadamente a 19,8E6 t. de dióxido de carbono valente en un horizonte de sucesos comprendido entre los años 1997 y 2100 , proyectando el de clausura del relleno sanitario para el año 2033.

\section{Ira 9.}

. equivalente evitado por la no liberación de metano.

equivalente evitado por la no liberación de metano

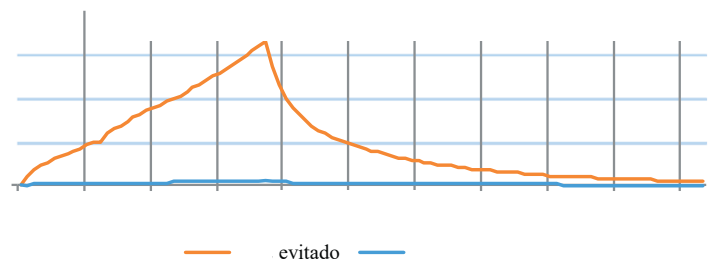


Es importante resaltar que todo proyecto de aprovechamiento energético debe estar enmarcado dentro de las políticas de reducción de gases de efecto invernadero. Actualmente la mayoría de los gobiernos trabajan en políticas sociales con el fin de disminuir la cantidad de RSU depositados en los rellenos sanitarios y estimulan proyectos relacionados con el reciclaje. La dificultad de desarrollar tecnologías en el país que aprovechen energéticamente fuentes no renovables radica, entre otras cosas, en los escasos recursos que se invierten en investigación, la poca información referente al tema, la complejidad de la normativa nacional, entre otros factores.

De acuerdo con las razones expuestas, finalmente se concluye que es fundamental involucrar varios sectores como la academia y la industria privada, con el fin de realizar inversión en tecnologías alternativas y garantizar la viabilidad técnica y económica de este tipo de proyectos a mediano y largo plazo.

\section{Agradecimiento}

Los autores ofrecen un especial agradecimiento a la Vicerrectoría de Investigaciones, Innovación y Extensión de la Universidad Tecnológica de Pereira y al grupo de investigación en Gestión Energética - GENERGÉTICA, por el apoyo recibido para el desarrollo de este capítulo.

\section{Bibliografía}

[1] M. Santos, A. v. Elk y C. Romanel, «A correction in the CDM methodological tool for estimating methane emissions from solid waste disposal sites,» Journal of Environmental Management, vol. 164, nº 0301-4797, pp. 151-160, 2015.

[2] R. V. Karanjekar y e. al, «Estimating methane emissions from landfills based on rainfall, ambient temperature, and waste composition: The CLEEN model,» Waste Management, vol. 46, nº 0956-053X, pp. 389-398, 2015.

[3] M. I. Mandujano, A. Felix y A. M. Martinez, BIOGAS, energía y fertilizantes a partir de desechos orgánicos, Cuernavaca Mexico: OLADE, serie publicaciones especiales, 1981.

[4] M. C. C. Sarmiento, «D WASTE- Waste Managemente for everyone,» 24 Octubre 2012. [En línea]. Available: http://www.d-waste.com/new-infographics/item/114-solid-wastemanagement-in-colombia.html. [Último acceso: 1 marzo 2017].

[5] N. J. Themelis y P. A. Ulloa, «Methane generation in landfills,» Renewable Energy, vol. 32, no 0960-1481, p. 1243-1257, August 2007.

[6] S. Teixeira y e. al, «Prospective application of municipal solid wastes for energy production in Portugal,» Energy Policy, vol. 71, nº 0301-4215, pp. 159-168, 2014. 
N. Bolan y e. al, «Landfills as a biorefinery to produce biomass and capture biogas,» Bioresource Technology, vol. 135, nº 0960-8524, p. 578-587, 2013.

G. I. d. E. s. C. C. IPCC, «Cambio climático 2014- Mitigación del cambio climático,,» IPCC, Berna-Suiza, 2015.

Secretaria de planeación municipal de Risaralda, «Plan de Desarrollo de Pereira,» Alcaldía de Pereira, 12 2008. [En línea]. Available: http://planeacion.risaralda.gov.co/Documentos/site/planeacion/documentos/plan_de_desar rollo/2008-2011. [Último acceso: 23 2017].

ATESA DE OCCIDENTE S.A E.S.P, «Informe de caracterización de residuos a disponer en el relleno sanitario La Glorita de la ciudad de Pereira,» Pereira, Colombia, 2015.

R. Broun y M. Sattler, «A comparison of greenhouse gas emissions and potential electricity recovery from conventional and bioreactor landfills,» Journal of Cleaner Production, vol. 112, no 0959-6526, pp. 2664-2673, 2016.

J. Bogner y e. al, «Chapter 10. Contribution of Working Group III to the Fourth Assessment Report of the IPCC,» de Waste Management, In Climate Change 2007: Mitigation., United Kingdom and New York, Cambridge University Press, 2007, pp. 587-613.

INTERGOVERNMENTAL PANEL ON CLIMATE CHANGE- IPCC, «2006 IPCC Guidelines for National Greenhouse Gas Inventories,» NATIONAL GREENHOUSE GAS INVENTORIES PROGRAMME, Washington D.C., United States of America, 2006.

A. Alexander y e. al, «Landfill Gas Emissions Model (LandGEM) Version 3.02 User's Guide,» Environmental Protection Agency-EPA, Washington DC, 2006.

M. Zamorano y e. al, «Study of the energy potential of the biogas produced by an urban waste landfill in Southern Spain,» Renewable and Sustainable Energy Reviews, vol. 11, $\mathrm{n}^{\circ}$ 1364-0321, p. 909-922, 2007.

Golder Associates, «GasSim 2.5,» Golder Associates, February 2012. [En línea]. Available: http://www.gassim.co.uk/. [Último acceso: 7 March 2017]. 


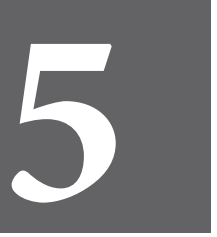

CAPÍTULO CINCO 



\section{Potencial productivo, energético y exergético de biomasa residual agrícola para propós}

de gasificar

\section{Productive, energy and exergy potential of agricultural biomass residues for gasifica}

\section{David A. Serrato, Álvaro Restrepo, Juan E. Tibaquirá}

Universidad Tecnológica de Pereira

daserrato@utp.edu.co, arestrep@utp.edu.co,juantiba@utp.edu.co

\section{Resumen}

En este capítulo es considerada la estimación del potencial productivo, potencial energétic exergético a nivel nacional y departamental de tres residuos agrícolas de interés; cuesco de pa de aceite, cascarilla de café y cascarilla de arroz, provenientes de cultivos representat: disponibles en Colombia, biomasa considerada como una fuente renovable de energía de 1 neutro, a partir de la cual pueden sintetizarse energéticos en fase gaseosa como el "synধ mediante procesos de gasificación, los cuales tienen el potencial para reducir la dependenci: fuentes de energía de origen fósil asociadas a la alta tasa de emisiones de gases de efi invernadero y emisiones contaminantes en el mundo. Fue propuesto un modelo matemático co fin de estimar el potencial energético teórico de la biomasa residual, con el fin de identificar ] cuales departamentos podría considerarse la implementación de sistemas de generación de pote híbridos basados en el acoplamiento de una celda de combustible de óxido sólido (SOFC) y microturbina a gas (MGT), sistemas compactos a pequeña escala que pueden ser utilizados regiones o zonas no interconectadas a una red central de suministro de energía eléctrica, y los cu incentivan el uso de estrategias energéticas de autoabastecimiento mediante el aprovechamient dicho recurso energético. Fue estimado un potencial energético y exergético considerando lo: departamentos identificados como aquellos cuya producción conjunta representa un 96,2\% d generación de residuos, de $\sim 5.585$ TJ y 7.161 TJ, respectivamente. Por otro lado, fue estim que el sistema híbrido tiene una capacidad de generación neta de potencia de $2,831 \mathrm{~kW}$ por c $\mathrm{kg} / \mathrm{h}$ de biomasa que ingresa al gasificador, cuando es utilizado syngas obtenido a partir $\mathrm{d}$ gasificación de cuesco de palma de aceite, y de 2,219 kW por kg/h de biomasa y de $1,716 \mathrm{~kW}$ $\mathrm{kg} / \mathrm{h}$ de biomasa cuando el sistema es alimentado con syngas obtenido a partir de la gasificació 
bras claves: biomasa, energía, exergía, gasificación.

\section{tract}

is chapter is considered the estimation of national and municipal productive, energy and exergy ntial of three agricultural residues in Colombia; palm oil kernel, coffee husk and rice husk, aass identified as a zero carbon dioxide renewable energy source, from which it is possible to hetize a secondary and more flexible energy source in gaseous phase such as the syngas by fication processes, which own the potential to reduce the dependency from fossil energy ces linked to high rates of greenhouse and polluting gas emissions in the world. It was presented athematical model in order to estimate the theoretical potential of the agricultural residual ass and to identify which regions and municipalities in Colombia could be considered as ible locations of hybrid power generation systems based on a solid oxide fuel cell (SOFC) and cro gas turbine (MGT), compact and small scale systems which could be used in regions and interconnected zones to an electrical network system, promoting the implementation of energy agement strategies of self-supplying by feeding these type of systems with this king of energy ce locally available. Is was estimated that the energy and exergy potential for 18 regions whose ied production of agricultural residues accounts $96,2 \%$, is $\sim 5.585 \mathrm{TJ}$ and $\sim 7.161 \mathrm{TJ}$, ectively. By the other hand, it was estimated that the hybrid power generation system has a er generation net capacity of $2,831 \mathrm{~kW}$ per $\mathrm{kg} / \mathrm{h}$ of biomass when the systems is fed with syngas ined by the gasification of palm oil kernel, , a power generation net capacity of 2,219 kW per of biomass and $1,716 \mathrm{~kW}$ per $\mathrm{kg} / \mathrm{h}$ of biomass when the system is fed with syngas obtained ıe gasification of coffee husk and rice husk, respectively. Keywords: biomass, energy, exergy, fication

\section{oducción}

1 abastecimiento diversificado y sostenible de la energía dado el aumento en el consumo de recurso a nivel mundial, efecto de un crecimiento progresivo de la demanda asociada a la iplicación de las necesidades energéticas de los seres humanos y al aumento continuo de la ación mundial, es uno de los desafíos críticos que enfrenta la humanidad en la actualidad, en scenario donde el suministro de energía se garantiza principalmente mediante la utilización de tes de origen fósil como el petróleo. el carbón v el gas natural 「11. 
Considerando las proyecciones futuras, de acuerdo con la IEA - International Energy Ag [2], se estima un aumento en la demanda de energía a nivel mundial del 1,6\% en promedio a durante el 2006 y el 2030, de 472 EJ (11.730 Mtoe) a 714 EJ (17.010 Mtoe). Según la EIA Energy Information Administration [3], entre las fuentes de energía disponibles a futuro, el petr y otros combustibles líquidos seguirán siendo las fuentes de energía de mayor uso, a pesar de entre los años 2012 y 2040 se estima una reducción del 3\% de su consumo en el mercado energr global. Sin embargo, y en contraste a esta tendencia, se pronostica que el aumento en el cons de combustibles líquidos será sólo del 1,1\% en promedio anual en el sector transporte, y del 1 en promedio anual en el sector industrial; con subsecuentes reducciones en el sector residenc eléctrico donde se consideran seriamente la utilización de alternativas ligadas a fuentes de en renovable, que de acuerdo a las proyecciones, serán las fuentes de más rápido crecimiento con tasa de expansión del 2,6\% en promedio anual entre el 2012 y el 2040.

Entre las fuentes de energía renovable disponibles, la biomasa es considerada una fuente de neutro, siendo la única fuente de energía renovable que puede ser transformada en un prod energético en fase sólida, líquida o gaseosa mediante múltiples procesos de conversión energı [4]. De acuerdo con Long H. et al. [5], la producción de bioenergía basada en biomasa suple c el 9-13\% del consumo total de energía a nivel mundial, lo cual supone ser una de las fuente energía renovable más prometedoras en el futuro; ser una fuente de energía disponible localm [6]; y de ser una fuente con el potencial de reducir la dependencia existente de los combustible origen fósil, contribuyendo en consecuencia a la disminución de las tasas de emisión de gasє efecto invernadero y emisiones contaminantes [7].

Siendo una realidad mundial, en Colombia la utilización de biomasa como fuente energética no se contabiliza en la canasta energética actual o en sus proyecciones futuras a corto y med plazo, lo que indica que no ha sido considerada aún como una alternativa energética promiso pesar de poseer una alta disponibilidad de recurso en toda la extensión de su territorio [8] acuerdo con Gonzalez-Salazar MA et al. [7], desafíos importantes deben ser contemplados hacer uso de la biomasa, entre los que se encuentran, la competencia por el uso de la tierr deforestación, la contaminación y la reducción de las fuentes hídricas. Por consiguiente, ha identificado que es esencial la formulación de una estrategia estructural para el aprovechami de la biomasa como fuente de energía, la cual involucra tecnologías que ya han sido desarroll 
diante procesos de transformación biológica, termoquímica y bioquímica.

Considerando lo anterior, y dadas las circunstancias nacionales asociadas con una tasa $\mathrm{d}_{\mathrm{i}}$ cimiento demográfico constante; los retos financieros, económicos y ambientales actuales : uros, así como la dinámica climática de Colombia, y considerando que a la fecha no se evidenci: implementación de sistemas de generación de potencia híbridos para el aprovechamient rgético de la biomasa; se propone la formulación de estrategias para la construcción de enarios de abastecimiento energético diversificado, en el marco de la promoción de la seguridar rgética, el uso racional y eficiente de los recursos naturales y la minimización de los riesgo bientales ocasionados por el uso continuado de fuentes energéticas altamente contaminantes. Es z orden de ideas, se pretende sentar la bases para construir una alternativa como solución dı oabastecimiento energético a poblaciones con cobertura parcial de los servicios básicos y col ponibilidad local de residuos agrícolas y/o agroindustriales, como es el caso de las Zonas $\mathrm{n}$ arconectadas - ZNI a la red eléctrica nacional donde el uso de estos residuos como fuente de rgía puedan ser utilizados en un sistema de generación de potencia híbrido a pequeña escala npacto y modular; que involucre su acoplamiento a una unidad de gasificación de biomasa Ide la materia orgánica en fase sólida sea convertida en un combustible en fase gaseosa con e l pueda generarse energía eléctrica a parte de celdas de combustibles y una turbomáquina nica. Sin embargo, es necesario durante el nacimiento de estas estrategias que involucran el usı la biomasa como fuente de energía, el desarrollo y/o implementación de modelos matemático : permitan estimar el potencial productivo y energético de la biomasa, así como estimar su piedades conociendo su caracterización fisicoquímica, modelos que se presentan y tratan en estı ítulo para residuos agrícolas en un contexto colombiano.

\section{jetivos}

sarrollar una metodología para la estimación del potencial productivo, energético y exergéticı residuos agrícolas para propósitos de gasificación

- Caracterizar las proniedades fisicoauímicas de los residuos agrícolas suscentibles a se 
- Implementar un modelo matemático para la estimación del potencial productivo, energé y exergético de los residuos agrícolas seleccionados para propósitos de gasificación.

- Identificar y caracterizar el potencial productivo y energético de los residuos agríc identificados a nivel nacional, por departamentos y para Zonas No Interconectadas (Z con disponibilidad local de recursos.

- Estimación del potencial de generación de potencia en un sistema híbrido basado en celda de combustible de óxido sólido y una microturbina a gas (SOFC-MGT).

\section{Referente teórico}

En 2005, de acuerdo con Sikarwar VS y Zhao M. [9], UNFCCC - United Nations Framen Convention on Climate Change fue establecida una definición ampliamente aceptada de lo qu considera biomasa:

Un material orgánico no fósil y biodegradable de origen vegetal, animal o proveniente microorganismos. Se incluyen productos, bio-productos, residuos y desechos agrícc forestales y aquellos provenientes de ciertas industrias, así como las fracciones no fósil biodegradables de los residuos sólidos urbanos.

En un sentido amplio, un material puede ser considerado biomasa si es de composición orgál y es derivada de las plantas y/o animales o sus desechos.

Cuando la radiación solar es interceptada por las plantas el dióxido de carbono del ambient convertido en carbohidratos en presencia de agua mediante el proceso de fotosíntesis, y se almac en forma de energía química en la vegetación terrestre o acuática. A su vez, sirviendo de alim a los animales, la energía almacenada en las plantas se transfiere a la biomasa animal y se convi en excreta [10]. Cuando la biomasa es quemada o es utilizada en procesos de conversión energé una vez transformada en otros tipos de combustible más versátiles en fase sólida, liquida o gase el carbono de la biomasa reacciona con el oxígeno del aire para formar dióxido de carbono, el । es liberado a la atmósfera. De presentarse una combustión completa la cantidad de carb generado en el proceso es igual a la cantidad que fue absorbida de la atmósfera durante la etap: crecimiento de la especie vegetal. Por consiguiente, no se identifica una adición neta de $\mathrm{CO}_{2}$ atmósfera y la biomasa puede considerarse como un "sumidero" de carbono. Así, se manifiest: ciclo de emisión de "zero" carbono [10]. 
رe acuerdo con Anrentelat J. et al. [11], la gasiricacion na probado ser un modo eniciente y ible de utilizar la biomasa como fuente de energía, lo que ha atraído la atención creciente hacia esarrollo de tecnologías relacionadas con este proceso, principalmente en la producción binada de calor de proceso y potencia eléctrica, lo que es una tecnología prometedora. Según เ K y De S. [12], el proceso de gasificación integrado a una planta de generación de potencia binada es una opción futura sustentable en la generación de potencia de $\mathrm{CO}_{2}$ neutro, con el cual $\mathrm{n}$ ciclo de cogeneración es posible incrementar la eficiencia térmica global de una planta dado igen y composición de la fuente.

a demanda de biomasa en una planta a pequeña escala puede ser fácilmente suplida por zrial orgánico de áreas circundantes como los residuos agrícolas y forestales, productos de la istria alimentaria o residuos del procesamiento de la madera. Sin embargo, a pesar de sus nciales beneficios, el desarrollo de estas plantas de generación alimentadas con biomasa no ha ampliamente implementadas como se hubiese esperado en países con alta disponibilidad de fuente de energía [13]. En relación a lo anterior, una de las alternativas prometedoras para la ti-generación de energía de acuerdo con El-Emam R.S. [14], es la integración de la gasificación iomasa a celdas de combustible de óxido sólido (SOFC). Según Ud Din Z y Zainal Z.A. [15], $\mathrm{s}$ sistemas pueden operar con eficiencias mayores comparados con sistemas de generación de ncia basados en motores de combustión interna. Eficiencias del orden de 50-60\% pueden ser nzadas si el flujo de gas que sale de la celda de combustible es utilizado en turbinas a gas y la ción de calor remanente en la celda de combustible, utilizado en aplicaciones o servicios que lieran calor de proceso.

ıctualmente, el escenario más económico para el uso de la biomasa como fuente de energía, es ,eneración "co-firing” en plantas de generación de potencia a carbón. Esto se explica ;iderando la alta eficiencia eléctrica de estas centrales en comparación con plantas de sración a pequeña escala descentralizadas [16]. Como alternativa, según Ud Din Z y Zainal ZA , la gasificación de biomasa en un gasificador promete ser una estrategia más eficiente parada con la combustión de biomasa en ciclos de potencia de vapor, particularmente a pequeña la. Por otro lado, según Doherty W, Reynolds A y Kennedy D [18], el uso de SOFCs acopladas ;temas de gasificación de biomasa muestra ser una alternativa de generación prometedora ya se combinan las bondades de las fuentes de energía renovable y las características de alta 
eficiencia de las celdas de combustible. Estos sistemas denominados (BG-SOFC), ofrecen configuración modular ideal en aplicaciones de generación descentralizada de calor y pote combinada (CHP). A continuación, en la Fig. 1, se presenta esquemáticamente la integración e la fase de conversión energética de la biomasa y aprovechamiento del gas de síntesis "syngas", 1 la implementación de un sistema integrado BGSOFC.

\section{Figura 1.}

Esquema técnico de un sistema integrado Gasificación de Biomasa-Celda de Combustible B SOFC.

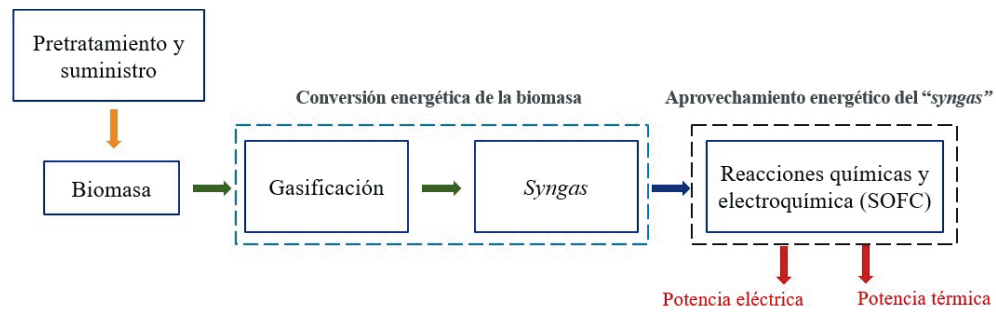

\section{Selección de residuos}

Son seleccionados como cultivos de interés para el proceso de gasificación, el arroz, el café palma de aceite. Para el arroz fueron identificados la paja y la cascarilla como sus princip residuos. Una gran proporción de la paja de arroz es incinerada o dispuesta en cuerpos de agu que ocasiona serios impactos ambientales, y la fracción remate es dispuesta en establos par alimentación equina. La paja de arroz es uno de los residuos que presenta mayor complejidad 1 ser dispuesta debido a las grandes cantidades producidas, su humedad superior al $70 \%$ y su dispersión. Debido a su contenido de humedad no es considerada viable para procesos conversión termoquímica pero sí para procesos de biodigestión anaeróbica [19]. Por otro lad pesar de ser comercializada en establos, granjas y para actividades de jardinería, se estima qu $44 \%$ del total de cascarilla generada en el país, la cual se estima entre 280.000 t y 700.000 t pu 
carilla de arroz es la cobertura exterior del grano, la cual corresponde entre el $14 \%$ y el $35 \%$ di peso [19].

Para el café fueron identificados los tallos, la pulpa y la cascarilla como sus principales residuos ; tallos son utilizados por los productores en el proceso de tostión y secado de los granos, ? resentan un excelente producto en los sistemas de compostaje. La pulpa es utilizada por lo npesinos como fertilizante y alimento para animales. Su dispersión es significativamente alta lo que no es considerada viable para procesos de conversión termoquímica. Sin embargo, se h: ntificado que la pulpa de café posee un alto potencial para la producción de biogás y etanol dadi omposición de su fracción orgánica y su contenido de humedad [19]. Por otro lado, la cascarilla sual es obtenida como producto del beneficio del café, es la capa que recubre la semilla, : resenta el 4,2\% del peso del fruto. Además, posee excelentes propiedades combustibles y e ısiderada una disponibilidad del $25 \%$ para procesos de conversión energética [20].

Para la palma de aceite fueron identificados el rachis y el cuesco como sus principales residuos z ha identificado que el $83 \%$, y el $57 \%$ de estos pueden ser empleados en procesos de conversió rgética, como una alternativa al uso que actualmente se les da en el mercado. El rachis, a pesa presentar un gran potencial para la generación de potencia y producción de fertilizante ánicos, debido a su alto contenido de potasio en las cenizas, induce problemas de operación es deras y gasificadores [19]. Por otro lado, el cuesco o endocarpio es un material duro que proteg llmendra del fruto, tiene excelentes propiedades combustibles, posee baja humedad y tiene li Itaja de presentarse de manera concentrada, a diferencia de otros residuos que se presentan d nera más dispersa e implican mayores costos de recolección y transporte hasta los sitios dı cesamiento [21]

De acuerdo con lo anterior, es seleccionada la cascarilla de arroz, la cascarilla de café y el cuescr palma de aceite ya que poseen un alto contenido de carbono, lo que indica una mayo babilidad de formación de gases combustibles; bajo contenido de materia inorgánica, lo qu mite menores tasas de formación de ceniza; un alto contenido de material volátil, lo cua rementa el potencial para la generación de potencia; una humedad entre el $10-15 \%$, lo cua mite prescindir del proceso de secado "in situ", lo cual es ventajoso considerando que este es u1 
disminuir la probabilidad de generación de escoria; un bajo porcentaje de potasio en la ceniza, lo que disminuye la probabilidad de ocurrencia de aglomeración y desfluidización del lecho si la gasificación se lleva a cabo bajo régimen de lecho fluidizado, permitiendo prolongar la vida útil de los equipos y garantizar el régimen de flujo al interior del gasificador [19,20,22,23]. A continuación, en la Tabla 1 se presenta el valor de área cultivada, rendimiento de cultivo y producción anual promedio entre los años 2007 y 2017 de los cultivos seleccionados, construida a partir de la base de datos de acceso libre Agronet MinAgricultura-Red de Información del Sector Agropecuario Colombiano [24].

\section{Tabla 1.}

Área cosechada, producción y rendimiento promedio nacional de cultivos agrícolas de interés para procesos de transformación termoquímica.

\begin{tabular}{llll}
\hline Arroz (Total) & 396.693 & 3 & 2.234 .654
\end{tabular}

Café

\section{Modelos matemáticos de estimación de potencial}

\section{Potencial productivo}

Mediante la ec.(1), es posible estimar el potencial teórico nacional de generación de residuo por cultivo $C R^{\&}$ [t/año], considerando aquellos cultivos que, de acuerdo con su producción promedio anual durante los años 2007 y 2017, presentan potencialidad para ser utilizados en procesos de conversión energética; y sólo aquellos que, de acuerdo con su composición fisicoquímica pueden ser utilizados en procesos de gasificación [7]. 
le, $K P K^{*}$, es la traccion de cultivo que se transtorma en residuo para cada uno de los cultivos Por otro lado, sólo puede disponerse de una fracción del residuo para ser aprovechado como rso energético por limitación del mercado agrícola actual, el potencial técnico nacional de ración de biomasa residual agrícola $C R{ }^{\&} \quad$ [t/año], que podría aprovecharse para la idad ya mencionada, puede estimarse entonces, mediante la ec.(2):

onde, $R P R$,,* es el factor de disponibilidad, el cual representa la fracción de residuo que puede provechado como recurso energético en procesos de conversión energética. Por otro lado, con n de estimar el potencial productivo de los residuos generados a partir de biomasa residual sola con potencialidad para la generación de energía mediante procesos de gasificación de lasa en Colombia, y disponibles por departamento $\quad C R$, , se propone la ec.(3):

$$
C R, .=((C R, \&(*, 0)
$$

onde, $R P R *^{*}$, es el porcentaje de participación mayoritario anual promedio de residuo generado departamento y por cultivo, calculado al considerar sólo aquellos departamentos que ssentan una participación conjunta entre el 95\% y el 98\% de la producción nacional promedio ultivo específico considerando el registro histórico disponible entre los años 2007-2017.

\section{ncial energético}

on base en los estudios de investigación llevados a cabo por Gonzalez-Salazar M.A et al. [7], esenta el modelo analítico con el cual es posible estimar el potencial energético bruto nacional esiduos agrícolas, el cual, define la disponibilidad de materia orgánica para procesos de 'ersión energética. Así, considerando el potencial productivo de generación de residuo onible por cultivo, la fracción másica de la humedad en la biomasa $x_{3}$, , el poder calorífico por luo, y la entalpía de vaporización del agua a $25^{\circ} \mathrm{C}$ definida como $h_{5}, 678$, el potencial energético 
mediante la ec.(4):

donde, el poder calorífico inferior en base húmeda $P C I^{?}{ }^{*}$; , necesario en la estimació1 potencial energético neto de las biomasas, considera la fracción másica de agua en fase líquic cada biomasa $\left(x_{3}\right)$, y puede calcularse a partir del poder calorífico en base seca mediante la e [26]:

$$
P C I:>^{*} ;=(1-x 3) P C S: \mathrm{B}^{*} ;-x 3 h 5,678
$$

donde, el contenido energético de la biomasa o Poder Calorífico Superior - PCS, es cantidad de energía almacenada por unidad de masa y es usualmente medida como el calı combustión, la cual, es la energía total liberada en forma de calor cuando se lleva a cabc combustión completa utilizando oxígeno como oxidante bajo condiciones estándar, de la cu obtienen como productos dióxido de carbono, agua en fase líquida, nitrógeno y dióxido de a: [27]. Así, el poder calorífico superior $P C S_{:}^{\mathrm{B}_{*}}$ en base seca $(\% d b)$ de la biomasa residual agrí puede estimarse a partir de los porcentajes másicos de carbono $\left(z_{\mathrm{D}}\right)$, hidrógeno $\left(z_{6}\right)$, azufre nitrógeno $\left(z_{\mathrm{F}}\right)$, oxígeno $\left(z_{8}\right)$ y ceniza $\left(z_{\mathrm{G}}\right)$ en base seca obtenidos mediante análisis elemen análisis próximo. De acuerdo con la correlación descrita en la ec.(6), es posible estimar el r calorífico superior de la biomasa residual agrícola en base seca en $[\mathrm{kJ} / \mathrm{kg}]$. Esta correlación propuesta por [26,28], posee un error porcentual medio del 1,45\% y un error (MBE) del 0, Esta correlación permite la estimación del poder calorífico superior de combustibles sól líquidos y gaseosos la cual incluye biomasa terrestre y acuática, biomasa de residuos industr: residuos sólidos urbanos, carbón y coque para fracciones de porcentaje en peso de carbono, hidrógeno, oxígeno, nitrógeno, azufre y ceniza comprendidos entre los rangos $0 \% \leq z_{\mathrm{D}} \leq 92$, 
ectivamente. Esta correlacion, la cual se presenta en la ec.(6), ha sido adoptada por la Agencia "nacional de Energía - IEA para estimar el poder calorífico de diferentes biomasas [28].

$$
P C S^{\mathrm{B}_{*}}=34,91 z_{\mathrm{C}}+117,83 z_{\mathrm{H}}+10,05 z_{\mathrm{S}}-1,51 z_{\mathrm{N}}-10,34 z_{\mathrm{O}}-2,11 z_{A}
$$

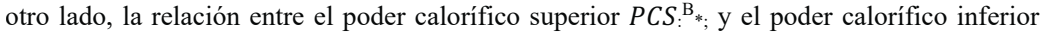
$\mathrm{B}_{* ;}$ en base seca para la biomasa residual agrícola se expresa mediante la ec.(7) [26]:

$$
P C I: \mathrm{B}^{*} ;=P C S: \mathrm{B}^{*} ;-\mathrm{W} 100 z \underline{6} \times \mathrm{MMWW} 6[778 h 5, \mathbf{H} 2 \mathbf{0}
$$

onde, $M W_{67} 8, M W_{67}$, y $h_{5,67} 8=2441,7 \mathrm{~kJ} / \mathrm{kg}$ [29], representan el peso molecular del agua, el , molecular del hidrógeno y la entalpía de vaporización del agua a $25^{\circ} \mathrm{C}$, respectivamente. A inuación, en la Tabla 2 y la Tabla 3, se presenta el análisis elemental y el análisis próximo en seca de las biomasas objeto de este estudio. Fueron considerados valores de referencia para smbia de la composición de los residuos de interés en base seca libre de ceniza (w/w \% d.a.f) base húmeda (w/w\% a.r.b).

la 2.

lisis elemental de la biomasa residual agrícola ( $w / w \%)$

\begin{tabular}{ccccccc}
\hline Residuo & C & H & O & N & S & Ref. \\
\hline
\end{tabular}

ascarilla de arroz (d.a f), 2. Cascarilla de café (d.a.f), 3. Cuesco de ı de aceite (d.a.f).

\begin{tabular}{lllll}
\hline Residuo & $\vdots$ & A & M & Ref. \\
\hline
\end{tabular}

ascarilla de arroz (a r.b), 2. Cascarilla de café (a r.b), 3. Cuesco de palma de aceite (a.r.b, Material volátil; FC: Carbono fijo; A: Ceniza; M: Humedad. 


\section{Potencial exergético}

Con base en de la correlación utilizada por [32,33], y planteada por Szargut et al. [34]. ropone la ec.(8), elaborada con el fin de estimar el potencial exergético nacional anual de jiomasas seleccionadas $E x_{:}^{{ }^{{ }_{*}}}{ }_{;}$.

$\left.{ }_{678} e f ;, 678\right) g$

$$
E x:{ }^{\& *} ;=\left(* C R,{ }^{\&}, * \text { 'ex: }{ }^{\text {b*c }}, *-x 3, *(\ldots \beta \text { _ }\right.
$$

Considerando las correlaciones propuestas por Szargut y Styryska, la exergía química d racción orgánica de la biomasa en base seca [kJ/kg], puede calcularse mediante la ec.(9) [35]. sxergía química asociada a la fracción inorgánica o ceniza, la cual representa una contribuciór nenos del $0,2 \%$ respecto de la exergía química de la fracción orgánica, podría deprecic ıludiendo a la recomendación establecida por Szargut et al. [34]. Bajo esta consideración, por lecirse entonces que $e x_{:}{ }^{\mathrm{b}} ; \mathrm{c} \approx e x_{\mathrm{i} 3}{ }^{\mathrm{bc}}$.

$$
\text { exi3bc }=\beta P C I: \mathrm{B}^{*} ;+9683 z \mathrm{E}
$$

donde, $\beta$ es la tasa de exergía química estándar para compuestos sólidos como la biomasa esidual agrícola, la cual puede calcularse mediante la correlación presentada en la ec.(10) baj zondición $\mathrm{z}_{8} / \mathrm{z}_{\mathrm{D}} \leq 2[36]$ :

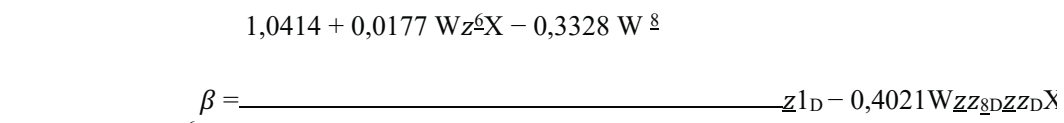

$11+0,0537 \mathrm{~W} \underline{z}_{Z}{ }^{6}{ }_{\mathrm{D}} \mathrm{Xo}$

Finalmente, con el fin de estimar el potencial energético y exergético de residuo agríc senerado y disponible por cultivo y por departamento $E: * ;$ y $E x: *$; se propone la ec.(11): 
(12), las cuales consideran el porcentaje de participación de cada departamento en la producció un determinado residuo agrícola $R P R *$.

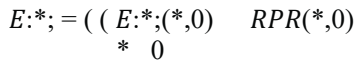

$\&$

\section{tencial energético de la gasificación de biomasa en un sistema SOFC-MGT}

Basado en los estudios llevados a cabo por Gonzalez-Salazar MA et al. [7], se propone la ec.(13 a ec.(14) para así estimar el potencial energético nacional de la gasificación de la biomas idual agrícola en Colombia en [TJ] de los cultivos seleccionados en un sistema de potenci rrido basado en una celda de combustible de óxido sólido y una microturbina a gas. $(j=1$ scarilla de arroz, $j=2$ : Cascarilla de café, $j=3$ : Cuesco de palma de aceite)

667

$$
\begin{aligned}
& E \mathrm{qr}=3,154 \quad \begin{array}{c}
x \\
0 *
\end{array} \quad 10((\quad \mathrm{u} k \mathrm{w}, 0 C R,(*, 0)+k \mathrm{x}, 0 \mathrm{y}
\end{aligned}
$$

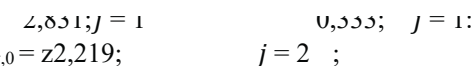$$
j=2 \text {; }
$$$$
1,716 ; j=3 \quad 0,633 ; j=3 ;
$$ 


\section{Resultados}

De acuerdo con la ec.(2) y la ec.(3), se tiene que el potencial productivo nacional teórico y técnico de generación por cultivo y por residuo es de $1.374 .833 \mathrm{t}$ /año y $390.341 \mathrm{t} /$ año respectivamente. De lo anterior, se infiere que sólo el 18,5 \% de la producción nacional anual promedio de los cultivos anteriormente mencionados estimada en 7.436 .314 t/año, corresponde a la producción anual promedio de los residuos seleccionados, y de estos, cerca del $28,4 \%$ de acuerdo con las limitaciones del mercado, podría ser utilizados en proceso de conversión energética. Así mismo, se identifica que sólo el 5,25\% de la producción nacional anual promedio de los cultivos de interés, corresponde a residuos que podrían aprovecharse. Fue identificado que el departamento del Meta posee el mayor potencial productivo de generación de residuos que podrían utilizarse como materia prima para procesos de gasificación de biomasa. Por otro lado, fue identificado que el departamento de Risaralda posee el menor potencial productivo de los residuos considerados con una participación de $\sim 0,14 \%$ y que los departamentos del Meta, Tolima, Casanare, Cesar, Huila y Santander donde se concentra aproximadamente el $80 \%$ de la generación de residuos, presentan conjuntamente una potencialidad productiva de residuos que pueden ser aprovechados en procesos de gasificación de biomasa de $\sim 299.317$ t/año.

Fue estimada una producción promedio de 377.685 t/año de residuos con disponibilidad para ser aprovechados en procesos de gasificación de biomasa, la cual representa cerca del 96,8\% de la totalidad del potencial de generación de residuos estimada por parte de 18 de los 32 departamentos que representan entre el $95 \%$ y el $98 \%$ de participación en la generación de dichos residuos. Por otro lado, se estima que, en promedio, alrededor de 12.656 t/año del potencial de generación de residuos, el cual representa entre el $2 \%$ y el $5 \%$ restante de participación por parte de los otros 14 departamentos, podría no ser aprovechado fácilmente debido a que no se podría garantizar la concentración de los residuos en una ubicación geográfica específica que permita un flujo de alimentación mínimo recomendable de $100 \mathrm{~kg} / \mathrm{h}$ equivalente a $876 \mathrm{t} /$ año de residuo hacia un gasificador a pequeña escala [37]. A continuación, en la Fig. 2, se presenta el potencial productivo departamental de los cultivos agrícolas seleccionados para propósitos de gasificación.

Fionra ? 


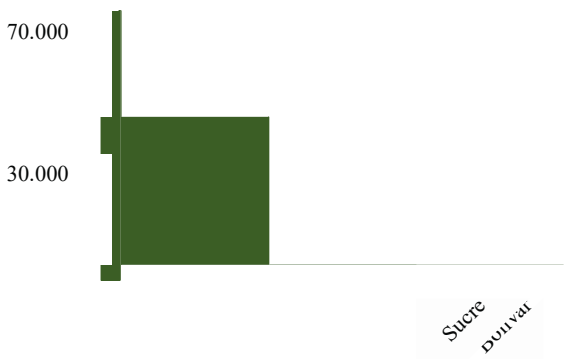

Para el caso de los departamentos de Caldas, Quindío y Risaralda; Valle del Cauca, Cauca y ıriño; Cundinamarca, Santander, Norte de Santander y Cesar; cuyo potencial de generación dividual de cascarilla de café se encuentra por debajo de este límite recomendado, se plantea que residuo sea centralizado en uno de los departamentos de cada uno de los tres grupos, para así sanzar un potencial de alimentación por encima del límite de $\sim 1.558 \mathrm{t}$ /año, $\sim 1.574$ t/año y $\sim 1.046$ ño, respectivamente.

A partir de los valores analizados de la base de datos de acceso libre [24], se identifica que los partamentos que poseen Zonas No Interconectadas - ZNI con acceso a energía eléctrica son: ıriño, Chocó, Cauca, Guainía, Caquetá, Amazonas, Antioquia, Putumayo, Valle del Cauca, ıupés, Vichada, Meta, Guaviare, Magdalena y Casanare. Por otro lado, se identifica que los partamentos que no poseen Zonas No Interconectadas corresponden a la mayor parte de la región ıribe y la región Andina que comprende el centro del país. Mediante un análisis de Pareto, se zntificó que los departamentos de Nariño, Chocó, Cauca y Guainía concentran aproximadamente $80 \%$ de las localidades no interconectadas a la red eléctrica del país a una proporción del 38,51\%, $, 14 \%, 11,94 \%$ y $3,76 \%$, respectivamente.

Por otro lado, dado que de los cultivos seleccionados mediante los criterios anteriormente puestos no presentan participación representativa a nivel nacional por parte de los departamentos 
propuso incluir la participación del cultivo de arroz secano manual para el departamento del $\mathrm{Ch}$ el cual representaría una producción promedio de cascarilla de 2.771 t/año para este departam abriendo la posibilidad de generación eléctrica a partir de proceso de gasificación de biomas partir de los valores analizados de la base de datos de acceso libre [24], fue identificado q1 99,3\% de los 45.517 usuarios de Nariño, el 53,9\% de los 29.715 usuarios del Chocó, el 100 ? los 14.114 usuarios del Cauca y el 70,9 \% de los 4.439 usuarios de Guainía no interconect suplen sus necesidades de energía eléctrica mediante generadores diésel.

Para el departamento de Guainía no se registra producción de los cultivos de interés pa: presente estudio. Sin embargo, se identificó que cerca del $87,9 \%$ de la producción de cult agrícolas, se concentra en los cultivos de yuca y plátano, con una participación del $65,59 \%$ y $22,33 \%$, respectivamente. Se ha identificado que los residuos de estos cultivos son más apropi para procesos de fermentación y biodigestión anaeróbica. Por otro lado, se identificó que, si el departamento del Meta manifiesta ser el departamento con mayor potencial para la genera de energía a partir de biomasa residual agrícola con una participación de $\sim 21,6 \%$ entre lo departamentos identificados, sólo concentra el 1,23\% de las ZNI. Es así como se propone c una solución alternativa para la generación de energía eléctrica descentraliza a partir de resi agrícolas en los departamentos de Nariño, Chocó y Cauca, el aprovechamiento energéticc biogás generado a partir de la biodigestión anaeróbica de la paja de arroz y la pulpa de caf sistemas de generación de potencia.

A continuación, en la Tabla 4, de acuerdo con los modelos expuestos, se presenta el valo poder calorífico superior e inferior en base seca, el poder calorífico inferior en base húmeda exergía química de la fracción orgánica e inorgánica de las biomasas seleccionadas.

Tabla 4.

Poder calorifico de biomasa residual agrícola destinada a procesos de gasificación

\begin{tabular}{|c|c|c|c|}
\hline Residuo & $\operatorname{PCS}_{\text {bio }}[\mathrm{M}$. & $P C I^{s_{b i o}}[\mathrm{MJ} / \mathrm{kg}]$ & 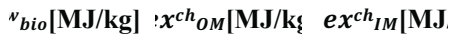 \\
\hline
\end{tabular}




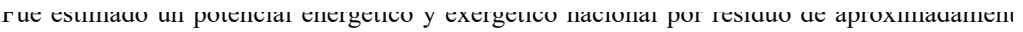
5.805 TJ y 7.445 TJ por año, lo cual corresponde a la disponibilidad energética que podría aprovecharse con fines de generación de potencia y calor combinado (CHP) en el sistema d potencia híbrido acoplado a un proceso de gasificación de biomasa BG-SOFC-MGT. continuación, en la Tabla 5, se presentan los potenciales energético y exergético por residuo considerando el valor promedio anual en $[\mathrm{TJ}]$ de los potenciales productivos a nivel nacional.

Tabla 5.

Potencial energético y exergético bruto de la biomasa residual agrícola objeto de estudio.

\begin{tabular}{|c|c|c|c|c|c|}
\hline Cultivo* & Residuo & $n_{r, i}[\mathbf{t} / \mathbf{a n ̃ o ]}$ & Enbio,i & {$[\mathrm{TJ}]$} & Exnbioi $[\mathrm{TJ}]$ \\
\hline 2 & Cascarilla & 67.775 & $1.954,6$ & & $2.603,7$ \\
\hline 5 & Cascarilla & 7.868 & 110,9 & & 147,8 \\
\hline
\end{tabular}

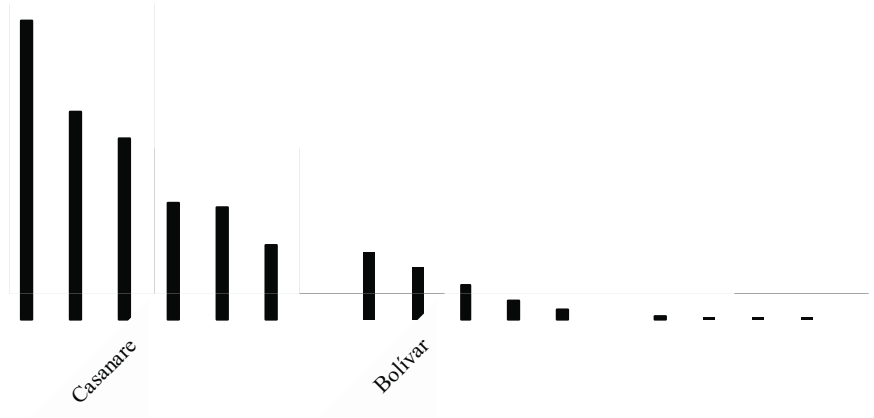

residuos agrícolas de interés para propósitos de conversión energética en procesos gasificación. 
Figura. 3.

Dotencial energético y exergético bruto departamental para propósitos de gasificación.

Fue identificado que el departamento del Meta posee el mayor potencial energético y exergé sara propósitos de generación a partir de cascarilla de arroz y cuesco de palma. Así mismo dentificó que el $84 \%$ y el 78,6\% del potencial energético y exergético total a partir de los resid ;eleccionados se concentra en los departamentos del Meta, Tolima, Casanare, Santander, Ce Santander y Norte de Santander. Por otro lado, dado que fueron considerados sólo aque lepartamentos cuya producción conjunta representa un 96,2 \% de la generación de residuos iene que el potencial energético y exergético considerando los 18 departamentos identificados le $\sim 5.585 \mathrm{TJ}$ y $\sim 7.161 \mathrm{TJ}$, respectivamente.

El potencial energético y exergético conjunto para la cascarilla de café, residuo que mostró sajo potencial productivo por debajo del límite de 876 t/año para los departamentos ubicados e sentro occidente del país: Caldas, Quindío y Risaralda, se tiene un potencial productivo, energé v exergético de $\sim 1.558$ t/año, $\sim 21,97$ TJ y $\sim 29,26$ TJ, respectivamente. Por otro lado, entre lepartamentos ubicados en la zona suroccidente del país para el mismo residuo: Valle del Cal Zauca y Nariño, se tiene un potencial productivo, energético y exergético conjunto de $\sim 1.574 \mathrm{t} / \mathrm{a}$ $-22,19$ TJ y $\sim 29,6$ TJ respectivamente. Finalmente, entre los departamentos ubicados en la z sentro y nororiente del país para el mismo residuo: Cundinamarca, Santander, Norte de Santan ${ }_{\gamma}$ Cesar, se tiene un potencial productivo, energético y exergético conjunto de $\sim 1.046$ t/año, $\sim 14$ ГJ y $\sim 19,7$ TJ respectivamente. A continuación, en la Tabla 6, se presenta el potencial energé $\checkmark$ exergético bruto de los residuos agrícolas provenientes de los residuos de café y arroz sec 
ual para el departamento de Narıno y Choco promedio anual, considerando su alta :entración de ZNI.

la 6.

:ncial energético exergético bruto anual de los residuos agrícolas provenientes de los cultivos afé y arroz secano manual para el departamento de Nariño y Chocó.

\begin{tabular}{|c|c|c|c|c|c|c|}
\hline epartamento & Cultivo & esiduo & ${ }^{\cdot, i}[\mathbf{t} / \mathbf{a}$ & $E x^{d_{b i o}}$ & $\begin{array}{c}\text { \# Usuarios } \\
\text { ZNI }\end{array}$ & $\begin{array}{c}\text { \# Usuarios } \\
\text { con } \\
\text { plantas }\end{array}$ \\
\hline Nariño & Café & ıscarilla & 315 & 5,9 & 45.517 & 45.187 \\
\hline & - & & & $\cdots$ & $\ldots \ldots$ & $\cdots \ldots \ldots$ \\
\hline Guainía & - & - & - & - & 4.439 & 3.146 \\
\hline
\end{tabular}

'onsiderando que el consumo de energía eléctrica por habitante en Colombia equivale a ximadamente $984 \mathrm{kWh} / \mathrm{año}$ y que cada usuario representa una vivienda compuesta en nedio por $\sim 3,6$ personas [38,39]; para Nariño, empleando conjuntamente los residuos de café y co de palma y suponiendo que toda la energía contenida en el residuo pudiese aprovecharse :onsiderar las limitaciones impuestas por la Segunda Ley de la Termodinámica cuando este es vechado en un sistema de generación de potencia, se estima que podría generarse energía siente para cerca de 23.824 habitantes por año como máximo, lo que equivaldría a un imiento del $14,5 \%$ de los usuarios no interconectados en este departamento y a una posibilidad ustitución tecnológica del 14,64\% de generadores diésel mediante los cuales se abastecen. Para có, podría generarse energía suficiente para cerca de 9.113 habitantes por año como máximo, ue equivaldría a un cubrimiento del $8,52 \%$ de los usuarios no interconectados en este ırtamento y a una posibilidad de sustitución tecnológica del 15,79\%. Finalmente, para el ırtamento del Cauca podría generarse energía suficiente para cerca de 2.474 habitantes por año o máximo, lo que equivaldría a un cubrimiento del $4,87 \%$ de los usuarios no interconectados ste departamento y a una posibilidad de sustitución tecnológica igualmente del 4,87\%.

'on el fin de estimar el potencial energético teórico anual $E$ de los residuos agrícolas iderados en el presente estudio, se realizó un análisis de regresión donde se presenta la 
del tlujo de biomasa procesada para cada uno de los residuos considerados. En esta se observa que la relación entre ambas variables es lineal, donde para los tres casos, se obtuvo un coeficiente de correlación $\mathrm{R}^{2}=1$. Así mismo, fue identificado que, para la cascarilla de arroz, la cascarilla de café y el cuesco de palma de aceite se tiene una generación neta de potencia de $1,716 \mathrm{~kW} /(\mathrm{kg} / \mathrm{h}), 2,219$ $\mathrm{kW} /(\mathrm{kg} / \mathrm{h})$ y $2,831 \mathrm{~kW} /(\mathrm{kg} / \mathrm{h})$, respectivamente. A continuación, en la Fig. 4, se presentan los resultados de dicho análisis.

Figura 4.

Potencia del sistema en función del flujo de biomasa residual procesada

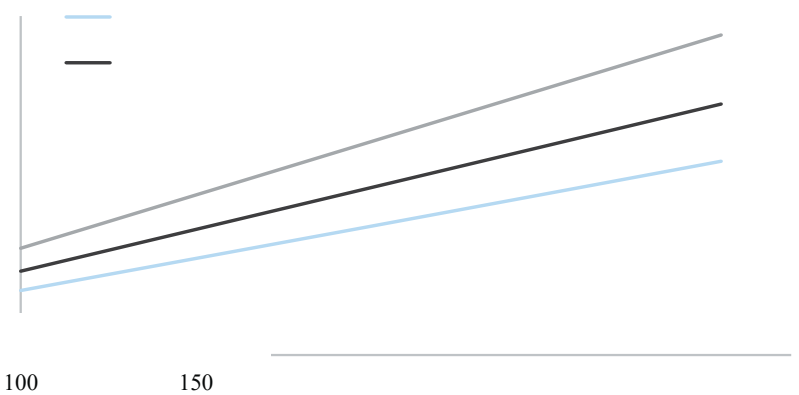

Cascarilla de $c . .$.

A continuación, en la Fig. 5, se presenta el potencial energético y exergético departamental de los residuos agrícolas de interés.

1.400

Figura 5.

Potencial energético teórico anual a nivel departamental en un sistema híbrido SOFC-MGT. 
$1.4 U U$

ura 5.

encial energético teórico anual a nivel departamental en un sistema híbrido SOFC-MGT.

1.000

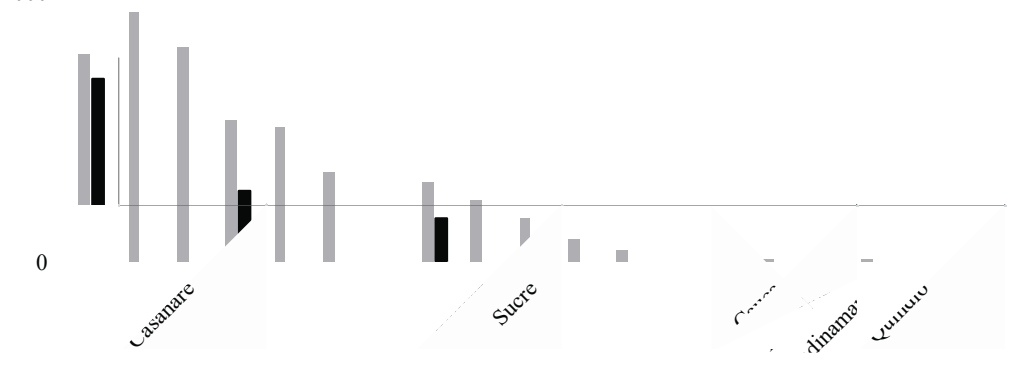

- Teórico

:ontinuación, en la Tabla 7, se presenta el potencial energético y exergético teórico de la ificación de biomasa a partir los residuos agrícolas provenientes de los residuos de café y arroz ano manual para el departamento de Nariño y Chocó, considerando su aprovechamiento en ur ema de generación de potencia híbrido SOFC-MGT acoplado a una unidad de gasificación de masa.

Ja 7.

encial energético teórico anual de los residuos agrícolas provenientes de los cultivos de café $\}$ oz secano manual para el departamento de Nariño y Chocó.

\begin{tabular}{cccc} 
Nariño & Café & Cascarilla & 2,54 \\
& & & \\
Guainía & - & - & - \\
\hline
\end{tabular}

:ontinuación, en la Fig. 6, se presenta el potencial energético y exergético teórico de lo: artamentos donde se concentra el mayor porcentaje de ZNI, de la gasificación de los residuo: ícolas de interés para propósitos de conversión energética en un sistema de generación de encia híbrido SOFC-MGT. 


\section{Figura 6.}

Potencial energético y exergético teórico a nivel departamental de la gasificación de biomasa aprovechamiento en un sistema de generación de potencia híbrido SOFC-MGT.

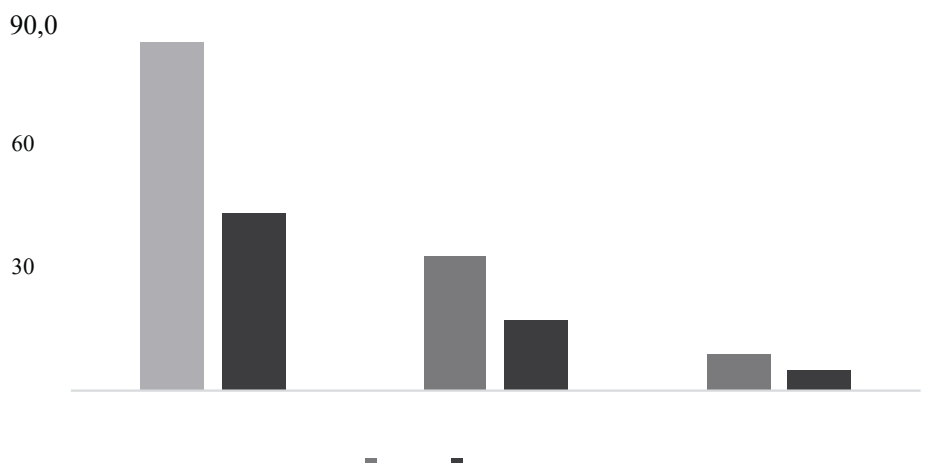

De la Figura 6, se estima que, para el departamento de Nariño, podría generarse energía sufic a partir de sistemas de generación de potencia híbridos, para cerca de 12.124 habitantes por como máximo, lo que equivaldría a un cubrimiento del 7,40\% de los usuarios no interconec1 en este departamento y a una posibilidad de sustitución tecnológica del 7,45\% de generadores d mediante los cuales se abastecen. Para Chocó, podría generarse energía suficiente para cerc 4.827 habitantes por año como máximo, lo que equivaldría a un cubrimiento del $4,51 \% \mathrm{~d}$ usuarios no interconectados en este departamento y a una posibilidad de sustitución tecnológic $8,36 \%$. Finalmente, para el departamento del Cauca podría generarse energía suficiente para ، de

1.408 habitantes por año como máximo, lo que equivaldría a un cubrimiento del $2,77 \% \mathrm{~d}$ usuarios no interconectados en este departamento y a una posibilidad de sustitución tecnols 


\section{nclusiones}

- Aun cuando los departamentos con el mayor potencial para la gasificación de biomas: considerando los residuos estudiados no exhiben un porcentaje significativo de Zonas Nc Interconectadas al sistema eléctrico nacional, se propone la implementación de sistemas que puedan utilizar estas fuentes para la generación de energía y así, no desaprovechar dich potencial.

- Se concluye que, el departamento del Meta, Tolima, Casanare, Cesar, Santander y Norte dı Santander, presentan el mayor potencial energético, dado que son los departamentos dond se concentra un poco más del $80 \%$ del potencial energético conjunto a nivel nacional. Esto: en particular tienen en común, la producción de palma de aceite a excepción del departamento del Tolima.

- Se concluye que, el departamento del Huila, a pesar de poseer un gran potencial productivi de residuos del café, su potencial energético asociado al aprovechamiento de estos en ur sistema de generación de potencia híbrido resultó ser menor al del departamento del Magdalena y de Norte de Santander, cuyo potencial productivo de este residuo fue meno a este.

- Se concluye que, el cuesco de palma de aceite tiene mayor potencial para la generación di energía en el sistema híbrido, dado que fue identificado que, utilizando este residuo, el sistema tiene una capacidad de generación neta de potencia de $2,831 \mathrm{~kW} /(\mathrm{kg} / \mathrm{h})$, superior : la cascarilla de arroz y la cascarilla de café, con los cuales el sistema propuesto posee un: capacidad de generación neta de potencia de $1,716 \mathrm{~kW} /(\mathrm{kg} / \mathrm{h})$ y $2,219 \mathrm{~kW} /(\mathrm{kg} / \mathrm{h})$, respectivamente.

- Entre los departamentos en los cuales se presentan ZNI con acceso a energía eléctric: mediante generadores diésel, Nariño presenta un mayor potencial energético asociado al aprovechamiento de los residuos que fueron evaluados en el presente estudio, y principalmente, a diferencia de los departamentos del Chocó y Cauca, por ser un departamento que cultiva la palma de aceite. 
Los autores ofrecen un especial agradecimiento a la Vicerrectoría de Investigaciones, Innovación y Extensión de la Universidad Tecnológica de Pereira y al grupo de investigación en Gestión Energética - GENERGÉTICA, por el apoyo recibido para el desarrollo de este capítulo.

\section{Bibliografía}

[1] Cheng Y, Thow Z, Wang C-H. Biomass gasification with CO2 in a fluidized bed. Powder Technol 2016;296:87-101. https://doi.org/10.1016/j.powtec.2014.12.041.

[2] El Bassam N. Handbook of Bioenergy Crops: A Complete Reference to Species, Development and Applications. London: 2010.

[3] U.S Energy Information Administration. International Energy Outlook 2016: With Projections to 2040. 2016.

[4] Gómez-Barea A, Leckner B. Modeling of biomass gasification in fluidized bed. Prog Energy Combust Sci 2010;36:444- 509. https://doi.org/10.1016/j.pecs.2009.12.002.

[5] Long H, Li X, Wang H, Jia J. Biomass resources and their bioenergy potential estimation: A review. Renew Sustain Energy Rev 2013;26:344-52. https://doi.org/10.1016/j.rser.2013.05.035.

[6] Jia J, Abudula A, Wei L, Sun B, Shi Y. Thermodynamic modeling of an integrated biomass gasification and solid oxide fuel cell system. Renew Energy 2015;81:400-10. https://doi.org/10.1016/j.renene.2015.03.030.

[7] Gonzalez-Salazar MA, Morini M, Pinelli M, Spina PR, Venturini M, Finkenrath M, et al. Methodology for estimating biomass energy potential and its application to Colombia. Appl Energy 2014;136:781-96. https://doi.org/10.1016/j.apenergy.2014.07.004.

[8] Unidad de Planeación Minero-Energética-UPME. Potencialidades de los cultivos energéticos y residuos agrícolas en Colombia. 2003.

[9] Sikarwar VS, Zhao M. Biomass Gasification. Elsevier Inc.; 2017. https://doi.org/10.1016/B978-0-12-409548-9.10533-0.

[10] Saidur R, Abdelaziz EA, Demirbas A, Hossain MS, Mekhilef S. A review on biomass as a fuel for boilers. Renew Sustain Energy Rev 2011;15:2262-89. https://doi.org/10.1016/j.rser.2011.02.015. 
A review of state of the art technology and near future perspectives. Appl Therm En 2013;50:1407-17. https://doi.org/10.1016/j.applthermaleng.2011.12.040.

Jana K, De S. Biomass integrated gasification combined cogeneration with or without $\mathrm{CO}^{\prime}$ capture - A comparative thermodynamic study. Renew Energy 2014;72:243-52 https://doi.org/10.1016/j.renene.2014.07.027.

Amirante R, Tamburrano P. Novel, cost-effective configurations of combined power plant for small-scale cogeneration from biomass: Feasibility study and performance optimization Energy Convers Manag 2015;97:111-20. https://doi.org/10.1016/j.enconman.2015.03.047.

El-Emam RS. Thermal modeling and efficiency assessment of an integrated biomass gasification and solid oxide fuel cell system. Int J Hydrogen Energy 2015;40:7694-706 https://doi.org/10.1016/j.ijhydene.2015.02.061.

Ud Din Z, Zainal ZA. Biomass integrated gasification-SOFC systems: Technology overview. Renew Sustain Energy Rev 2016;53:1356-76 https://doi.org/10.1016/j.rser.2015.09.013.

Bang-Møller C, Rokni M, Elmegaard B. Exergy analysis and optimization of a biomass gasification, solid oxide fuel cell and micro gas turbine hybrid system. Energ: 2011;36:4740-52. https://doi.org/10.1016/j.energy.2011.05.005.

Ud Din Z, Zainal ZA. Biomass integrated gasification-SOFC systems: Technology overview. Renew Sustain Energy Rev 2016;53:1356-76 https://doi.org/10.1016/j.rser.2015.09.013.

Doherty W, Reynolds A, Kennedy D. Process simulation of biomass gasification integrater with a solid oxide fuel cell stack. J Power Sources 2015;277:292-303 https://doi.org/10.1016/j.jpowsour.2014.11.125.

Tibocha Guzmán DA. Fluid-dynamic analysis of a fluidized bed reactor. 2018.

Rodríguez Valencia N, Zambrano Franco DA. Los subproductos de café: Fuente de energí: renovable. Av Técnicos Cenicafé 2010;328:8.

Gómez A, Rincón S, Klose W. Carbón activado de cuesco de palma: Estudio d termogravimetría y estructura. Universidad Nacional de Colombia - Universidad de Kassel 2010.

Cai J, He Y, Yu X, Banks SW, Yang Y, Zhang X, et al. Review of physicochemical properties and analytical characterization of lignocellulosic biomass. Renew Sustain Energ: Rev 2017;76:309-22. https://doi.org/10.1016/j.rser.2017.03.072.

Sánchez RA, Durán Peralta HA, Aguiar Urriago LM, Uribe Aldana N, Rojas Forero AYV Modelo para la gasificación del cuesco de palma aceitera. Ingenium 2017;18. 


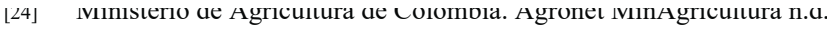

[25] (UPME) U de PME. Atlas del Potencial Energético de la Biomasa Residual en Colon 2010 .

[26] Peduzzi E, Boissonnet G, Maréchal F. Biomass modelling: Estimating thermodync properties from the elemental composition. Fuel 2016;181:207 https://doi.org/10.1016/j.fuel.2016.04.111.

[27] Eboh FC, Ahlström P, Richards T. Estimating the specific chemical exergy of munic solid waste. Energy Sci Eng 2016;4:217-31. https://doi.org/10.1002/ese3.121.

[28] Song G, Xiao J, Zhao H, Shen L. A unified correlation for estimating specific chem exergy of solid and liquid fuels. Energy 2012;40:164 https://doi.org/10.1016/j.energy.2012.02.016.

[29] Çengel YA, Boles MA. Thermodynamics: An Engineering Approach. Eighth. Mc C Hill; 2015.

[30] Vélez JF, Chejne F, Valdés CF, Emery EJ, Londoño CA. Co-gasification of Colombian and biomass in fluidized bed: An experimental study. Fuel 2009;88:424 https://doi.org/10.1016/j.fuel.2008.10.018.

[31] Cáceres Martínez LE. Technical evaluation of available residual biomass in Colombic its thermochemical conversion in fluidized bed reactors. Universidad Nacional de Colon 2018 .

[32] Qian H, Zhu W, Fan S, Liu C, Lu X, Wang Z, et al. Prediction models for chemical ex of biomass on dry basis from ultimate analysis using available electron concepts. En 2017;131:251-8. https://doi.org/10.1016/j.energy.2017.05.037.

[33] Zhang Y, Zhao W, Li B, Zhang H, Jiang B, Ke C. Two equations for estimating the exı of woody biomass based on the exergy of ash. Energy 2016;106:400 https://doi.org/10.1016/j.energy.2016.03.040.

[34] Szargut J, Morris DR, Steward FR. Exergy analysis of thermal, chemical and metallur६ processes. Springer-Verlag; 1988.

[35] Song G, Shen L, Xiao J. Estimating specific chemical exergy of biomass from basic ana] data. Ind Eng Chem Res 2011;50:9758-66. https://doi.org/10.1021/ie200534n.

[36] Manatura K, Lu J, Wu K, Hsu H. Exergy analysis on torrefied rice husk pellet in fluid bed gasification. Appl Therm Eng 2017;111:1016 https://doi.org/10.1016/j.applthermaleng.2016.09.135.

[37] Diniz Filho PT, Silveira JL, Tuna CE, Lamas WDQ. Energetic, ecologic and fluid-dync analysis of a fluidized bed gasifier operating with sugar cane bagasse. Appl Therm 2013;57:116-24. https://doi.org/10.1016/j.applthermaleng.2013.01.045. 
Una mirada investigativa en la ingeniería.Gestión energética y telecomunicaciones

Ghaffarpour Z, Mahmoudi M, Mosaffa AH, Garousi Farshi L. Thermoeconomic assessmen of a novel integrated biomass based power generation system including gas turbine cycle solid oxide fuel cell and Rankine cycle. Energy Convers Manag 2018;161:1-12 https://doi.org/10.1016/j.enconman.2018.01.071.

Promigas. Informe del Sector Gas Natural 2018. 2018. 
Vicerrectoría de Investigaciones, Innovación y Extensión $\quad$ eISBN 978-958-722-497-9

Colección Trabajos de Investigación 